\title{
"Divided Kingdom, 561" A Case Study: Communicating Historical Narratives Through Board Games.
}

\author{
By \\ Maximilian Stewart-Hawley Cronkite
}

A thesis submitted to the Faculty of Graduate and Postdoctoral Affairs in partial fulfillment of the requirements for the degree of

\author{
Master of Arts \\ In \\ History \\ Carleton University \\ Ottawa, Ontario
}

(C) 2021

Maximilian Stewart-Hawley Cronkite 


\begin{abstract}
This thesis explores the potential of communicating complex ideas about the past through board games. The thesis will start with exploring and defining its theoretical understanding of historical narratives and procedural rhetoric. Then, the thesis will continue with how other scholars have discussed the role of and potential that games have in the imparting of historical knowledge. Using this established methodology and theory of game-based learning, this thesis will analyze three historical board games for their ability to impart historical understanding. After the analysis of the three case studies this thesis will showcase an annotated version of the rules for the historical board game: Divided Kingdom, 561 which was created for this thesis. In the annotated rulebook, and design journal that follows it, the author elaborates on the game's intention as a pedagogical tool and how it is designed to communicate historical understanding of sixth century Frankish Gaul.
\end{abstract}




\section{Acknowledgements}

This thesis is dedicated to Karen Hawley. An alumnus of Carleton University, passionate activist, and loving mother. From her I drew my determination, curiosity, and compassion to not only finish this thesis but to go through life with confidence and empathy.

I would like to thank my partner Abbey Wright for her unyielding supporting during a difficult two years and graduating first so she could warn me of the many pitfalls of writing a thesis.

I would like to thank my father, David Cronkite for gifting me a love for board games and creativity. It is thanks to him that the first book I ever read was likely a rulebook.

Thank you to the Crafty Bandits for all the wonderful mutual support. Without the creative outlet of Dungeons and Dragons this project would be all the more difficult.

Thank you to Shawn Graham for the digital and game expertise and allowing me to playtest his own historical board game, showing me it was an achievable goal.

Finally, I would like to thank Marc Saurette for agreeing to take on this project in its earliest incarnation during my undergraduate thesis. I would not be here if it were not for his trust in my vision and his continual support for and encouragement of my ideas. 


\section{Table of Contents}

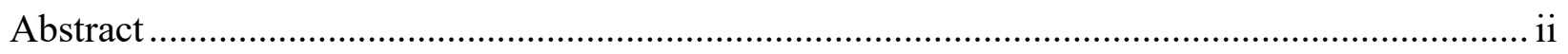

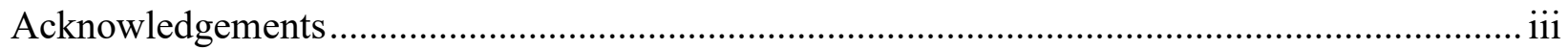

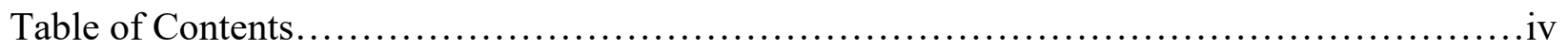

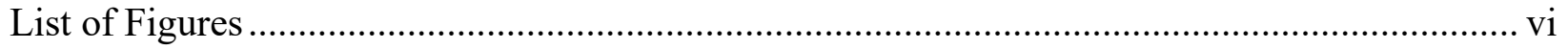

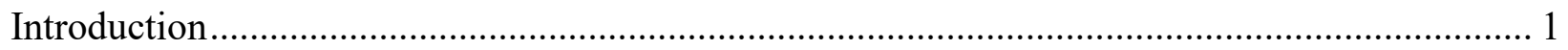

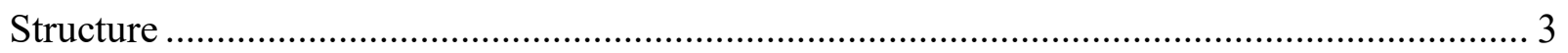

Chapter One: History and Game Studies - A Look at Theory …………………….................. 5

The Rhetoric of Procedurality and Board Games ………...................................................... 8

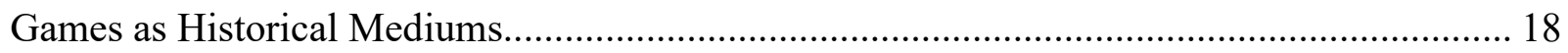

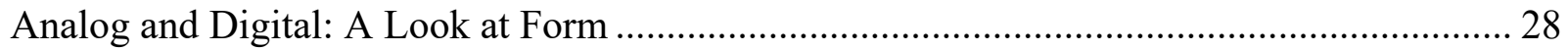

Chapter Two: Case Studies - Applying Theory ……………................................................... 35

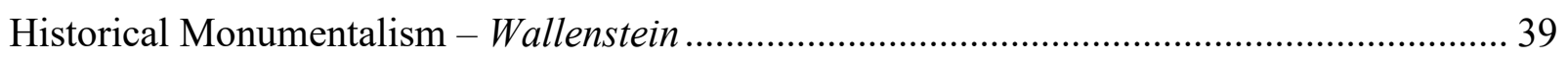

A Macro History of All Civilization - Western Empires ....................................................... 53

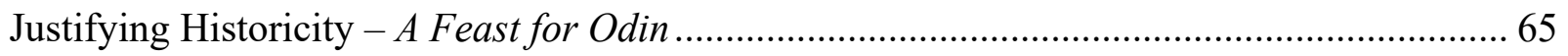

Conclusion - Board Games as a Viable Medium ………………....................................... 75

Chapter Four: Annotated Rulebook - Divided Kingdom, 561 .................................................. 78

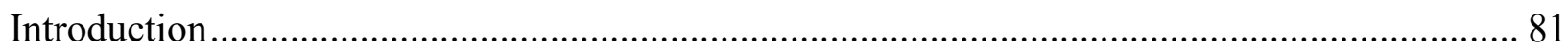

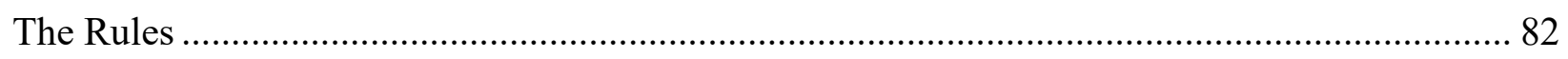

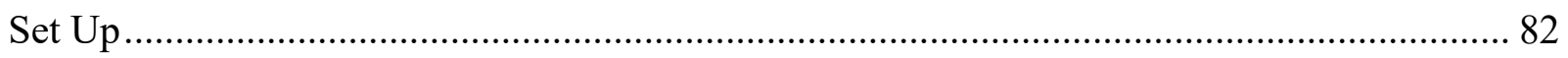

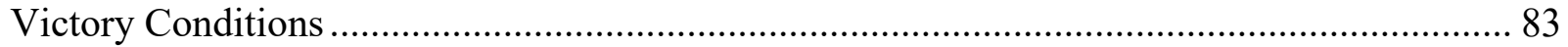

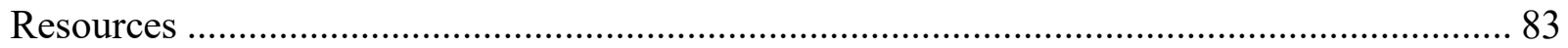

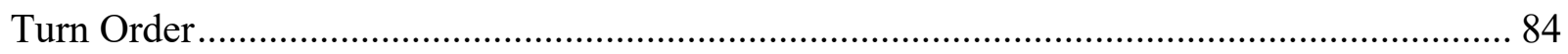

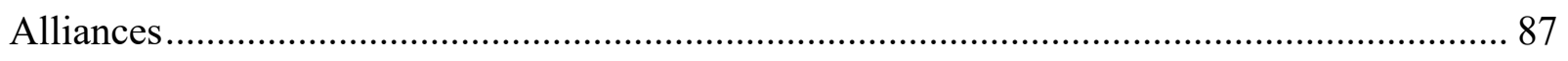

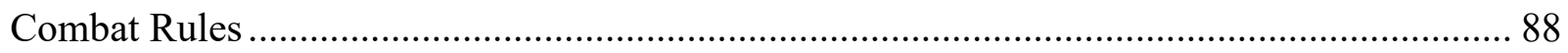

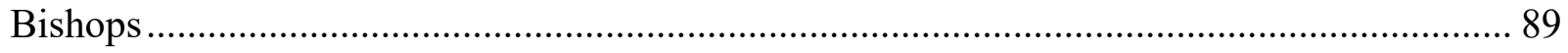

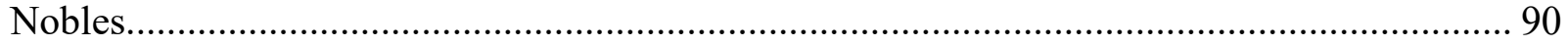

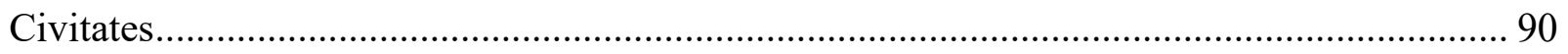

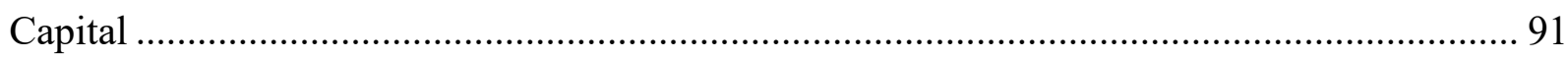

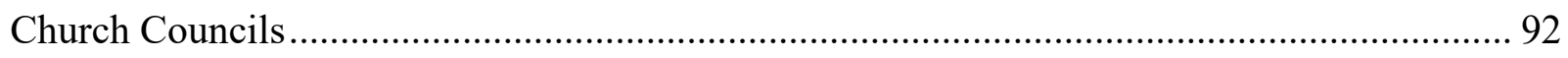

Invaders 


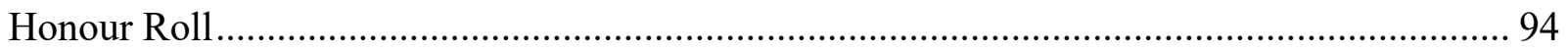

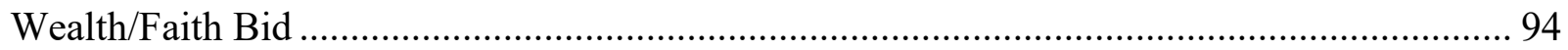

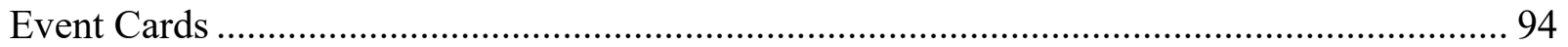

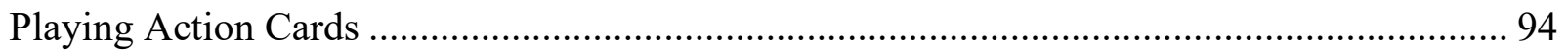

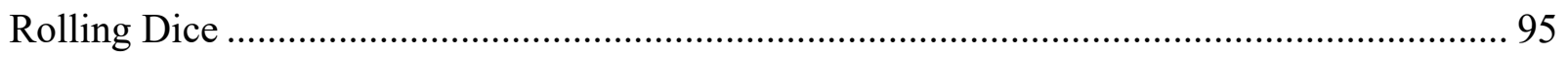

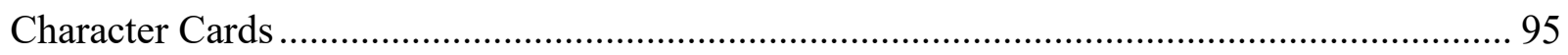

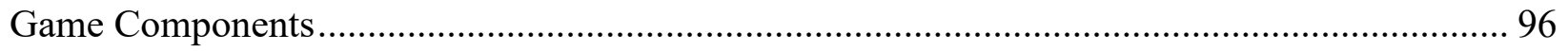

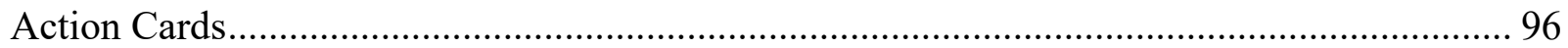

Bishop Figure ............................................................................................................. 99

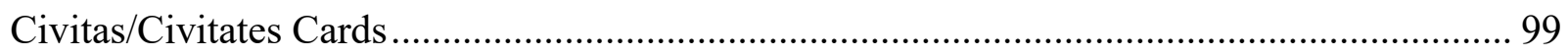

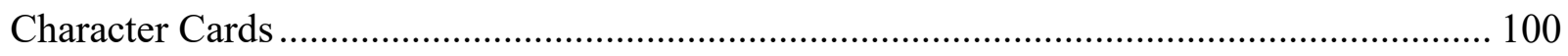

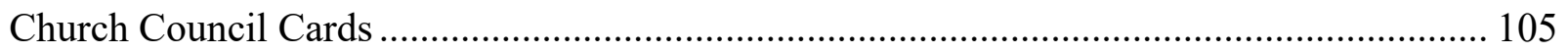

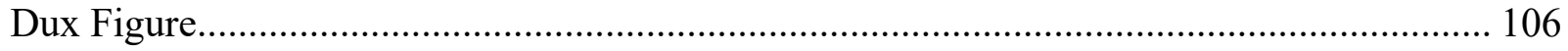

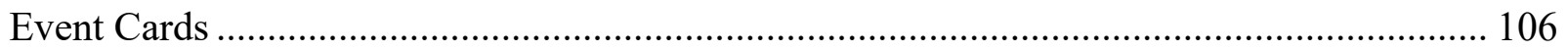

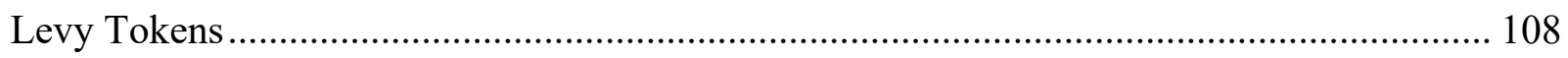

Metropolitan Bishoprics Board ................................................................................ 108

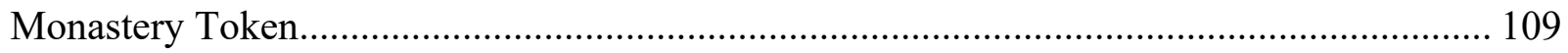

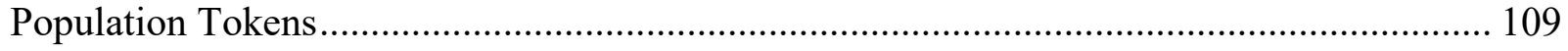

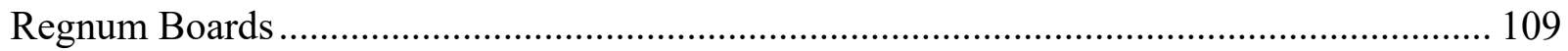

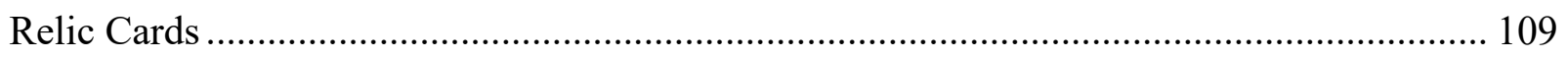

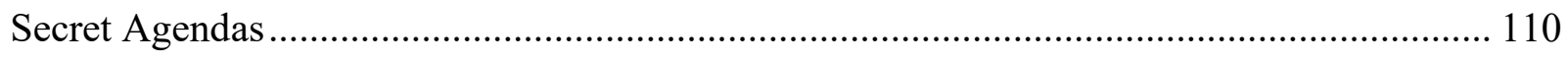

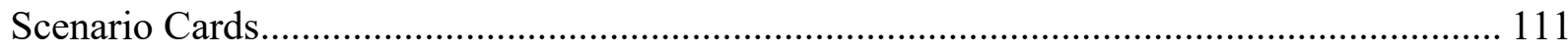

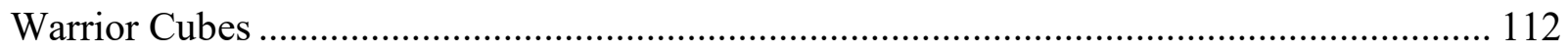

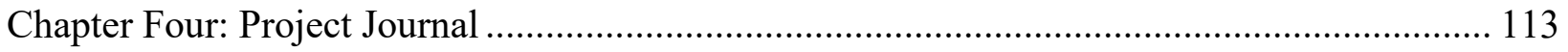

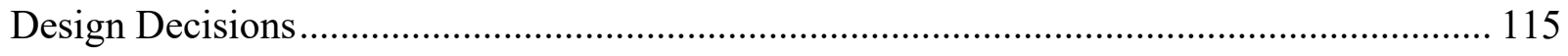

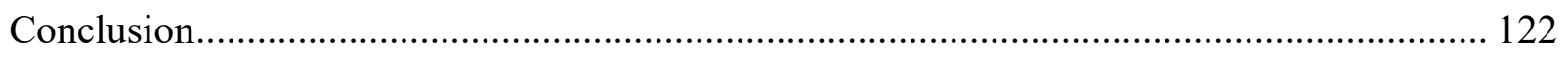

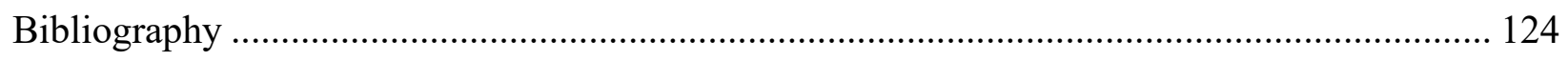




\section{List of Figures}

Figure 1: What a typical board setup would look like.

Figure 2: Upper: Albrecht von Wallenstein by Anthony van Dyck, 1629; Lower: Wallenstein

Cover.

Figure 3: The dice tower mechanic, from page 12 of the Wallenstein Rulebook. 46

Figure 4: Events cards, the top portion represents the particular game effect this round and the bottom shows the amount of grain lost (if it is winter). From page 2 of the Rulebook. 49 Figure 5: From page 14-15 of the rulebook depicting the main board and division of the different playable civilizations. 53

Figure 6: Archeological Succession Table 55

Figure 7: Trade card depicting commodities and calamities that can be traded to players blindly. From page 9 of the Rulebook. 57

Figure 8: Major Calamity of Iconoclasm and Heresy and the certain advancements that positively and negatively affect its outcome. From page 33 of the rulebook 58 Figure 9: Action Board showcasing the various actions a player can take by placing their Viking warriors on the relevant space. 65

Figure 10: Islands featured in the base game. They are used in the same way as the player board (figure 3). 66

Figure 11: From https://www.creakingshelves.com/a-feast-for-odin-review/, showing how goods are placed on the player board - including furs, bedrolls, casks, a bolt of cloth, as well as bones and meat from hunting.

Figure 12: From page 10 of 'A Feast for Odin' rulebook showing the rules for setting the "Banquet Table". 
Figure 13: Cover illustration for Divided Kingdom, 561 by: Alex Hawley, 2021. See description

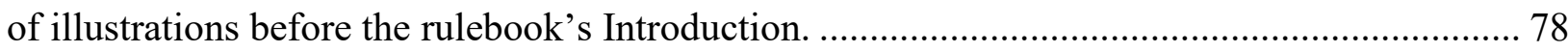

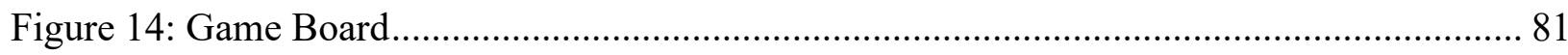

Figure 15: Metropolitan Bishopric Board used for tallying church council votes and control of

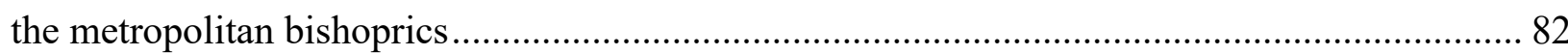

Figure 16: Regnum Board. Each player has one of these to track their resources, relic cards,

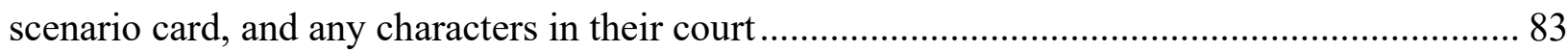

Figure 17: Season and year tracker on the main game board ................................................. 84

Figure 18: Pax and Bellum chart, tracks which players are at war.............................................. 85

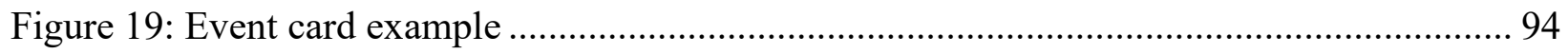

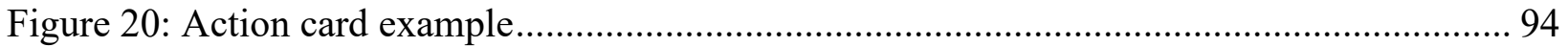

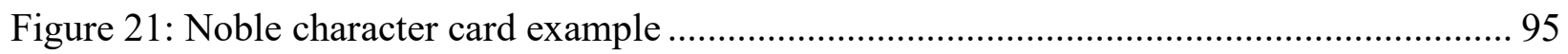

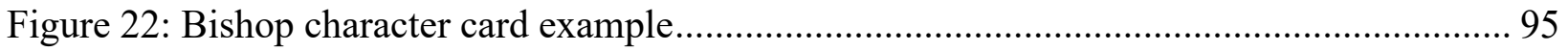

Figure 23: Example of travel research through https://omnesviae.org. Bolded locations refer to

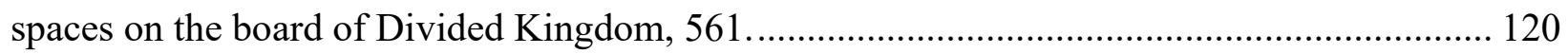
Figure 24: Screen capture from Omnes Viae showing the network of Roman roads and locations

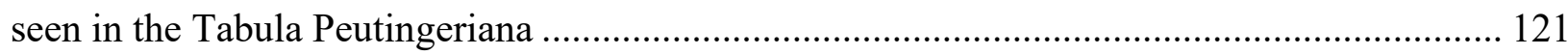




\section{Introduction}

The bishop, author, and (later) saint, Gregory of Tours positioned himself as a foundational source for the history of sixth-century Merovingian Gaul when he wrote his Decem libri historiarum or as it is more commonly known today, the Historia Francorum. His 'History of the Franks' as well as his hagiographical work remain the major sources and objects of inquiry for the Merovingian period. ${ }^{1}$ My goal, however, is to use Gregory of Tours as the basis for historical play.

My M.A. project investigates the use of analog/board games as a medium for communicating complex historical arguments and historiographical inquiry. Through a dual inquiry into the nature of History as a discipline and the field of Game Studies, my M.A. project engages with the key theoretical questions:

- How can board games facilitate academic discussions of history?

- Do board games have the ability for the player to understand complex historical discussions? Can they function as a pedagogical tool?

- Can a board game challenge and make clear the fluctuation between 'found' and 'made' medievalisms, as defined by Louise D'Arcens? ${ }^{2}$

- Do board games have the potential to provide a pedagogical alternative to reading traditional historical text extracts, such as those presented in annotated primary source editions?

\footnotetext{
${ }^{1}$ Walter Goffart, The Narrators of Barbarian History, University of Notre Dame Press, 1988; Ian Wood, The Merovingian Kingdoms, 450-751, Routledge, 1993; Martin Heinzelmann, Gregory of Tours: History and Society in the Sixth Century, Cambridge University Press, 2001. See references for a more extensive list.

${ }^{2}$ Louise D'Arcens, "Introduction, Medievalism: scope and complexity," in The Cambridge Companion to Medievalism, Cambridge University Press, 2016, 2.
} 
I define the act of history, for the purposes of this project, as a narrative endeavour that seeks to better understand how the past both viewed itself and constructed meaning. Specifically, I wish to present a medieval History - how one individual, Gregory of Tours, presented his contemporary world to posterity. How does Gregory define his past and present? Moreover, what does this tell us about his relationship as a bishop to other identifiable hierarchies and structures, i.e., Germanic and Gallo-Roman aristocracies, the wider ecclesiastical structures, gender relationships, other religious groups (primarily Arians and Jews), definitions of the spiritual and secular, the general population, and a plethora of other sociocultural themes identified and defined by post-modern scholars.

Embarking on the endeavour of illustrating the world that Gregory of Tours presents to his readers in the Historia Francorum requires a thorough understanding of the primary source material as well as the dearth of secondary sources. While Gregory has been the subject of numerous analyses, I seek to engage with how Gregory can be presented fundamentally differently - by allowing an audience to experience his mindset through a simulation of his world. My project seeks to offer the audience the chance to inhabit Gregory's work/world not simply by reading text, but by experiencing its narrative through gameplay. My project primarily focusses on books IV-VII of Gregory's Historia Francorum which recounts the lives of the four sons of King Chlothar and the division of the Frankish kingdom in 561. The game texts and dynamics reflect and showcase the intrinsic themes of Gregory's text while simultaneously engaging with current understanding of the historian's craft. My project does not simply reproduce Gregory's mindset and worldview but seeks to challenge his historical representation in light of current findings about Merovingian society. 


\section{Structure}

To test whether game play could be reasonably viewed as a valid form of historical presentation, I have created a board game based on a Gregory's History of the Franks (See Chapter 3). This game is the product of the process of inquiry presented in this thesis: I offer conclusions about how scholars have theorized the relationship of games and history, I have sought to deepen my knowledge through applying these conclusions to existing boardgames, and then I present how my game develops from and in relationship to these methodological and practical considerations.

In my initial theoretical introductory chapter, I question how the medium of a board game (which includes the rulebook and physical components such as a play space, physical pieces, and cards) can communicate a historical argument about the past. I look at the rhetoric utilized in Game Studies as well as history and how the two disciplines offer a theoretical justification and a methodology for disseminating historical knowledge.

After my investigation of the rhetoric, goals, and structure of the field of game studies and how it intersects with the study of history, I investigate three board game case studies. The case study chapter links to the theoretical discussions in the previous chapter and illustrate the connection of the two fields of study. The analysis of these case studies allows me to determine what design practices best articulate complex and developed narratives of the past through their gameplay.

The third chapter of this M.A project will be an annotated rule book of the game Divided Kingdom, 561 which was the case study developed for this project. The annotated rulebook consists of an instructional guide to how the case study functions, the many components that 
constitute it, and the inclusion of annotations and footnotes that explicitly illustrate the historical research that informed and justified the game's many design decisions.

The fourth and final chapter will be a more informal project journal/conclusion that investigates and charts the design process of the case study and overall project. In it, I will evaluate the outcome of the engagement with my key theoretical question and the overall validity of my M.A. thesis as a form of historical inquiry. 


\section{Chapter One: History and Game Studies - A Look at Theory}

The field of History has traditionally privileged the printed word as its dominant medium of communication, but the recent proliferation of audio-visual opportunities for historical storytelling (documentary film, radio, the current vogue of podcasts) have challenged the typical paradigm. Increasingly, historians have started to examine the immersive possibilities of videogames to do the same. I suggest that physical games - board games which have been largely overlooked - might also have the same potential to communicate complex historical arguments. To make this claim, I will first outline some of the major developments in scholarship exploring games and gaming. As an incipient field of research, Games Studies remains a diverse and somewhat undefined field. In the following chapter, I provide overviews of and critique the major approaches which define the field and justify my thesis project. However, it is crucial to first define the history-making process.

I find it is important to explain first how I define the construction of history if this thesis project is going to contend that board games can perform as a legitimate medium in the construction of historical meaning. History, according to Alun Munslow, is a "narrative making process" that seeks to represent the past through the collection of agreed upon facts and then presentation of those facts through a constructed narrative. ${ }^{3}$ The endeavour of history is not to create perfect simulations of the past and past events, since it goes beyond the impossible task of recovering the past by engaging in what Munslow calls a "story-discourse." ${ }^{4}$ This storydiscourse focuses as much on 'how' history is being told (discourse) as 'what' is being told (story). While historians usually imagine narrative as taking written form, it is not tied to one

\footnotetext{
${ }^{3}$ Alun Munslow, Narrative and History, Palgrave-Macmillan, 2007, 1.

${ }^{4}$ Ibid., 6 .
} 
form - it can be oral, written, played, dramatized, etc. So, what I will be exploring in this chapter and throughout this thesis is how the 'form' of historical narrative construction can be renegotiated beyond the written medium, and specifically constructed within the confines of board game design.

Historical board games can be understood to fall into the general category of "reenactment" (both ludic and physical) - a common contemporary form of popular historical engagement. Reenactment, or "historical performance," as Jerome de Groot describes it, is an example of "contemporary society's obsession with 'authenticity" as legitimacy is conflated with personal and embodied experiences. ${ }^{5}$ Re-enactment, however, tends to be associated with a social performance of the past in groups, often with meticulously crafted costumes, and largely associated with re-creating material culture of the past. While games often ask players to simulate a past world in the minds of the players, there is a different engagement with the past which makes the experience different. I find "historical representation" to be a better concept to ground the goal of my project, and how games might offer insight in how to portray the historical process of representing and constructing the past. My goal is not simply to allow players to simulate the past as they choose, but to imbue the process with a critical historical mindset. In the creation of 'proper' history there are semiotic representations that include references to, explanations of, and meanings for the past. ${ }^{6}$ This is the kind of history that is rarely tackled by re-enactments of the past but, as I will show in this project, games and specifically board games are a medium in which this critical construction of history through abstract semiotic representations can refer, explain, and provide meaning for abstract concepts of the past. This is

\footnotetext{
${ }^{5}$ Jerome de Groot, Consuming History: Historians and Heritage in Contemporary Popular Culture, Oxon: Routledge, 2009, 103-4.

${ }^{6}$ Munslow, 9 .
} 
because board games are a collection of semiotic representations that refer to, explain, and provide meaning to the process of their particular (in this case historical) referent.

We generally understand that the traditional definition of history sees it as an intellectual process relying on a foundation of verifiable facts and evidence which are organized by the author to present an argument about the past. The context of past events is constructed through the use of found evidence in order to illustrate and posit ideas surrounding social hierarchies, structural relationships, as well as cultural meaning and significance. What survives from the past is reordered and reimagined by the contemporary historian to better understand what has come before. This 'form' of written history has been prioritized largely because surviving evidence that is used in western-empirical academia is itself written. Written history has also been constructed and prioritized based on its ability to allow for individual verification through footnotes and other references to its evidence. However, through this chapter, I will explore how board games can similarly provide this type of verification (which is an essential aspect to what a historian does) while simultaneously constructing and illustrating a narratological argument about the past.

History cannot be defined only as a narrative endeavour. It requires a justification of the procedures used in the construction of its narrative and a certain self-reflexivity in order to become a part of the wider historiography. History cannot stop itself at telling a story, it must go beyond to justify its unique ability to interpret the past - a viewpoint that argues for both the tangible and intangible perceptions of memory. It is a constant renegotiation of the past based on the analysis of tangible/verifiable 'evidence.' Of course, what constitutes evidence has shifted over time to include written material, archeological findings, and oral histories. Furthermore, the methodologies in which historians engage with these varied forms of evidence and the 
conclusions that are made from their analyses constitutes the act of History. Not only how the historical narrative is communicated but also how it is constructed and how it is researched are key components to the process of developing History.

To help define the medium of board games and how their construction and operation aid in presenting historical narratives, I turn to Ian Bogost's concept of procedural rhetoric, which he uses to understand the underlying logic that motivates human actors in the present and in the past. $^{7}$

\section{The Rhetoric of Procedurality and Board Games}

The often-cited concept of Procedural Rhetoric was developed by Ian Bogost in 2007 to provide a way of conceptualising and expressing processes, or as Bogost puts it, “...the art of persuasion through rule-based representations and interactions rather than the spoken word, writing, images, or moving pictures." 8 The term "processes" is a vague term that can be, and will be in this project, applied in many situations and contexts. It can refer to historical processes, such as how societies function or the many intricate constituent parts that work together to form a whole. Processes can also relate to the mechanical structure of a game - how a game's many rules work together to constitute a larger collective entity and produce meaning/fun. By exploring Bogost's rhetoric on conceptualizing and expressing processes, I will be able to demonstrate how the processes of a game can communicate the processes of a historical society.

Firstly, the rhetorical concept of procedurality is a way of understanding and defining how the creation and enactment of processes can impart knowledge. Processes define the way

\footnotetext{
${ }^{7}$ Ian Bogost, Persuasive Games: The Expressive Power of Videogames, Cambridge: MIT Press, $2007,8$.

${ }^{8}$ Bogost, ix.
} 
things work and uncover the underlying "logic that drives the operation of systems..." Within the context of board games, those systems of operation would be the rules and specific mechanics of the game that drive the gameplay itself. For example, in chess each piece (bishops, pawns, knights) has its own way of operating and all of those pieces and the outcomes of their actions (taking pieces off, crowning pawns, checkmate, etc.) constitute that rule-based system of operation. All of these movements are subordinate to the overarching endgame of capturing the king. It is not only how the rules work, but how action is connected to outcome (checkmate) and the underlying web of the multiple actions and multiple outcomes that create possibilities for play. Players must understand both the rules and the goal (e.g. different layers of processes) in order to play the game, even if there understanding is imperfect. I am interested in thinking about procedurality in games, because it is through processes that players engage and learn with the thought/ ideas embodied in the game. Understanding processes is thus an essential foundation not only for analysing how game designers use the past in games, but also for understanding and expressing how to build games when our goal is to communicate complex historical ideas.

Bogost's concept of procedural rhetoric gives a framework for how games communicate ideas through their procedures which form the underlying structure. The logic of a game defines the actions available to players. That logic and the consequent process of the actions dictate the possibilities afforded to the players or the outcomes of those various actions. Bogost notes analog games as an example of "human-enacted processes" specifically, as it is people that execute the rules instead of a computer. ${ }^{10} \mathrm{He}$ notes that the involvement of humans in the making of the process becomes a challenge when discussing and enacting procedurality because it adds

\footnotetext{
${ }^{9}$ Bogost., 3 .

${ }^{10}$ Ibid., 10.
} 
the unpredictability of human behaviour in the enacting of rule-based procedures (e.g. unfamiliarity or partial understanding of rules or using idiosyncratic "house rules"). Although you cannot fully determine human behaviour and their enactment of designed processes as intended, the crafting of a process is still the same whether it is for a computer or analog medium. Furthermore, for the purposes of this project, I wish to focus on the development of an analog process (rules of a board game) to allow the human interactive component. ${ }^{11}$ For game design, procedural rhetoric is useful to guide the process of representing the complex history and the sociocultural reality of sixth-century Gaul as seen through the eyes of Gregory of Tours.

While I will argue that standard processes of historical scholarship do not have to be sacrificed when designing games, the rhetorical medium for communicating those ideas shifts from a stable explicit writing to one of procedure. Procedure is communicated through the 'rulebased' systems of behaviour rather than through words or images. ${ }^{12}$ Process, meaning both the understanding and enactment of it (both reading the rules of a game and playing it) is being used as a form of symbolic expression instead of language. Bogost describes this process as "procedural representation" wherein cultural, social, and historical processes are explained through other processes (such as rule-based systems found in board games). ${ }^{13}$ In the context of historical representation through the medium of games, these cultural and social systems of the past (in my case sixth-century Frankish Gaul) can be better understood through a medium that is also procedural (i.e. a rule-based system found in a board game) instead of the more abstract mode of representing processes through writing.

\footnotetext{
${ }^{11}$ Indeed, a future study (in non-Covid times) would be to evaluate the player experience of the analog board game. Unfortunately, this component was not able to be included in the current research project due to the impossibility of observed play tests.

${ }^{12}$ Ibid., 29.

${ }^{13}$ Ibid., 9.
} 
The question then arises, how can procedurality include independent verification of evidence when it seemingly imparts knowledge through the construction and 'running' or 'playing' of a program/game rather than the explicit use of textual elaboration and footnoting?

While games do not undergo the same rigorous process of peer review, source citation, and reproducibility of findings of scholarly writing, their historical messaging can function similarly to traditional forms of historical literacy. What is needed, outside of a simple inclusion of a list of historical facts, is twofold.

Firstly, the intermingling of historical data (either collected through original research or in the case of many commercial games the consultation with an academic professional in the relevant field) with the mechanical structure of the game that in tandem creates a resulting narrative that resembles complex historical processes which communicate a number of different socio-cultural and or political realities. Marc Arnaudo emphasizes the connection of historical data and a game's mechanical structure in his study of narrative design in modern boardgames, saying "to tell a playable story one must provide a framework of rules that is tailored to the needs of the representation." 14

Secondly, games that seek to communicate complex historical arguments need to include what Adam Chapman refers to as "extra-ludic and extra-diegetic" information which often appear outside of the 'play space' as extra-textual material such as primary and secondary sources presented to the player and can be engaged with at their own discretion. ${ }^{15}$ Many 'historical' games include extra-textual information as a tool to impress upon the player that it a

\footnotetext{
${ }^{14}$ Marc Arnaudo, Storytelling in the Modern Board Game: Narrative Trends in the Late-1960s to Today, McFarland, 2018, 80.

${ }^{15}$ Adam Chapman, Digital Games as History: How Videogames Represent the Past and Offer Access to Historical Practice, New York: Routledge, 2016, 131.
} 
'legitimate' form of history. However, without the above-mentioned factor of intermingling historical data with mechanical structure the provided extra-textual information (facts, glossaries, content description, informational 'pop-ups') do not explicitly express a narrative or thesis.

Analog games that communicate historical ideas possess alternative capabilities to that of written history that require consideration. One important aspect when comparing the two is that written history incorporates independent verification through the use of footnotes and peer review. A reader of written history can assess the validity of the arguments being made through their own independent research aided by the inclusion of referencing on the part of the author. Analog games have the potential to verify and contextualize their authorial/design decisions which may not be clear through simply playing the game.

The contextualization and justification of the game's procedure (and through it, the historical argument) can be further elaborated upon in its rulebook. The connection between the procedure of the game and its historical referents can be made clear through footnoting or in the detailing of how a rule is both constructed and interpreted, i.e., how the rule or mechanic negotiates with historical evidence. While this extra-textual information is not always provided in commercial board games, it is essential for games that wish to produce complex historical arguments akin to academic history.

Rulebooks break down the construction and function of the many procedures of the game and, with effort, those procedures can be explicitly linked to their historical referents in the same space. Board games require an understanding of the underlying structure in order to enact it's processes (as described by Bogost), i.e., a player has to read the rules first before they can play the game. A rulebook elaborates on the connection of each rule to the wider system - the expression and correlation of cause and effect. Rulebooks, as textual sources, can include forms 
of traditional written historical verification such as footnotes to explicitly link the game's processes to their historical referents.

Other game scholars have engaged with Bogost to further develop their own theories on the relation of history and gaming. The "gamic mode" approach developed by Jerremie Clyde, Howard Hopkins, and Glenn Wilkinson is one of them. ${ }^{16}$ These authors see procedural rhetoric as a way of presenting an argument through the collection of empirical evidence that is then constructed into a procedure that can then express the desired historical argument. This idea of the gamic mode suggests that the process found in procedural rhetoric is comparable to that found in scholarly monographs, and that process can be expressed through games as through its traditional written medium. ${ }^{17}$

Clyde and other scholars that use Bogost see procedural rhetoric as a necessary framework to communicate their construction of the past and a way to be "epistemologically recognizable to the majority of historians..." 18 The authors of the 'gamic mode' admit to history being procedural and an observation of past events that lead the historian to a "justifiable interpretation" rather than a rule or model imposed upon those observable events. ${ }^{19}$ Clyde et al. posit that commercial historical games do not follow the gamic mode (or any other form of scholarly history) and instead preference the pursuit of a "preferred past" instead of a justifiable/reasonable interpretation of evidence. The "preferred past," meaning a fabricated representation of the past based on a certain bias or agenda, is constructed because the

\footnotetext{
16 Jerremie Clyde, et al., "Beyond the 'Historical' Simulation: Using Theories of History to Inform Scholarly Game Design,” Loading... The Journal of the Canadian Game Studies Association, Vol. 6(9): 3-16.

${ }^{17}$ Clyde et. al., 13.

${ }^{18}$ Ibid., 7.

${ }^{19}$ Ibid., 10.
} 
“consequences and impact of a game's outcome is negotiated by the player" 20 instead of being defined by the collection and analysis of evidence. This means that the player is constructing the outcome instead of the outcome being a result of empirical evidence and logical deduction.

The gamic mode's interpretation of the player's role in facilitating the outcome of the game, as well as their interpretation of it (i.e. the historical messages they draw from playing the game), ignores the design process and how the rule or model (i.e. rules and mechanics of the game) can be developed through legitimate scholarly historical methods that use primary and secondary research to develop an argument about the past. The historical process/game that is being developed is the argument of the creator. The way in which the game functions and the narrative that guides the player as well as lets the player facilitate the direction of, is a product of the creator/historian's effort to abstractly represent their argument of the past.

Within Medieval Studies, there is debate about to what extent scholarly work on the Middle Ages can be differentiated from other forms of representation (which are traditionally seen as more "popular" and thus less valid). It is thus useful to connect this idea of scholarly work as a medievalism to the concept of the gamic mode. As defined by Louise D'Arcens, medievalism is a term used to describe representations of the medieval past - tentatively split into "medievalism of the 'found' Middle Ages and the medievalism of the 'made' Middle Ages." ${ }^{21}$ The found medievalism is considered to stem from 'found' evidence such as written documents, architecture, archeological artifacts, artwork, and so on. The made medievalism

\footnotetext{
${ }^{20}$ Clyde, 10.

${ }^{21}$ Louise D'Arcens, "Introduction, Medievalism: scope and complexity," in The Cambridge Companion to Medievalism, Cambridge University Press, 2016, 2.
} 
constitutes the Middle Ages of popular culture - 'modern' creations that illustrate a "conceptual" engagement with the medieval past rather than a "historical" one. ${ }^{22}$

Ultimately, the distinction between 'found' and 'made' medievalism is difficult to discern, as D'Arcens points out, since many made medievalisms are often “creative responses to medieval remnants and artifacts. ${ }^{, 23}$ Furthermore, found medievalisms are born out of the "disciplines of the archive" which are rooted in the progressivist rhetoric surrounding invented definitions of the 'modern' and 'premodern.' Found medievalisms may indeed derive from objects of the past, but they are nonetheless modern creations that are partially rooted in conceptions of the past that are also 'modern' inventions. The survival of “evidence” (e.g. found medievalisms) is not objective, but the result of choices, mostly after the medieval period, of what is worthy of saving and archiving.

D'Arcens' insistence that there cannot be a true distinction between and separation of 'found' and 'made' narratives of the medieval past, urges us to question traditional assertion of a distinguishable superiority to empirically-driven research. Games, as all forms of historical representations (or in our case, medievalisms) share a grounding in anachronistic relationships of past and present. The gamic mode contends that the design of a game, which is inherently a narrative endeavour, cannot communicate History on its own. However, the exploration of the 'made' and 'found' medievalism highlights the difficulty (impossibility?) of being able to define an objectionable truth about the past. The best that can be done is to formulate an argument based upon what can be known and express that argument through an appropriate medium that clearly and succinctly lays out the creator's process. Games, as will be explored below, can

${ }^{22}$ D'Arcens, 2.

${ }^{23}$ Ibid., 3. 
facilitate the construction and communication of a narrative just as traditional written history does.

Another crucial misconception in the gamic mode concerns the relationship between rules and narrative development (and the ultimate role of the player in this relationship). The game designer creates a framework of rules that allow for the facilitation of a narrative that is enacted by the players every time the game is played. The players do not independently create the narrative, but rather decide which of the many pre-set possibilities will be enacted by them in that game. Since the narratives are not 'created' by the player, the onus of historical validity is not put on the player but rather the designer, who must undoubtedly perform research when constructing their processes with an underlying historical argument - if they wish to make a game that can contend with scholarly processes and act as a type of historiographical offering. ${ }^{24}$ The argument of the creator is interpreted through the players understanding and enacting the rules (which represent a historical framework of processes). I contend, throughout this project that by reading and understanding the rules, players can (and should within a game that acts as a form of historiography) interpret the implicit historical argument made by the designer.

How historical information is presented in games is crucial to understanding how players will interact and interpret it. The gamic mode seems to conflate counter-history with alternate history even though I (and most historians) see the two as very different in their approaches to communicating historical meaning. Alternate history creates a new set of sociocultural meaning in order to present an alternate set of events - some more fantastical than others. They often extrapolate far in the future and pre-determine outcomes for the player. The popular videogame

\footnotetext{
${ }^{24}$ Maurice Suckling, "Simulating Saratoga: How Saratoga-Themed Board Games Function as Experiential Historiography,” Board Games Studies Journal 14, 2020: 83-108, 105.
} 
series Wolfenstein, for example simulates what life might be like had Nazi Germany won the Second World War. It "pre-determines" the Nazi victory of WWII, the invasion of America, and the invention of cyborg Nazis dogs. ${ }^{25}$ Another videogame series Dishonored is an alternate history game that looks at a future where whale oil continues to be a main source of energy and that Victorian values and customs have made it into the modern technological era. ${ }^{26}$ Counterfactual history, instead, does not present such fantastical worlds but instead seek to showcase different potential paths that history could take.

Defining the differences between alternative history and counterfactual history is essential as they are two different forms of historical engagement seen within a multitude of pop cultural mediums. The conflation of the two can deflate the validation of games as legitimate forms of history. Counterfactual games put players in a historical context and asks them to play within a historically researched and ruled framework - acting within the contextual norms of that period which places emphasis on complex historical discourses of "contingency, conditions, and

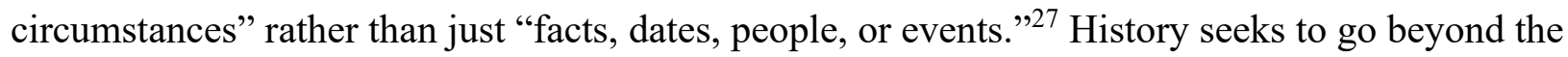
evidence, utilizing it to construct an argument that considers the contextual conditions and circumstances surrounding facts, dates, people, and events to better understand the past.

Counterfactual games address the problem of viewing history as a teleological endeavour and illustrates how historical actors were motivated and the forms of agency that were available to them within the given historical context - which can and should ultimately lead to varied

\footnotetext{
${ }^{25}$ Machine Games, Wolfenstein: New Order, Video Game, Published: Bethesda Softworks, 2014.

${ }^{26}$ Arkane Studios, Dishonoured, Video Game, Published: Bethesda Softworks, 2012.

${ }^{27}$ Matthew Wilhelm Kapell and Andrew B.R. Elliot, "Introduction: To Build a past that will 'Stand The Test of Time' - discovering historical facts, assembling historical narratives," in Kapell and Elliot, editors, Playing with the Past: Digital Games and the Simulation of History, Bloomsbury Academic, 2013, 13.
} 
outcomes. $^{28}$ It is an exploration of historical possibility and probability which can be enacted through procedural rhetoric and the medium of games. The rules and models that Clyde et al. frame as being restrictive and deterministic instead, in a counterfactual game, provide a framework that relegates what is possible and what is not in the historical context. This potential that games have to present counterfactuals puts games in a unique position for representing historical landscapes and the many relationships, motivations, and agendas that drive historical change.

The counterfactual position lends itself to a historical viewpoint that moves away from teleological and empirically-driven historiography. By representing a 'historical problem space' possibilities of historical outcomes can be explored and the elements that led to certain change can be better understood through experimentation - as long as that historical space is created through a complex understanding of the period being represented and it is properly represented through the abstract representations of the ludic functions of the game. ${ }^{29}$ The connection between historical narrative and game design will now be explored to better understand how games can be utilized as mediums for constructing and illustrating arguments about the past.

\section{$\underline{\text { Games as Historical Mediums }}$}

After having defined the rhetoric surrounding board games as well as the kind of narrativized counterfactual history that is optimal to explore through board games this chapter

\footnotetext{
${ }^{28}$ Tom Apperley, "Modding the Historians' Code: Historical Verismilitude and the Counterfactual Imagination," in Kapell and Elliot, editors, Playing with the Past: Digital Games and the Simulation of History, Bloomsbury Academic, 2013, 188.

${ }^{29}$ Jeramiah Mccall, "The Historical Problem Space Framework: Games as a Historical Medium," Game Studies, Vol., 20, No., 3, 2020, http://gamestudies.org/2003/articles/mccall.
} 
will explore how game scholars analyze the use of history within the medium of games to better understand how games may be designed to disseminate complex historical arguments.

There is a large contingent of historical game studies scholars that are not particularly invested in developing historically viable games, but rather focus on the analysis of how commercial games utilize and deploy historical themes. The goal of these analyses is not to identify and criticize their historical accuracies and inaccuracies but rather to understand how they engage with the past and what their presentation of the past may be communicating to their audience/players. In Adam Chapman’s article, “Is Sid Meier’s Civilization History?” he tackles the ideas of media and communications scholar, A.R. Galloway and his book Gaming: Essays on Algorithmic Culture, which sees any ideological critique in games being overtaken by history presented as quantifiable variables and devoid of meaningful representation of cultural shifts or societal change. ${ }^{30}$ That is to say, Galloway believes algorithm and procedure (that is found in the structure of video games) cannot constitute historical processes or lead to the development of 'good' history.

Chapman is not trying to posit that the subject of his analysis, Civilization, ${ }^{31}$ is an example of 'good' history represented by a game. Rather, he challenges Galloway's assertion that algorithm cannot constitute history by using Bogost's procedural rhetoric to argue that game algorithms in Civilization can constitute an empirical-analytical type of history. ${ }^{32}$ It is a narrative-making process, which in and of itself, can be a historical endeavour. It is not the format of games, Chapman argues, which are in opposition to historical knowledge, but the

\footnotetext{
${ }^{30}$ Adam Chapman, “Is Sid Meier's Civilization History?", Rethinking History, Vol. 17, No. 3, 2013: 312-332; A.R. Galloway, Gaming: Essays on Algorithmic Culture, University of Minnesota Press, 2006.

${ }^{31}$ Civilization

${ }^{32}$ Chapman, “Is Sid Meier's Civilization History?", 315.
} 
epistemological approach of the creator and how they organize facts and evidence of the past into a representational narrative. Chapman points out that historical videogames are forms of narrativization just like other modes of historical communication. They are algorithmic representations of historical data, arranging "evidence of the past into a narrative construct". ${ }^{33}$ The historian's conception of the evidence they gather, no matter the medium they use to present it, is being "transcoded" into a different format or mode than the one it originated from. Chapman calls the historian's task one of "creative transcoding," ${ }^{34}$ interpreting evidence of the past through creative means - and the eventual production of a representation of that historical information. Chapman thus sees videogames as a legitimate form of historical representation.

However, it is important to keep in mind that transcoding, and its process of production involve both a loss and a gain - like any other form of historical representation. The visual component of a video game might make it seem more immersive or realistic to players for example, but some elements must be generalized or simplified when one aspect or model stands in for a complex historical idea. Games construct historical narratives (like academic articles, books, movies, etc.) through the combination of rules and fictive/creative elements. The fictive world being portrayed (which in the case of historical games is often a fictive representation of a historical setting) is better understood through playing a game and grasping how the rules function in relation to the narrative being developed. This works both ways, "the world of the historical videogame is brought to life by action [of the player] and these actions (and their limitations) are in turn constructed in line with and supported by its fictive context". 35

\footnotetext{
${ }^{33}$ Chapman, 324.

${ }^{34}$ Ibid.

${ }^{35}$ Ibid., 315.
} 
I find that it is essential, when analysing historical games, to understand how the playfield (a space of player agency) relates to the fictive world being represented. It is the "interplay of both interaction (form) and historical context (content) that together allow videogames to function as history". ${ }^{36}$ It is critical to understand that games are narrative making endeavours just like history, but first it is important to understand how history is both considered and constructed as a narrative.

While I follow this approach laid out by Munslow in my production of historical narratives within my board game, I also think it is important to reflect on the many ways that games deploy different kinds of historical meaning and understanding. Historical games, whether they follow the approach laid out by Munslow, or a more empirical model, it is necessary to reflect on the many ways that games deploy different kinds of historical meaning and understanding.

Other historians such as Jason Begy in their work "Board Games and the Construction of Cultural Memory" focus on how a complex historical idea such as cultural memory can be understood and expressed through the medium of a board game. Begy does this through an analysis of the railroad's impact on our perceptions of time and space through a series of case studies on railroad themed games. ${ }^{37}$ Begy cites cultural historians of the nineteenth-century rail industry to compare how their metaphorical terms are constructed within games of the board game genre "18xx" (which features over 100 games that recreate the race to build railways in North America in the nineteenth-century). ${ }^{38}$ Rather than focusing on historical places and people,

\footnotetext{
${ }^{36}$ Chapman, 315.

37 Jason Begy, "Board Games and the Construction of Cultural Memory," Games and Culture 12, no. 7-8 (November 1, 2017): 718-38, 734.

${ }^{38}$ Ibid., 726.
} 
Begy focuses on the analysis of historical concepts primarily laid out by Wolfgang Schivelbusch, ${ }^{39}$ like that of the annihilation of space and time with the introduction of rail. To Begy, board games are participating in cultural memory in their "capacity to simulate abstract ideas specific to a historical period". 40

Begy as well as others have argued that board games excel at representation through abstraction and are therefore suited to represent abstract cultural terms and metaphors. ${ }^{41}$ A game that succeeds at storytelling utilizes effective abstract representations of more complex systems representing wealth/victory/resources through a track or physical pieces, which can portray an entire world through a two-dimensional play space. Just as board games represent complex processes and narratives through (various levels of detail) abstract representations, so too could they represent abstract and complex ideas from historical periods. They simply use a different medium as to historians who attempt to represent historical complexities through the form of academic writing.

Begy looks at the abstraction that these " $18 \mathrm{xx}$ " genre of board games use to understand the structural metaphors posited by Schivelbusch's cultural history of the railroad. These structural metaphors included the loss of cultural concepts of time and space, the creation of new space, and the diminishing of the 'character' or 'aura' of a physical space - all of which are changes brought about by the adoption of the railroad. ${ }^{42}$ The board games that Begy discusses showcases these cultural metaphors through abstract representations. For example, placing railway markers over a map of the continental United States, connecting different American

\footnotetext{
${ }^{39}$ Wolfgang Schivelbusch, The Railway Journey. Los Angeles: The University of California Press, 1986.

${ }^{40}$ Begy, 719.

${ }^{41}$ Suckling, "Simulating Saratoga," 104.

42 Begy, 723.
} 
cities together through rail and annihilating that space and therefore making its easier (i.e. faster) to ship goods. ${ }^{43}$ Space no longer functions as a barrier which links to Schivelbusch's metaphor of the annihilation of space that was felt contemporarily in the nineteenth-century. Begy also cites Schivelbusch's use of the primary source Heinrich Hein who wrote on the 'killing of space' by the railways in 1843 and how that cultural attitude and memory is still expressed in board games of the " $18 \mathrm{xx}$ " genre. ${ }^{44}$

The important distinction between Begy's analysis of board games and my own is what is expected of the designer and player, or what is explicit in the creation and play of the game. The link that Begy makes here, between the annihilation of space in the historical and game space, is not one that will be made by players, or even the designer. I doubt the designer, or even less likely the players, would be familiar with Heine's description of the annihilation of space that the growing development of railways caused. For my process to function as history, I need to be explicit in the development process and directly link historical representations to mechanical game functions to express and to impart ideas on historical relationships and motivations. What I find useful in Begy's work is how it highlights that historical perceptions of cultural processes, essentially abstract ideas, can be validly represented within the medium of a board game.

Another useful tool for defining the intersection of board games and history is Scott Metzger and Richard Paxton's work "Gaming History: A Framework for What Videogames Teach About the Past". It provides a much needed and useful typological framework for analysing and discussing the potential benefits games can have for social studies - but more

\footnotetext{
${ }^{43}$ Begy, 729.
}

${ }^{44}$ Ibid., 728. 
specifically how they shape a player's engagement with the past. ${ }^{45}$ Like television and films, video games have become a pop culture medium that introduces its audience to a plethora of historical representations. The difference between films and games is that games allow for active engagement with the historical representations presented. The historical representations in games can be controlled and modified by the player, allowing them to replay certain historical moments and often recreate different outcomes for them.

Metzger and Paxton rightly see games as a unique form of popular culture that has taken root in the everyday experience of many students - from history and other disciplinary backgrounds. They offer a very different approach to representing history in comparison to television, movies, and books; an approach that lets players take control (to a certain extent) of the historical representations being presented. This idea of control is the distinguishing factor within the medium of games (both analog and digital) that sets it aside from other forms of historical communication.

Other scholars have touched on this idea of control and active participation and the unique ability it has to facilitate historical understanding. Lisa Gilbert, for example, conducted a qualitative interview study on a cross-section of high-school students where the students contrasted their experience of playing the historically-inspired video game Assassin's Creed to standard classroom learning. ${ }^{46}$ First, Gilbert identified two forms of narrative construction in the game itself, linear and branching. Branching narratives in video games allow a player's actions to change the course of the story, and as a result lead to different sets of consequences. Linear

\footnotetext{
${ }^{45}$ Scott Alan Metzger and Richard J. Paxton, "Gaming History: A Framework for What Video Games Teach About the Past", Theory \& Research in Social Education, Vol. 44, No. 4, 2016: 532-564.

${ }^{46}$ Lisa Gilbert, “Assassin's Creed reminds us that history is human experience: Students' senses of empathy while playing a narrative video game," Theory \& Research in Social Education, 47:1, 2019.
} 
narrative structures represent a more traditional storytelling approach that can add more "psychological depth" but has a static chain of events that lead from beginning to end. ${ }^{47}$ Gilbert points out that games have been integrating both these storytelling paths (linear and branching) to illicit a deep connection to the character that players inhabit - most importantly to this work, “the potential to create empathy for other people's situations and perspectives in life". ${ }^{48}$

By playing imagined characters and interacting with a branching narrative structure that reveals consequences to actions taken within the created world, players potentially develop a sense of empathy not only towards the character but the world they inhabit and the circumstances in which the characters live and act. That empathy and understanding for the sociocultural contextual situation of the historical agent can also be understood as an understanding of the designers (implicit perhaps) argument about the past - the goal of the historical process as previously laid out by Clyde.

Adam Chapman's more recent work, Digital Games as History, provides a caveat to understanding how these linear and branching narratives actually function in commercial games. ${ }^{49}$ While players will form attachments to the characters being depicted, what keeps them involved is the combat (in the case of 'historical action games') or any other type of 'spatial challenge'. This type of ludonarrative (the narrative that is constructed/progressed through play) is being constructed through "spatially focused material action in the past (e.g. combat and exploration) rather than, for example, political, cultural, or intellectual history." 50 A focus on particular aspects of the material past further entrenches ideas of history as focused on martial

\footnotetext{
47 Gilbert, 110.

${ }^{48}$ Ibid., 111.

49 Adam Chapman, Digital Games as History: How Videogames Represent the Past and Offer Access to Historical Practice, New York: Routledge, 2016.

${ }^{50}$ Chapman, Digital Games as History, 180.
} 
elements or exploration and denies deeper and more complex narratives about history. It should be noted that history can be (and has been) guilty of pursuing selective narratives. This can take the form of ignoring silences in found materials such as the roles of women, the treatment of Jewish communities, and the dynamic between elite and non-elite in Medieval Christian Europe. A focus on military or exploration themes that often define historical video-games means that they communicate very traditional (even antiquated) ideas of the past, as far as historical scholarship is concerned.

Commercial videogames build on the established game dynamics of developed genres (which make a new game knowable and navigable by players) and thus never find themselves grounded in historical scholarship/thought. History is often used in videogames only because it provides the player with an existing knowledge base to help ease play (e.g. players will know and don't have learn that, for example, a "sword" is used for killing). This problematic foundation is what I seek to challenge by building a game founded on an engagement with more complex historical narratives in order to inform on the 'political, cultural, and intellectual' aspects of sixth-century Gaul. There is this duality to games studies, where some try to build a game, or understand how a game can contend with 'proper' academic history. The other side, like Chapman, Gilbert, Squire, and Metzger and Paxton, that try to understand how history is being portrayed ('or deployed') in commercial games that have the ultimate goal of creating an enjoyable and 'playable' game that fits within certain genre definitions. The duality is important to understand in the development of my own thesis project as my game needs to be playable in order to convincingly illustrate my historical argument to the players.

What Metzger and Paxton are trying to achieve with "Gaming History: A Framework for What Videogames Teach About the Past" is look at how video games 'deploy' historical 
elements and how that varied method of deployment affects a player's engagement with the historical content. The 'deployment' of history is described as a designed representation of the past, used to reflect "a perspective, interest, or purpose... [it is] an intentional 'use' of history though all its historical, cultural, or political implications may not be entirely conscious and can emerge from received values or cultural assumptions". ${ }^{51}$ The study of medievalisms helps to identify the provenance of these cultural assumptions. Moreover, a game developed with the goal to subvert these cultural assumptions can better engage and produce a game that tackles complex historical arguments about the past.

There is a reason, however, that commercial game companies fall back on historical generalizations and tropes. Video game companies that are producing these 'historical' games are utilizing history for many of its 'ready-made' narrative structures, not necessarily to 'teach' about history. Playability, how enjoyable the game is, and ultimately marketability come before historical accuracy, something that should be kept in mind when analyzing the impact of these games' historical message. Nonetheless, Metzger and Paxton see videogames as formational for what many students today "know" about history - along with other forms of pop-culture.

Whether or not the games under analysis are communicating 'accurate' or even 'realistic' ideas of the past, historical narratives are still being created and disseminated to the public under these categorizations. One of the forms of historical deployment that Metzger and Paxton define is Antiquarian deployment which "uses the past for ossified objectification and attachment." Antiquarian deployment specifically focuses on material history and the recreation of objects with great detail in order to claim authenticity and a representation of reality, and therefore

\footnotetext{
${ }^{51}$ Metzger and Paxton, 533.

52 Ibid., 537.
} 
history. While focusing on material history is still pushing a historical evaluation and potential argument about the importance of physical objects to understanding the past, it is conflating the historical process and the past as one and the same.

Many of the scholars discussed so far are working with the subject of videogames (as opposed to analog/board games). Although many of their ideas can be related to analog games, it is important to point out some distinctions and certain ways in which analog games can prosper over their digital counterparts for the purpose of illustrating a complex argument about the past.

\section{Analog and Digital: A Look at Form}

Adam Chapman notes that one distinction between board games and videogames is the idea of 'black-boxing.' Board games require you to familiarize yourself with the rules before playing the game, whereas videogames black-box information and lead you through the experience and inform you of the rules only when you need to know them. ${ }^{53}$ Chapman makes the claim that this difference between mediums gives video games a more historically accurate representation of historical knowledge since historical actors would not have information about the possibilities or consequences of their actions. I would disagree with this historical assumption as historical actors would be very knowledgeable about their position within their historical context, even if some information is intuitive. It is the player, playing as a historical agent who is not clued in on the motivations, agendas, and agency that their player character(s) have. They are the ones that need to better understand the wholly different historical context in which they must now operate.

\footnotetext{
${ }^{53}$ Chapman, Digital Games as History, 187.
} 
Learning the rules of a board game before playing should clue the player in on the possibilities that are afforded to the character they are inhabiting - a context and world their character grew up in and would understand far better than the person playing them. Chapman's comment on the historical agent not knowing the consequences of their actions is valid. However, in the structure of a board game, there are always other players you are competing with, possibly with an imperfect understanding of the rules. This reflects the uncertainty of strategy and decisions as there are always other agents that may be working against your plans.

Board games need to establish their rules so that the player understands the historical context they are playing within, and the actions that are historically possible for their character to perform. That uncertainty, which undoubtedly existed for historical agents, appropriately comes from the fact you cannot read the minds of your opponents, and their actions may change the outcome of your efforts. Players need to read the rules first not just for them to be able to play, but it is also to get them into the position/mindset of the agents they are going to portray. These historical agents are already clued into their position and agency that is afforded to them in their position. Historical kings, bishops, queens, and nobles all understood what their roles in society were - not to say they never challenged those roles - but often they knowingly acted within its rules and structures to succeed and achieve their own goals. In a game, therefore, the rules act as a contextual primer for players that describes and explains the complex underlying sociocultural rules of the character and historical world the player will be inhabiting (and that real historical actors would know). Video games function quite differently, as they do not come with a rulebook and therefore, they do not receive an official contextual primer prior to playing the game. 
Video games treat the player as a newborn, someone who needs to work their way through and understand the rules of the historical context and can, within circumscribed boundaries, develop their own choices and thus character identity. In my game, players will be inhabiting agents that have lived and operated in the historical world, and therefore are clued into the possibilities afforded them and the ways in which they can express their agency. This predetermination of action is enacted in a board game by the players reading the rules beforehand so that they can better represent their characters. Rulebooks allow for a more explicit representation of historical actors and forces - something which History aims to do. Moreover, rulebooks can afford the space to the designer to make explicit their historical argument through the design of the game.

I believe that the rulebooks for board games can have a similar pedagogical effect for the player when compared to a video game's slow feeding of rules to a player over time. The ability for the clear dissemination of historical information is all of course dependent on the essential connection of historical narrative and mechanical function in the game which is an important aspect for narrative driven games to have.

Board games and video games also progress the narrative in their respective mediums differently. Movies, and the vast majority of video games with only one ending, progress their narrative outside of player choice. Board games have an open story structure where the actions of the players drive the narrative, and the ending (whoever wins the game), is not pre-determined. Counter-factual history within games constitutes an 'open story structure,' where the game/historical narrative of the game is not deterministic. This allows the players to explore the possibilities of a historical event and the probabilities and possibilities of a given historical context. An open story structure allows for exploration and investigation within a curated 
(through research) space. Open should not be misconstrued as 'endless,' however. The existence of rules indicates a limiting structure. That limitation is there in order to control and relegate the understanding of the designer's historical argument. Limitation, established through the design of the game, helps to communicate the possibilities and probabilities of the given historical context.

The way in which board games are built allows for greater openness, meaning they allow for more player control over the development of the narrative. This can be facilitated through the random generation of outcomes either produced through dice rolls or drawing cards. Chris Klug in his work "Dice as Dramaturge" hails board games/pencil-and-paper games as providing a "foundation for the emotional experience; tangibly manifesting the world to the players as they manipulate the world's totems - the dice. ${ }^{.54}$ The random generation of events through drawing cards and the outcome of those events through dice rolls help to constitute an open story structure wherein players feel connected to the outcome of the narrative but are still limited in what can happen.

Video games as well as movies, according to Marc Arnaudo, do not possess this playerto-narrative connection but rather "independent momentum", where the development of the narrative is independent of player/viewer engagement. ${ }^{55}$ The closer involvement that the players have with the progression of the narrative in board games is also seen in the deployment of strategy on the part of the player while playing. Arnaudo posits that the strategy developed by the player mirrors that of the world being depicted, as long as there is a strong tie between the ludic function of the game and the narrative being represented. Arnaudo states, "Consistent game

\footnotetext{
${ }^{54}$ Chris Klug, "Dice as Dramaturge," in Tabletop: Analog Game Design, Edited by Greg Costikyan and Drew Davidson, Pittsburgh: ETC Press, 2011: 39-47.

${ }^{55}$ Arnaudo, 33.
} 
mechanics and evocative components may be very effective in creating the illusion of a fictional world and in depicting processes that supposedly occur within it." ${ }^{, 56}$ Variability on the options of players that directly relate to narrative development is thus a crucial aspect to consider when developing a game in order to communicate historical ideas/argument. The function (mechanics) of the game needs to directly relate to the narrative being portrayed so the players can see the causal effect of their actions on the larger process of the narrative/argument of the historical creator.

Analysing how games are designed and how they function is crucial to understanding how they may communicate historical themes and ideas. Marc Arnaudo's book Storytelling in The Modern Board Game, provides a useful indicator of how (to many degrees) narrative operates within the structure of board games specifically. Representation within games functions on a spectrum according to Arnaudo ranging from completely abstract to prominent representation. He positions the representation of games along this spectrum according to how their game components (mechanics, rules, and physical/aesthetic aspects) relate to the theme being portrayed. He gives the example of checkers being a completely abstract example where the simple mechanics of moving circular disks represents the theme of two armies waging war. Games on the other side of the spectrum that feature prominent representation would have their components specifically devised to "fit the theme in a mimetic fashion" 57 such as tabletop wargaming that simulates the conflict of specific historical events. ${ }^{58}$

\footnotetext{
${ }^{56}$ Arnaudo, 33.

${ }^{57}$ Ibid., 9.

${ }^{58}$ Warlord Games is a leading creator and distributor of multiple tabletop historical simulation games, used for recreating multiple historical scenarios ranging from the time of Caesar, Napoleon, WWII, and many periods in between https://store.warlordgames.com.
} 
Moderate and prominent representational games have strong, concrete, and identifiable themes that are represented through gameplay. It is this crucial relation, Arnaudo posits, between rules, physical components, the actions of the player(s), and the way those aspects drive and develop the narrative of the game revealing its theme and purpose that makes for a narrative experience through the medium of a board game. If I am to construct a historical argument about the past within this medium, I have to understand the aspects of both how it is constructed and the best ways in which to facilitate the communication of my narrative.

Part of my work will be arguing that games have an impact on how people perceive the past, especially around games that label themselves as 'historically accurate' or 'authentic'. These games often have the potential to perpetuate false ideas of history or drastically outdated methods of approaching historical topics (oversimplification or the ignoring of 'othered' groups), such as how Adam Chapman identified Sid Meyer's Civilization as perpetuating the empiricalanalytical approach to history. By developing an approach to communicating complex historical ideas through the medium of games, we can both produce games that tackle inaccurate or harmful narratives as well as illustrate how games have continued to perpetuate some of these misconceptions specifically about the Middle Ages.

My game Divided Kingdom, 561 seeks to do more than simulate the past (a very difficult thing to do in a board game without the help of visual and aural representations) as seen in video games, or digital-ludic-reenactments, and traditional physical reenactment. ${ }^{59}$ It seeks to present a complex and well researched argument about the past that challenges popular conceptions of the Middle Ages that are often perpetuated within the medium of board games through the

\footnotetext{
${ }^{59}$ Chapman, 255.
} 
application of the theories listed in this chapter regarding the role of narrative in both History and games.

This project will now turn to an analysis of three board game case studies to better illustrate how board games communicate historical arguments. 


\section{Chapter Two: Case Studies - Applying Theory}

Board game design depends on precedents. Knowledge of pre-existing games (by both designers and players) constitutes a shared mental library of actions, rules, practices, and assumed knowledge about how games work. My own choices as a designer are determined in part by what games I have played before and what they have taught me is a typical (or fun) mechanic. ${ }^{60}$ I want to explore how this gaming history, therefore, suggests both how my choices are influenced, but also how this gaming past proposes useful pathways for design. I analyze three games to explore how their design facilitates historical learning. Moreover, I will investigate if that historical learning can, with intent, communicate complex historical ideas and relationships.

This chapter will discuss three case studies of historically-themed board games: Wallenstein,${ }^{61}$ Western Empires, ${ }^{62}$ and A Feast for Odin, ${ }^{63}$ in light of the discussion in the previous chapter. I interpret how they demonstrate Scott Metzger and Richard Paxton's categorization of the various ways that games 'deploy' history and look at how each game uniquely utilizes 'dynamic interactivity. ${ }^{64}$ I will also look at them with respect to Adam Chapman's "ecological approach" and definition of "open-ontological story structure" to better understand the designed connection between player action and narrative development in games. ${ }^{65}$

\footnotetext{
${ }^{60}$ The term I use here, mechanic, has a specific meaning when applied to board games. It differs from a 'rule' in that it constitutes a structure which often includes a collection of individual rules. If we take a common example, chess, we can identify the mechanic of moving within a grid structure with black and white spaces. Then, we can isolate the individual rules that make up the general mechanic of moving - the individual ways in which each distinct piece moves as well as the rule that lets pawns move two spaces on their first move.

${ }^{61}$ Dirk Henn, Wallenstein, Board Game, Queen Games, 2012.

62 John Rodriguez and Flo de Hann, Western Empires, Board Game, 999 Games, 2019.

${ }^{63}$ Uwe Rosenberg, A Feast for Odin, Board Game, Z-Man Games, 2016.

${ }^{64}$ Scott Alan Metzger and Richard J. Paxton, "Gaming History: A Framework for What Video Games Teach About the Past," Theory \& Research in Social Education, 44:4, 2016: 532-564.

${ }^{65}$ Adam Chapman, Digital History as Games: How Videogames Represent the Past and Offer Access to Historical Practice, New York: Routledge, 2016, pages 223 and 186.
} 
Marc Arnaudo's work on how games combine narrative and thoughtful design to create story experiences will be a useful study for analyzing the mechanical structure and functions of games. ${ }^{66}$ Finally, I will discuss Jeremiah McCall's framework of creating a 'Historical Problem Space' and the extent to which these individual games create a space for historical literacy. ${ }^{67}$

My starting point is the popular board game review, catalogue, and forum site Board Game Geek which offers some metrics (where applicable) in these case studies, as well as for its role in community engagement with these board games. ${ }^{68}$ The BBG website has over 20,000 ranked board games and 1,493,012 registered users as of Feb. 4, 2017, and features a Top 200 list of board games with 1.9 million registered users making it a well-engaged with community. ${ }^{69}$ The site has been used by other scholars for its pervasiveness as a "community hub" for board game reviews, as well as for a metric for analysing the pervasive inequality in gender and racial representation within board games. ${ }^{70}$

The application of these theoretical frameworks and considerations will aid in the development of the third chapter of this thesis, the annotated rulebook. I can better know how to communicate a complex historical narrative through the design of Divided Kingdom, 561 by understanding how these three historically-themed board games work (successfully or not) to establish a historical narrative through their design. What becomes clear throughout these case

\footnotetext{
${ }^{66}$ Marc Arnaudo, Storytelling in the Modern Board Game: Narrative Trends from the Late 1960s to Today, McFarland, 2018.

${ }^{67}$ Jeremiah McCall, "The Historical Problem Space Framework: Games as a Historical Medium," Game Studies, Volume 20, Issue 3, $2020<$ http://gamestudies.org/2003/articles/mccall $>$.

${ }^{68}$ Scott Alden, Board Game Geek, Website, 2001, https://boardgamegeek.com/.

${ }^{69}$ Tanya Pobuda, "Assessing Gender and Racial Representation in the Board Game Industry," Analog Game Studies, 2018, https://analoggamestudies.org/2018/12/assessing-gender-and-racial-representation-in-top-ratedboardgamegeek-games/.

${ }^{70}$ Shelly Jones and Tanya Pobuda, "An Analysis of Gender-Inclusive language and Imagery in Top-Ranked Board Game Rulebooks,” Analog Game Studies, December 6, 2020, https://analoggamestudies.org/2020/12/an-analysis-ofgender-inclusive-language-and-imagery-in-top-ranked-board-game-rulebooks/.
} 
studies is that board games possess the informational, technological, and narrative potential to tackle what we can consider 'complex history.' The theories applied to these case studies have allowed me to understand the narrative potential that board games possess as well as their capacity to communicate abstract ideas within a minimal (compared to the academic literature) textual space through the use of images, physical pieces, and mechanical structures (rules).

In addition to exploring the application of these various historical game studies theories and frameworks, these case studies allow me to show how board games typically communicate historical narratives. Each game, through its unique mechanics, evinces a varying level of historical complexity and each offers a different kind of historical narrative. For example, Wallenstein shows no desire to challenge typical narratives or to nuance its subject matter with a complex level of historical knowledge. It utilizes 'monumental' forms of nationalised history that draw upon well-known figures and monuments from the Thirty-Years War in order to create a sense of 'authenticity' based in familiarity. ${ }^{71}$ Western Empires makes an attempt at a more complex idea of history through asking game-players to interrogate assumptions about sociocultural and historical processes. It favours western-empirical forms of history and attempts to devise a formula for 'historical success'. The last case study, A Feast for Odin, communicates a complex version of history in comparison to the other case studies. It challenges false conceptions of the 'Viking Age' and attempts to illustrate a more nuanced picture of this period through a look at a variety of historical and socio-cultural factors.

The narrative and historical function of the various mechanics of these games (and what works well and does not) provide the foundation for me to develop my historical game - the

\footnotetext{
${ }^{71}$ Metzger and Paxton, "Gaming History," 546.
} 
main thrust of this project, Divided Kingdom, 561. In breaking down the function of the game mechanics of these three case studies I demonstrate how they communicate complex implicit historical narratives. I interrogate to what extent do those narratives line up with academic conceptions of the represented historical processes. This chapter thus seeks to answer, are they communicating a historical picture that speaks to more than an antiquated and/or pop cultural version of that history? Are they attempting to engage with the complexity of the periods they are representing or merely producing a product that will give the impression of 'authenticity'? My goal is to showcase that, through game design, board games have the capability of asserting new and engaging historical perspectives.

My study concludes that there are varying degrees of historical complexity established through the design and function of the three board game case studies. Every game analyzed in this chapter indeed develops its own historical narrative and assumptions about the past. The effort of understanding how these games construct and communicate these individual narratives highlights the possibility of board games as a viable medium for complex historical learning. The ultimate justification of this claim, that is established throughout this chapter, will aid in the creation of a functioning board game that actively seeks to present a historical argument about the past through a narrative structure. The case studies highlight the potential board games have to construct a narrative and the many ways in which they create and develop a narrative through their design. 


\section{$\underline{\text { Historical Monumentalism - Wallenstein }}$}

The first example I wish to analyze is Wallenstein - a tabletop board game designed by Dirk Henn and published by Queen Games in 2002 with a second edition released in $2012 .{ }^{72}$ It is played by three to five people vying for territorial control of the many provinces of seventeenth-century Germany during the Thirty Years War

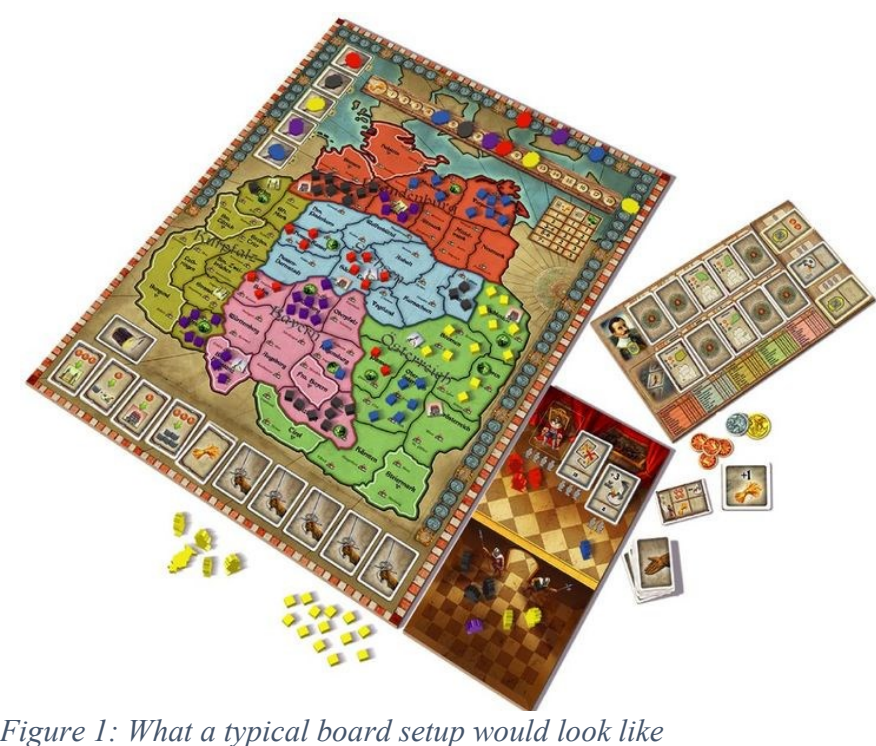

(1618-1648). The game has been commercially successful, as well as being recognized by the game community as a design success - achieving Runner-Up for the International Gamers Award for Best Advanced Strategy Game in 2003. Wallenstein attempts to communicate a clear historical narrative and thesis about the Thirty Years War. However, its narrative monumentalizes the history of the Thirty Years War rather than constructing an articulate and complex historical argument. Wallenstein represents a historical game that has little to no connection between the mechanics and operation of the game and the historical narrative being communicated. Without these two aspects working in tandem, one affecting the other, the resulting historical statement made is far too generalized and unable to communicate a complex argument about the past. The absent connection between narrative and mechanics makes Wallenstein an excellent first case study to help understand what not to do when constructing a

\footnotetext{
${ }^{72}$ The second edition offered slight variations on the rules as well as some aesthetic changes. There are also two expansions to the game that introduce new rules - "Emperor's Court" and "Landsknecht." My analysis discusses these expansions since they are included in the second edition base game, which is the most widely circulating version.
} 
historical board game - if indeed the goal of the design is to critically engage with sociocultural relationships of the past.

Board Game Geek (BBG) features over three-hundred reviews for Wallenstein (Second Edition) and over 12,000 ratings. ${ }^{73}$ The site also provides community-generated categorizations of the game including: 'History-Thirty Years War,' 'Pike and Shot,' 'Renaissance,' 'Economic,' and 'Territory Building.' These descriptors indicate the nature and type of game to which Wallenstein is generally perceived to belong; users highlight their awareness of its historical nature and link it to broad historical periods like the 'Renaissance.' The descriptor of 'pike and shot' categorizes it as a historical strategic war games - by referencing an early-modern military formation of black powder weapons and pikes. ${ }^{74}$ When interacting with these categorizations, readers perceive narrative and ludic possibilities, allowing them to gauge their possible interest in the game or how the playstyle and theme might unfold together.

These tags also reveal the type of gameplay Wallenstein offers as 'territory building' and the more general category, 'economic'. The term 'territory building' evokes a familiar genre for seasoned board game players, defined on $B G G$ as, "Territory Building games have the players establish and/or amass control over a specific area. Often, these games employ Area Majority/Influence or Enclosure mechanics; the latter in which the areas are not delineated at the beginning of the game are instead created as the game progresses." ${ }^{, 75}$ These rather set and

\footnotetext{
${ }^{73}$ Board Game Geek, Wallenstein Second Edition, https://boardgamegeek.com/boardgame/109125/wallensteinsecond-edition.

${ }^{74}$ Warlord Games, Pike and Shotte, https://store.warlordgames.com/collections/pike-shotte.

${ }^{75}$ Board Game Geek, Territory Building, https://boardgamegeek.com/boardgamecategory/1086/territory-building.
} 
generalized mechanical functions both familiarize the players with the game's rules and 'flow' as

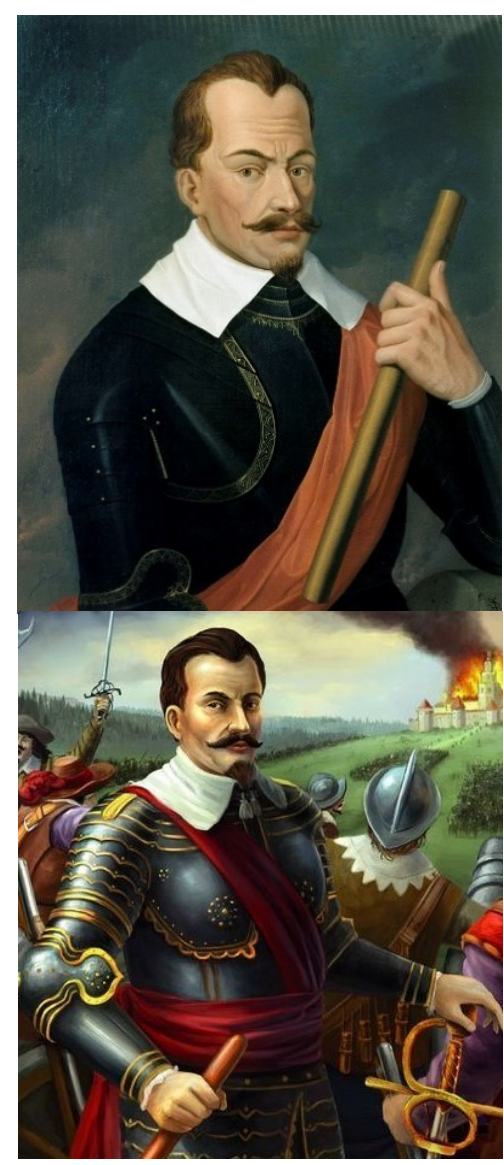

Figure 2: Upper: Albrecht von Wallenstein by Anthony van Dyck, 1629; Lower: Wallenstein Cover well as, more crucially, determine how the narrative will unfold.

In the game of Wallenstein, each player takes on the role of a military leader (and in the "Emperor's Court" expansion, you also must play as a courtier of the emperor) during the Thirty Years War. The information on your character is very limited. You are given their name, which includes their title - either "Graf (Count)" or "König (King)" - and the date of their birth and death. ${ }^{76}$ There is also a portrait of the characters that closely resembles their historical paintings (see figure 2). Aside from this, players are left to imagine why these characters are pitted against each other in combat - their personal motivations and/or loyalties are left to be filled in by the player. However, players do more than simply wage war on each other, the main goal of the game is to acquire victory points. This goal is achieved through

controlling counties and in order to construct the three types of buildings (trading posts, churches, and palaces) which accumulate victory points for them. Bonus points are awarded to players who possess the majority of a particular type of building in each region (denoted by colours, see figure 1). While players must focus on building up their victory points through conquest and building projects, they must also manage their treasury and food supplies.

\footnotetext{
${ }^{76}$ A sense of authenticity is conferred by using German titles. They are not translated from the original German but kept in the English edition.
} 
Statecraft becomes just as important as military leadership, as if you tax a certain territory too often, it may revolt when winter arrives - potentially leading to the loss of that territory.

As the simple gameplay suggests, the goal of Wallenstein is not to offer narratives of the past or provide a complex historical interpretation about the Thirty Years War. The lack of intent for communicating complex conceptions of the past is evident in the absence of any historical introduction or a narrative vignette explaining why characters are fighting against another. Based on the game materials alone, a player would learn some names of key historical actors (all of which were upper-class men), political communities and geographic places, and would be left with the idea that seventeenth-century Germany was riven by military and economic rivalry. Players would not question what the larger historical conflict of the Thirty Years War was nor what was the motivation of your particular character.

If we consider Metzger's and Paxton's guide to how games 'deploy' history, we could categorize Wallenstein as 'monumental' in its deployment of history. There is a sense of "connection to cultural heritage" for those connected to or informed in European history - many people have at least heard of the Thirty-Years War. $^{77}$ Understandably, to the native-born German creator Dirk Henn, the Thirty-Years War may be quite familiar as well as equally familiar to a broader German audience. The board represents the many provinces of seventeenth century central Europe (which would later form to become Germany). Henn is appealing to a sense of monumental history, something that will be elaborated on below. The place names would be familiar to a German audience (the initial country and language of publication) and evoke a shared sense of history without communicating any complex meaning about the past. Historical

\footnotetext{
${ }^{77}$ Metzger and Paxton, "Gaming History,” 546.
} 
representations are present in 'big names' of generals like Albrecht Wallenstein or Gustavus Adolphus, as well as in the old names and separation of modern-day Germany. In one of the expansions, The Emperor's Court, players are then introduced to 'the emperor' who is assumed to represent the Holy Roman Emperor at the time. There are no critical statements about history being made, however even though the game projects a vague sense of 'accuracy' where historical titles (in German) are thrown around and players are left to fill those monumental roles of waging warfare and participating in statesmanship. The 'monumental' approach to the deployment of historical themes remains uncritical and vague about the historical narrative that is being represented.

Within the world that is being represented in Wallenstein, there are features providing a sense of 'authenticity'. Adam Chapman describes this as an "ecological approach" which, in the context of games, is a concept describing the relationship between the player and the affordances given to them from the game. The affordances are actions a player can take within the structure of the game while playing as a determined historical agent (e.g. Albrecht von Wallenstein in the context of this case study). They allow the player to better understand what actions are historically afforded to their embodied historical agent and what kind of reaction(s) results from enacting upon those affordances. Chapman notes that the ecological affordances occur in a manufactured space and that the historical knowledge that results from them are "determined by their referential status." This means that it is the designer's understanding and interpretation of the represented past that informs the construction of the narrative and the larger historical message that is being communicated through it. ${ }^{78}$ The historical knowledge and educational intent of the game designer sets the groundwork for what message about historical processes will

\footnotetext{
${ }^{78}$ Chapman, Digital History as Games, 223.
} 
be created through the game's mechanical structure. As in academic work, the research stage is vitally important, and foundational, to the endeavour of history. Otherwise, popular conceptions of the past, and (as we have seen through Metzger and Paxton) monumentalized and nationalized history will be communicated in place of more complex and objective ideas of the past. These affordances attempt to represent the 'original' (historical) relationship by showcasing the possibilities and potential of historical action. The concept of ecological affordances put forward by Chapman is an essential framework to understanding how history is being used and communicated in games, as it represents the all-important connection between game function/mechanics and the communication of historical knowledge.

By applying the ecological approach to Wallenstein, I argue that it a relationship between the general people that inhabited the regions showcased in the game and the military and political figures whose identity the players assume. Taxation is an important affordance given to the player as a governor of multiple territories. With over-taxation of the people you govern, you risk peasant uprisings. Revolts over food shortages directed at the ruling elite were a concern during this period. A player comes to understand from these affordances of taxation that it must be done sparingly (and thus, must have been done sparingly historically). Moreover, when you move your armies into a 'neutral' (meaning unoccupied by another player) territory, you face resistance from the inhabitants (although it is quite meager compared to that of trained soldiers). Players are reminded by these rules that there is a living and breathing population that provides them with tax and food supplies but could also turn on them and resist their occupation; a resistance that has varying degrees depending on the amount you tax them or based on how severe your food shortage may be. Historical knowledge thus is gained by understanding the 
mechanics of the game. As the player interacts with the system, they better understand the historical system that Wallenstein represents.

The role between mechanics and the communication of history can also be understood through Metzger and Paxton's idea of 'dynamic interactivity. ${ }^{, 79}$ Dynamic interactivity is described as a key element that separates games from other forms of media - being the ability to interact with the media itself (unlike literature or film). It is this player interaction with the game that progresses the narrative, rather than the participant passively engaging with the narrative. If we understand this in the context of Wallenstein, player actions such as the failure to store enough grain or over-taxing a province, lead to further narrative experiences - the outbreak of peasant revolts may lead to losing the territory and therefore the loss of victory points (and ultimately the game). The structure of these games (or its 'ecological framework') is a web of interactivity between the game rules, the actions of the players (those afforded and those taken), and the narrative that results from those actions. This system facilitates an understanding of historical causation, or at least the limited historical causation understood and allowed by the designer. Thus, a game such as Wallenstein which does not have any overt function or desire to communicate historical complexities, still communicates ideas about the past through its intrinsic structure as a board game and its historical 'meta-story' or overlay.

\footnotetext{
${ }^{79}$ Metzger and Paxton, "Gaming History,” 557.
} 
Although there is little forced narrative (meaning the players largely construct their own narrative through their actions and imagination), there are many game mechanics in Wallenstein that encourage a narrative arc and let the players fill in the story as the game unfolds. One of the mechanics that stands out as unique among the historical wargaming genre is the 'dice tower' feature (Fig. 3). The 'dice tower' is a pre-built carboard structure that resembles a stone tower.

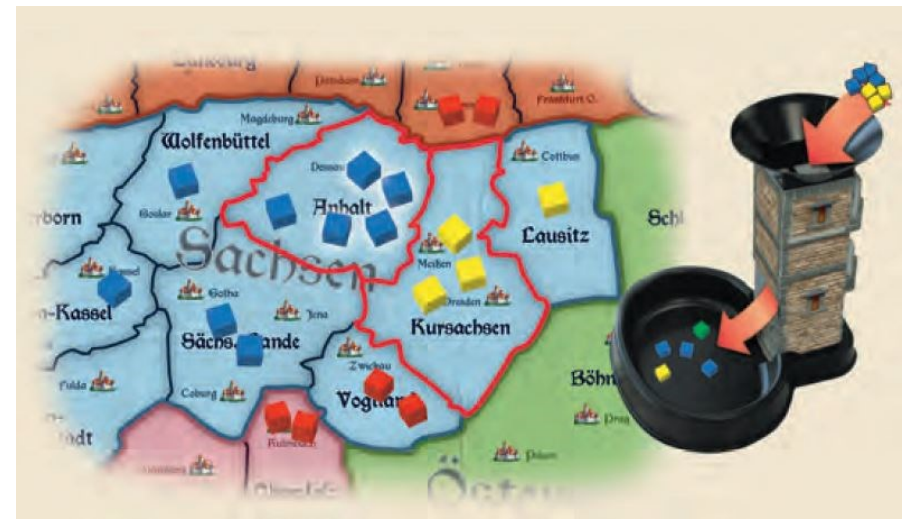

Figure 3: The dice tower mechanic, from page 12 of the Wallenstein Rulebook.
Inside are levels of carboard with segments cut out to obstruct the path down the tower into a collection tray. When two opposing armies face off in combat, the cubes representing the soldiers on the battlefield are thrown into the tower. Some will get caught on the

multiple levels and not come out, some will fall through to the collection tray, and previous cubes in the tower may fall out with each successive combat. The two opposing forces compare how many of their cubes have made it through the tower and into the tray, the winner of the combat is the player with the most cubes left over - placing them back onto the battlefield. If we are to treat games as a form of 'historical literacy' as Metzger and Paxton suggest, we can take this mechanic and interpret the historical message that is being curated by the author of the game. When it is decided that two armies will engage in combat, there is no strategy involved after that. The armies are thrown into the 'dice tower' and are left up to chance to determine who will win (and by how much). Perhaps the blue player sends twelve army cubes against the yellow player's seven cubes. It is entirely likely that yellow can come out victorious if blue's cubes become blocked inside the tower. Another potential factor is that some of yellow's cubes from 
previous engagements are dislodged and fall into the tray, resulting in yellow having more cubes in the result. It creates a sense of randomness when engaging in conflict, having more cubes (soldiers) is really the only advantage you can over someone. As part of the extra-game experience, players might construct a narrative about how the soldiers (i.e. cubes caught in the tower) have fled combat - and will potentially return in the future, or reinforcements arrive in the nick of time to aid in the conflict. It creates a tense dialogue that players construct on their own.

Another game scholar, Celia Pearce, sees the authors of games as 'context creators' or a facilitator for the players to become storytellers through their actions. ${ }^{80}$ In Wallenstein, it is very much up to the players to create the narrative. As my project endeavours to understand how (if at all) complex historical ideas can be communicated through the medium of board games, the designed narrative is at the forefront of this potential complex communication. If the burden of narrative understanding and development are on the player, the design process serves little to no purpose. Players will develop their own ideas of historical processes rather than have a designed argument of the past communicated to them - which is the goal of this project. This aspect of te game identifies a key nature of my own game, Divided Kingdom, 561 which wants to embody an argument about the past in the game and communicate it to the players. Rather than having the players formulate their own understanding of what the narrative of the game might be, it will be communicated explicitly through the mechanics and textual information of Divided Kingdom, 561.

Combat, as seen through the mechanics of the 'dice tower', provides an abstract outcome to conflict, leaving it to the players to decide the narrative reasoning for the outcome (or to

\footnotetext{
${ }^{80}$ Celia Pearce, “Towards a Game Theory of Game,” Electronic Book Review, 2004.
} 
ignore the reason altogether). Pearce puts emphasis on a 'play-centric context' for the development of narrative. Narrative is born out of the system of rules rather than the game primarily being a story that has playability. First and foremost, games are systems of rules. Pearce uses the term 'experiential' to define how the narrative operates in games. The term means that narrative develops out of the inherent conflict of the game that the players experience themselves. ${ }^{81}$ The mechanics of the 'dice tower' narratively facilitate how combat unfolds. The drive players have for conquering territories, the 'inherent conflict', unfolds a narrative throughout the game. This of course requires a narrative overlay that Pearce describes as a 'metastory.' The meta-story is present in the context given for the main conflict - the Thirty Years War as well as the goal of the game which is to conquer and develop territories. Understanding this connection between mechanic and narrative is essential to this thesis project and the development of a game that seeks to communicate a complex and informed historical narrative through the medium of a board game.

There are other mechanics within Wallenstein that add to the narrative experience and development of the game. Event cards represent the passing of the seasons. Each one adds a slight rule variation like additional costs for recruiting soldiers or taxation is limited to a certain amount of thalers (the game currency). Event cards will also determine how much food is lost when the winter turn arrives, adding a random element to how much you will have to stockpile to avoid revolts. This mechanic puts emphasis on the potential threat that winter poses to campaigning armies and the management of food supplies for large populations, as well as the fact that weather can be unpredictable. The event card in figure 4 adds the temporary rule that no battle can take place in a country that has a church building in it. There is no extra-textual

${ }^{81}$ Ibid., 3. 
information that accompanies this added rule, and no justification for its existence. It simply is added to increase the complexity of the gameplay. As with other game mechanics discussed in Wallenstein, the narrative that the event cards generate is solely up to the player to

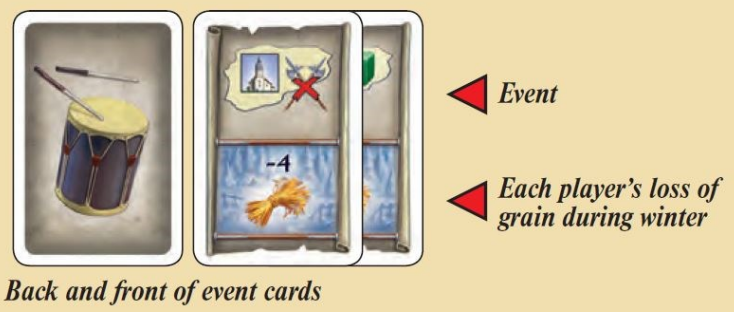

Figure 4: Events cards, the top portion represents the particular game effect this round and the bottom shows the amount of grain lost (if it is winter). From page 2 of the Rulebook. interpret. There is no given historical justification for churches to be subject to an armistice during a randomly chosen season. The event cards progress a narrative, however, it is not grounded in any historical justification. The meaning of the particular narrative development is not directly tied to a player action or historical precedent - it merely exists to make the game more 'dynamic' or 'eventful'.

Turn order is also presented in a way that randomizes each season. The ten different actions that are open to players are always randomized - meaning you may have to recruit soldiers before you raise taxes. This can ruin plans or provide unseen opportunities that were not available before. It adds a level of strategy to managing your territories and waging war simultaneously. However, this does not always equate to a plausible or realistic representation of the past. While it is likely designed as a twist on classic game genres such as 'worker placement', it still communicates and can be understood as a historical assumption about the past - the futility of planning in the face of unknowns such as weather and the actions of other historical agents.

While the history being presented in Wallenstein may seem (uncritically) as largely absent of pushing forward a historical narrative, we can still see how its game mechanics can 
facilitate a narrative experience and even go as far as to use it as a form of historical literacy. Wallenstein relies on randomized mechanics to facilitate a narrative that builds upon its metastory framework or 'the Thirty Years War'. What we can read from the creator's assumptions about this historical period is that warfare is random and chaotic. Peasants have the power to revolt and take territories if they are pushed to the limit form taxation or left to starve by their new rulers. We are told that people had a form of agency in the form of protest and revolt. From the 'emperor's court' expansion we can see that these lords had to also play the role of politician with the emperor in order to gain an advantage over other factions. There are historical themes and messages being implicitly conveyed about this period in the mechanics of the game. Although they are not always blatantly obvious or complex and critical, they are still present in the game's rules and development of story.

While it can still be argued that Wallenstein's gameplay produces a narrative about the past, I have shown that there is a disconnect between the operation of the game and the resulting narrative. The player plays an equal role with the design and function of the game in the production of the narrative. The monumental and generalized historical narrative of the Thirty Years War in Wallenstein can easily be swapped out with another period in time and still make the same generalized claims surrounding the chaotic nature of warfare, the role of the elite statesman, and the effect disgruntled populations can have on economic and political stability. The fluidity of the application of a historical context is evidenced by the "reimplementation" of the rules of Wallenstein in 2006 by the same designer and company into a brand-new game, Shogun. Shogun features identical components and gameplay (the notable dice tower mechanic) to Wallenstein but with the historical context of the Japanese Sengoku period (1467-1573CE). ${ }^{82}$

\footnotetext{
${ }^{82} \mathrm{https://boardgamegeek.com/boardgame/20551/shogun.}$
} 
The fluid application of historical context takes away any proper contextualization that the mechanics of the game may offer. If one aspect of the game can be removed without affecting the other, then there must have been no tangible connection in the first place. While I have argued here that Wallenstein is indeed communicating a historical narrative, the disconnect between its mechanics and narrative production is too tentative to constitute anything more than an over generalization of the historical period being represented.

The author Marc Arnaudo points out that the mechanics in a game often represent something outside their ludic function - and hopefully that ludic function and represented function work in tandem to tell a story. ${ }^{83}$ Wallenstein's 'dice tower', event cards, and revolt system all represent a thematic element that attempt to communicate an assumption about historical processes. The representational level of these components varies, sometimes the connection can be prominent (as in Wallenstein) or minimal (as in checkers). ${ }^{84}$ If the goal of the game designer were more outside of commercialization and playability (which it is often not), a complex historical picture could be conveyed through strong and poignant historical representations through the game's mechanical structure. Instead, for many games including Wallenstein, historical generalizations that line up with people's expectations of history - or the bare amount to convey a sense of historical authenticity - is all that is needed for an audience seeking pure entertainment. Having said this, even with a historical veneer or metastory that does not seek to communicate a complex historical picture, it still acts as a form of historical literature. It contributes to popular conceptions of the past, draws upon common tropes and beliefs and communicates all of this through a designed narrative that is facilitated through

\footnotetext{
${ }^{83}$ Arnaudo, Storytelling in the Modern Board Game, 20.

${ }^{84}$ Ibid., 9.
} 
the mechanics of the game. Wallenstein suggests the potential of board games as mediums that can facilitate the communication of more complex historical narratives - where the intent, drive, and desire for the communication of a complex historical argument is the only thing missing. 


\section{A Macro History of All Civilization - Western Empires}

The board game Western Empires was developed by John Rodriguez and Flo de Hann and is a 2015 adaptation of an older board game, Civilization, created by Francis Tresham in 1980. Rodriguez and de Hann published the first iteration of the game under the title Mega

Empires (originally being called Mega Civilization). The Mega Empires version included a much larger board that encapsulated both the 'eastern' and 'western' worlds as playable civilizations.

However, the focus of this

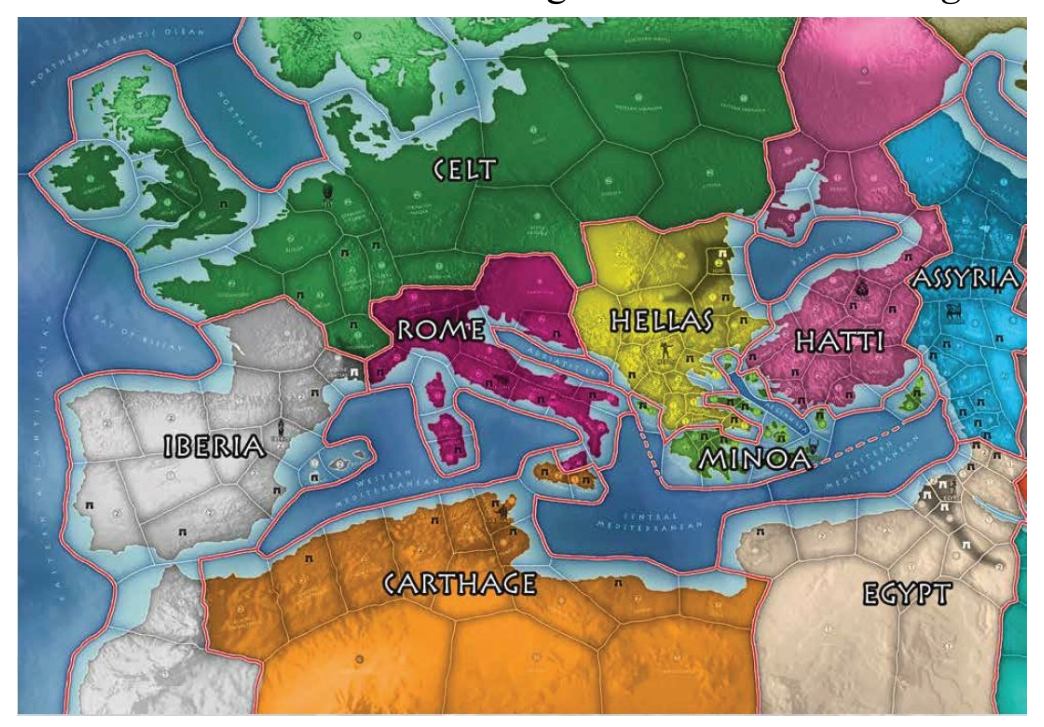

Figure 5: From page 14-15 of the rulebook depicting the main board and division of the different playable civilizations.

case study will be Western

Empires as it is the latest and most readily available version of the game. Western Empires saw a republication in 2019 as a paired down version of Mega Empires made for fewer players (five to nine as opposed to the original eighteen player game) and only includes civilizations that inhabited the Mediterranean world. Players take control of one of nine civilizations: The Iberians, Hellenes, Minoans, Hattians, Assyrians, Egyptians, Carthaginians, and Celts (figure 5). Players begin at the start of the Stone Age and continue through until the end of the Iron Age (approximately an 8000-year period as stated in the rulebook). Players/civilizations make their way through the game by expanding the territory and population of their peoples, seeking to develop the most prosperous nation as determined by "civilization advancements" (detailed below) and the number of urban centers they create. Western Empires makes an important 
distinction through both the mechanics and advertising of the game that distances itself from warfare that many other historical games have as a traditional focus. The introduction of the rulebook in Western Empires makes it clear that it is not a "wargame", making the goal of the game to advance past other civilizations through "cultural, economic, scientific, political, civic, and religious" means (although warfare is not entirely absent from the game) ${ }^{85}$ With the focus of the game being on the creation and maintenance of a Mediterranean civilization, Western Empires is asserting through the rulebook and mechanics of the game that victory is achieved by other factors. It thus also distinguishes itself from the wargaming genre. The focus of this game, instead, is to guide players through the processes of building a civilization, and how that is done in a setting inhabited by other growing civilizations - who will eventually compete for space and resources. The rules of Western Empires show the designers are making judgements about complex historical processes that are being narrated through the mechanical design of the game. They create a space, as mentioned earlier, that has players compete with other powerful cultural groups in a race to be the most 'successful' civilization - a process that is expressed narratively through the mechanical structure of the board game and success is measured by progressing through historical ages. ${ }^{86}$ To win, players must generate income, grow their civilization through

\footnotetext{
${ }^{85}$ John Rodriguez and Flo de Hann, Western Empires, Rulebook, 2019, 2.

${ }^{86}$ Players start off in the Stone age and make their way through the early/middle/late Bronze age and the early/middle/late Iron age.
} 
building urban centers and growing their population, develop a variety of different technologies (written record, mathematics, medicine, etc.), and purchase access to the next historical age by meeting its prerequisite through collecting the components just mentioned.

The Archeological Succession Table (A.S.T., see figure 6) is a game mechanic (unique to my knowledge) used to track a player/ civilization's progress through the multiple technological ages - starting in the Stone Age and ending in the Late Iron Age. Players have the opportunity to purchase advancements on this track as long as they have the prerequisites to the age they are advancing to. There are two kinds of prerequisites: a certain number of urban centers and the ownership of a number 'civilization advancements', of which there are a total of fifty-one. These 'civilization advancements' range from forms of government (democracy, monarchy, theocracy) to ideologies (philosophy, theology, rhetoric, deism, enlightenment), to more tangible forms of historical 'advancements' (mathematics, medicine, literacy, written record). Essentially, the A.S.T. acts as a record of your civilization's achievements and 'progress' as indicated by a variety of monumental developments found in the

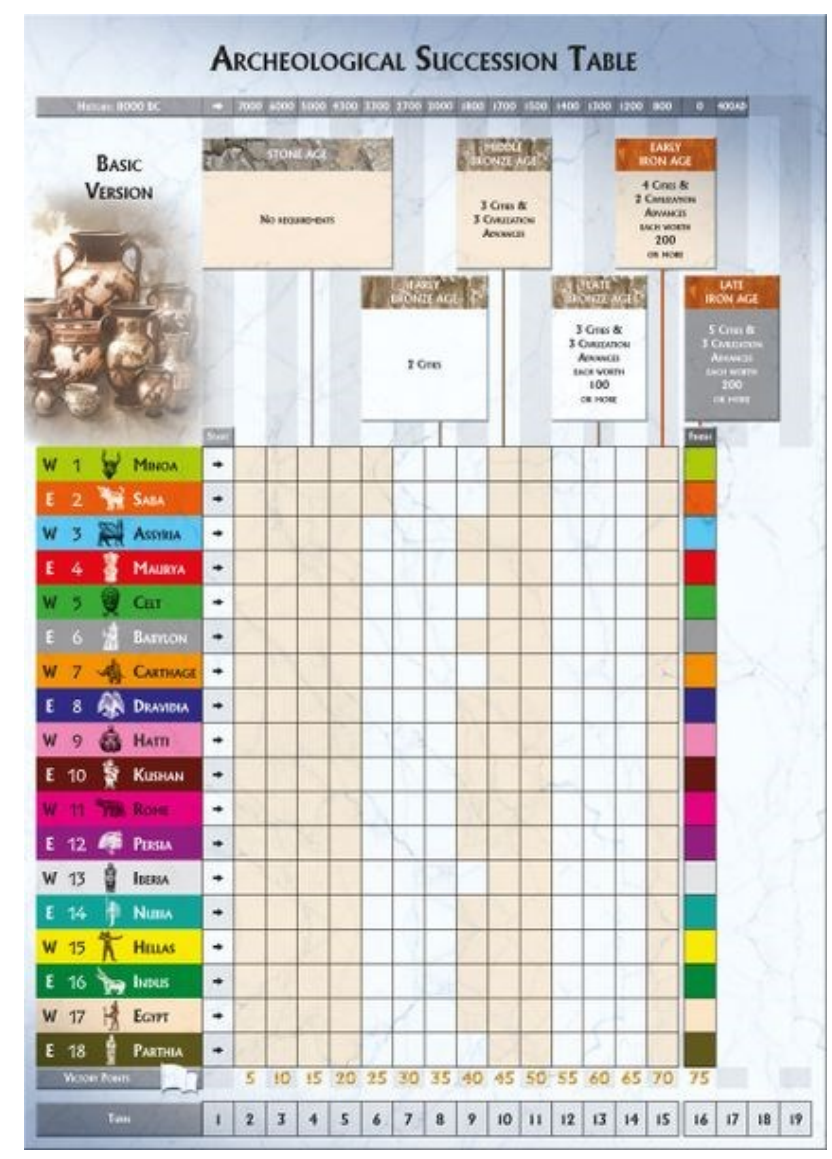

Figure 6: Archeological Succession Table historical record that would be familiar to the average player. The function of the A.S.T., in 
mechanical terms, works as a track for victory - the further a player advances along the track (all the way to the Late Iron Age) the closer they get to winning the game.

If we understand this mechanic through a narrative lens, it allows players to track which civilization has left the most prolific archeological footprint (hence the name 'archeological succession'). Players/civilizations will have a larger impact on the historical record if they create more urban centers - their presence will be more readily accessible to future archeologists. Similarly, the 'civilization advancements' make an impact on the archeological record which fits narratively because we can ascertain certain technological advancements from archeological finds such as calendars, mining, metalwork, and engineering capabilities (which are all featured in the game as 'civilization advancements') - they all leave evidence that can become available to us through the work of archeologists. The important aspect to understand from this particular game mechanic is how it relates to the larger narrative message of the game. The A.S.T. is the process by which the players/civilizations win the game - either by developing their civilization through the means of urban and technological 'advancement' and/or by hindering the ability for other players/civilizations to 'advance.' Success and victory are therefore achieved by being the most relevant or present in the archeological record which, in game terms, makes them the most 'successful.' 
The designers have narratively established a formula for 'historical success,' a definitive and objectifiable indicator for what makes a civilization legitimate or successful. This formula for legitimization -it should not go without being said- reproduces the traditional Western understanding of how 'civilization' and 'progress' should be defined. Civilization, within the confines of Western Empires, is a title which is relegated to only nine distinct groups of peoples (of course this is less applicable given that the game can be expanded to include another nine 'eastern civilizations', but that option does not have its own standalone game). All other operators in the game are referred to as 'barbarians' and 'pirates.' These nameless groups can possess cities but only function as a military obstacle to the players, never a cultural, political, or technological one (which the other players/civilizations do). A distinct historical narrative can be understood through

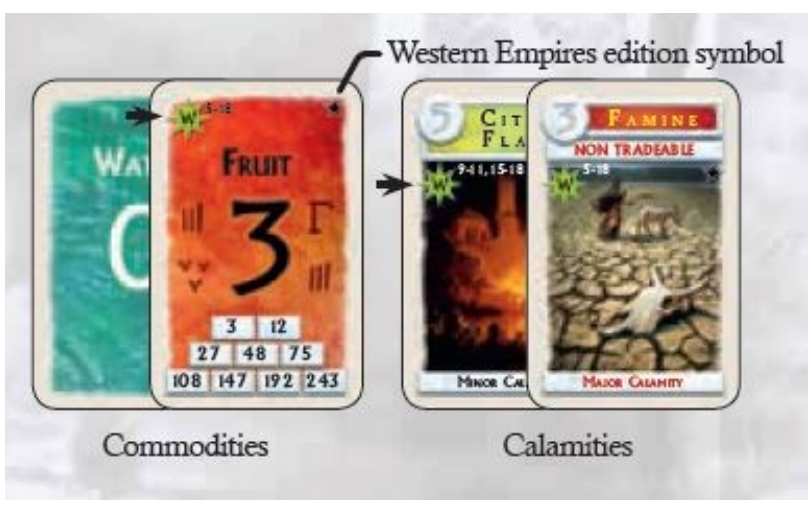

Figure 7: Trade card depicting commodities and calamities that can be traded to players blindly. From page 9 of the Rulebook.

the process of the A.S.T. mechanic in Western Empires. The game (through the work of the designers) is asserting a position about the importance of history and how archeological relevance relates to the legitimacy and success of a civilization.

Trade is the main way in which players advance their respective civilizations through economic gain and the acquisition of 'civilization advancement' cards. Rather than through territorial conquest, as seen in the previous case study of Wallenstein, economic negotiation is the way players can succeed in Western Empires. Players collect pairs of certain resources (fish, wine, fruit, ceramics, wool, etc.) by trading with other players and generating resources through their urban centers. Trading is one way in which players/civilizations communicate with each 
other, negotiating what cards they need and what cards they are willing to give away. This is how wealth is accumulated but also how 'calamities' are spread - hidden by one player within a trade of resources.

Calamities drive change in the game, alter the balance of power between civilizations, and can even bring one player/civilization to ruin - preventing them from operating anymore within the space of the game as well as the 'historical space' that is being played out through the

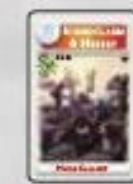

ICONOCLASM AND HERESY

Reduce 4 of your cities and select 2 other players that must reduce 1 of their cities as well The beneficiary may not be selected as a secondary victim

ĐI you hold 'Philosoplyy', reduce 2 less cities.

$\bigoplus$ If you hold 'Theology', reduce 3 less cities.

GIf you hold 'Monotheism', reduce 1 additional city.

ĐIf you hold 'Theocracy', you may choose to discard 2 commodity cards to prevent the city reduction effect for you.

-If, at the moment of resolving Iconoolasm and Hercy, the primary viatim has no cities (before taking into account any provention ffects) then the calamity is cancoled.

- Nose that while 'Philosophy', 'Theology' and/or 'Thoocracy' may prevent some or all ainy reduction for the primary viatim, this does not prevent the effects for any secondary viatims

Figure 8: Major Calamity of Iconoclasm and Heresy and the certain advancements that positively and negatively affect its outcome. From page 33 of the rulebook developing narrative. The calamities represent real threats that civilizations could potentially and have historically faced, ranging from natural ‘calamities' (cyclones, volcanic eruption, earthquakes, epidemics) to political 'calamities' (civil war, corruption, tyranny), and to social 'calamities' (civil disorder, iconoclasm/heresy, and vaguely 'superstition'). These disastrous events have specific effects (often destroying cities and/or population counters) that generally relate to their

title and can be avoided by a related preventative situation or 'civilization advancement' that is possessed by the targeted player/civilization. For example, the calamity 'Iconoclasm and Heresy' has a worsened effect against a player that has developed 'monotheism' as a 'civilization advancement' (figure 8). The same calamity can have its negative effect reduced if the player possesses the 'civilization advancements' of 'theocracy', 'theology', or 'philosophy'. This mechanical system within Western Empires communicates a complex interlinking of cultural and social ideals, institutional structures, and how a civilization might deal with drastic sociocultural 
change and upheaval. This system of calamities and 'civilization advancements' attempts to illustrate the different directions that a civilization might go in, and how they might deal with unique events and sociocultural issues. A society that focuses on a strict adherence to monotheistic ideals and not a culture of philosophical tradition and theological inquiry might be more prone to iconoclastic outbreaks and heretical movements like those that affected earlyChristianity. These are the types of historical processes that are ingrained in the mechanical structure of Western Empires. These historical processes that are a part of and are expressed through the mechanical structure, develop a historical narrative of their own.

Western Empires communicates these historical narratives in two ways. Firstly, through the individual actions of the player/civilization it communicates a particular and specific narrative through individualized playthroughs. Each iteration of the game will be different, and a new narrative about how the development of a civilization 'progresses' is created - i.e. will that civilization succeed because they traded more, or will they fail because a calamity they could not prepare for slowly or quickly broke apart their collective identity as a civilization. Secondly, the game communicates a grander narrative of historical processes, saying that there are definitive advancements within civilizations and that they are expressed in identical ways. Monotheism will always be prone to iconoclasm and heresy, and that theocracy is a solution to dissenting theological beliefs, or that civil disorder can be solved with decreased military efforts and an investment into the arts. ${ }^{87}$ From this mechanism there can be pulled complex ideas about history and the interconnectedness of important technological and intellectual developments - and a lot of time could be spent elaborating on these complex ideas, but the importance lies in how these

\footnotetext{
${ }^{87}$ The 'calamity' 'Civil Disorder' can be reduced by the civilization advancements of 'Music,' 'Law,' 'Drama and Poetry' but has more drastic effects if the civilization possesses 'Advanced Military' or 'Naval Warfare'.
} 
mechanisms facilitate what Adam Chapman describes as an open-ontological story structure. ${ }^{88}$ Essentially, the mechanics of the game are developed in a way that they innately communicate ideas about historical processes that in turn leads to the development and expression of unique historical narratives that inform the players about particular assumptions of historical processes.

The open-ontological story structure in game terms refer to the possibility of the player (through the unique construction of the game) to construct their own narrative as they progress through the game. Their path and conception of the fictional game world is, essentially, 'open.' These games do not have fixed outcomes that can be analyzed for their historical validity and messaging, but rather there is a complex web of possibilities and narrative outcomes that result from certain historical foundations that are created from the set of game mechanics. The most relevant mechanics for Western Empires being 'calamities,' 'civilization advancements,' and the ways in which their historical foundations (the concepts of historical meaning that are present in the mechanics) interact with each other to create a plethora of different narrative outcomes. These outcomes suggest and make claims about historical processes - sometimes complex, sometimes simple. We can view Western Empires, along with the case studies present in this project, as forms of historical literature, communicating historical meaning and constructing historical narratives through the procedure of the game itself.

It is important to understand what kind of history is being told through this game, and what kind of historical processes are being illustrated through the mechanics of Western Empires. Firstly, it is useful to identify how the game presents itself as a form of historical literacy. While absent in the game itself, on the company's website there are short, two-hundred-

\footnotetext{
${ }^{88}$ Chapman, Digital Games as History, 186.
} 
word descriptions of the nine playable civilizations. ${ }^{89}$ There is nothing historically profound about these descriptions, but they provide an understanding of the rise and fall of these groups of peoples as well as a highlight of a 'notable' aspect of the civilization. These descriptions do assert some historical claims such as, "Rome's legacy is woven into most of the empires of the West and Rome is often considered to have reached the pinnacle military and civic capabilities of the ancient world." Another reads, "the Hittites are known for their detailed and advanced laws addressing everything from criminal to civil issues. At the height of their power their logistical and military capabilities were nearly unmatched." These descriptions provide short breakdowns of the civilizations players are going to inhabit and can be viewed as a guide on how to run your own civilization and highlight the goals that a player can and should be striving for. Terms such as "advanced laws" or "logistical and military capabilities" instil in the reader that these are goals to be achieved and are the cornerstones to a 'successful' civilization.

When analysing these case studies, the important question arises of 'how does this game communicate history?' Even, as previously discussed with Wallenstein, if the game utilizes history as a "meta-story" or a thin thematic veneer that can be switched out with any other theme without ruining the mechanics of the game, does it still communicate a form of historical knowledge? Moreover, what is that message about history communicating about larger historical processes? Western Empires presents itself as a form of historical literacy and does communicate an idea about historical processes. In the video trailer for Western Empires they state that the appeal of the game is for "players that are dedicated to epic board games with a strong historical context" and offer the chance to "submerge yourself in the annals of history and experience the

\footnotetext{
${ }^{89} \mathrm{https}: / /$ www.westernempires.com/civilizations/.
} 
rise and fall of civilization." ${ }^{\circ 90}$ The language used in this ad gives players a sense that they are delving into a historical simulation, one that promises to give them a look at the "annals of history" and a better understanding about historical processes over an 8000 year span. Their advertised goal is to allow players to 'reenact' the rise of great civilizations - both experiencing and creating history.

As discussed, Western Empires is a game that spans a period of 8000 years and looks at how civilizations might develop over that long period. The game is communicating a form of macro history that generalizes a vast amount information in exchange for understanding larger trends and themes over an extended period of time. There is a lot of historical complexity that is lost by taking this approach, mostly due to constraints of making a commercial game for mass marketability and appeal, and players cannot understand the more intimate relationships of individual historical agents.

Jeremiah McCall creates a framework for understanding the development of a 'historical problem space' which allows game-scholars to explore the dynamic relationship between the components of a historical game. This holistic approach identifies four key components that are needed for the establishment of a 'historical problem space': player agents, a developed game world, components within that game world, and achievable goals or obstacles to overcome through interacting with the game world and its components. All of these key game aspects must also be grounded in some sort of historical reality. To elaborate, players are represented by a historical actor (whether non-fictional or 'historically inspired'). In the case of Western Empires, the player agent is not represented by an individual, but a historical civilization. The player agent

90999 Games, “Western Empires Trailer - 999 Games,” https://www.youtube.com/watch?v=bkmadlVm_Ak. 
(civilization) participates in a space that features specific historical locations (in the context of Western Empires, the Mediterranean world). This game world includes historical components ('civilization advancements', urban centres, populations, 'calamities') that the player/historical actor must utilize or overcome to reach a specific goal. ${ }^{91}$

By generalizing many of these components discussed by McCall, Western Empires loses the complexity of exploring the motivations and personal relationships of historical actors and how they might interact with the created historical game space that can, in the medium of a board game, function as an abstracted representation of a historical narrative. Individuals are replaced by expansive civilizations, and relationships are showcased over thousands of years. Sociocultural events, breakthroughs, and calamities are all taken away from their cultural and historical contexts. By developing a game that focuses on macro historical trends, an understanding of individual relationships and the nuances of cultural importance are lost. Focusing on individual agents, as McCall suggests, provides a greater understanding as to how an individual would interact with the represented historical game world and its many components. Focusing on individual relationships is a key aspect of historical game design that seeks to communicate a complex message through the medium of board games. Historical understanding already goes through a form of abstraction when translated into the medium of a board game. Abstracting that historical message further by encompassing the relationships between monumental civilizations over the course of 8,000 years, dilutes the message unnecessarily further.

${ }^{91}$ McCall, "The Historical Problem Space Framework." 
This concern with dilution leads me to design my own game to address the problem of over-generalization seen in Western Empires and provide a more specific temporal and geographical focus: a ten-year period within one sociocultural landscape (Frankish controlled Gaul). My project, Divided Kingdom, 561 thereby focuses on a specific historical space that has definitive abstractions of historical locations, objects, ideas, agents, and institutions. The 'history' of it goes beyond a simple meta-overlay or 'context'. It is grounded in historiographic and primary source research that is communicated through the medium of a board game by abstracting those complex ideas found in those two sources. Players engage with the history through informed textual and aesthetic elements that are a part of the mechanics of the game rather than being relegated to advertising gimmicks that attract players with historical overlays. Complex arguments about historical processes are a part of the development process and inform the creation of mechanics that drive the progress of the narrative within this medium of the board game. Through this case study, I have shown how the mechanics of a board game can communicate a narrative - and the ways in which that narrative can communicate certain ideas about historical processes. Divided Kingdom, 561 focuses on cultivating a more complex and specific historical problem space as opposed to the generalized macro-historical approach taken by Western Empires in order to showcase the potential board games have as a medium for historical expression. The development process, the ways in which I seek to abstract these complex historical ideas, and how it will all be communicated through the mechanical structure of the game, will be discussed in the annotated rulebook portion of this project. 


\section{Justifying Historicity - A Feast for Odin}

Uwe Rosenberg's 2016 A Feast for Odin is my final case study. The game asks each player to take control of a 'Viking Age' (ca. 750-1000 C.E.) village for which they must provide food, shelter, and trade goods. The very first sentence of the rulebook describes the game as "a saga in the form of a board game", showing their clear intention to translate a medieval literary genre into a playable form. ${ }^{92}$ Players can use their 'Viking' workers to perform a variety of tasks: raiding and pillaging, whale hunting, overseas trading, going to market, and animal husbandry. They do this by placing pieces in the shape of Viking warriors on a communal 'action board' with a plethora of spaces, each denoting a particular action a player can take (figure 9). A key component of $A$ Feast for Odin (as suggested by its name) is providing enough food

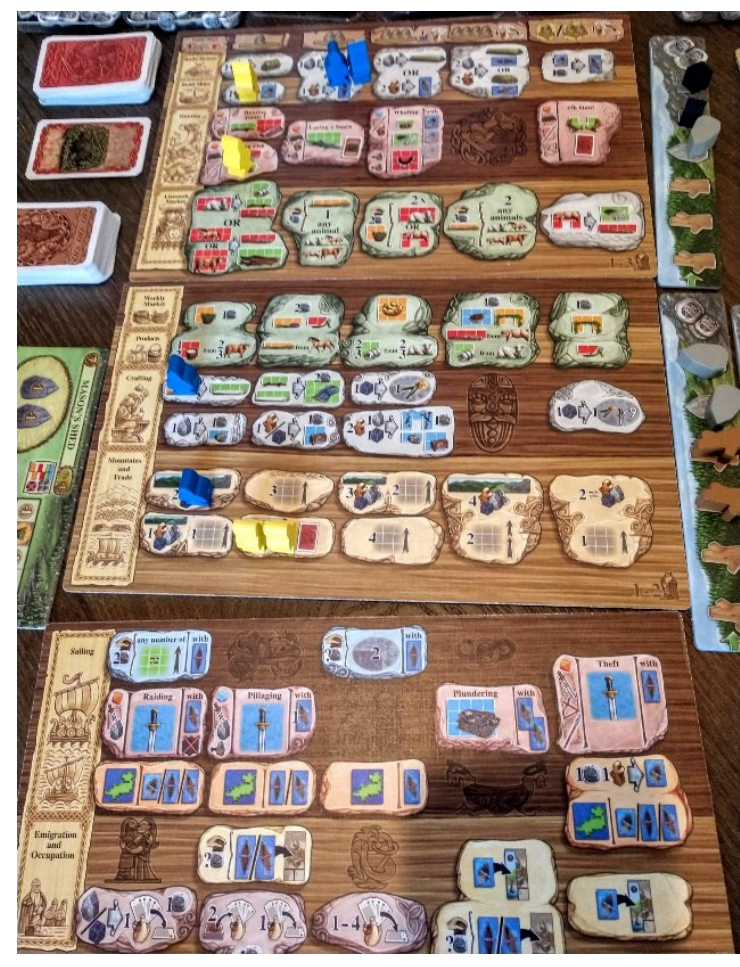

Figure 9: Action Board showcasing the various actions a player can take by placing their Viking warriors on the relevant space.

for your Vikings every game round with the food they purchase and produce, making sure they can perform their various tasks and actions. Players can also explore historical locations in expeditions to Iceland, the Faroe Islands, Shetland Islands, Greenland, and even as far as Newfoundland which are represented by separate boards with their own types of resources (figure 10). Players may also decrease the amount of food they must provide to their Vikings by founding colonies in these distant locations. Players win A Feast for Odin by achieving many

\footnotetext{
${ }^{92}$ Uwe Rosenberg, A Feast for Odin, Rulebook, 2016, page 1.
} 
different goals: economic goals (amount of silver coins, the construction of ships that are used to trade and raid, and the number of livestock bred); political goals (obtaining the "English Crown" and establishing colonies through emigration) and social goals (developing your village through building projects, attracting different occupational professionals, and exploring various lands outside of Scandinavia).

The physical layout of $A$ Feast for Odin makes up an integral part of the game's function. In order to achieve the above mentioned economic, political, and social goals, players are required to take into consideration the physical placement of their collected and produced goods (figure 11). In essence, a mini game of tile organization is embedded into the larger structure of the game. More importantly, the tiles feature historically relevant visualizations representing textiles, weapons, animal products, coinage, and other Viking 'goods.' The result would be a board filled with a collection of Viking era materials giving a sense of what was prized and valued in Viking Age society.

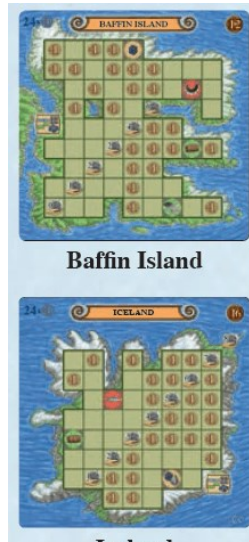

Iceland

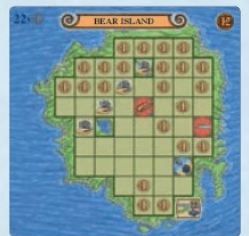

Bear Island

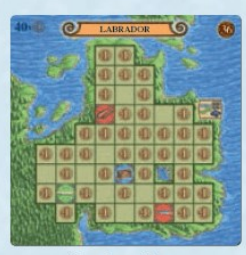

Labrador

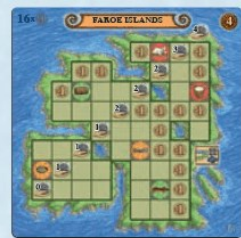

Faroe Islands

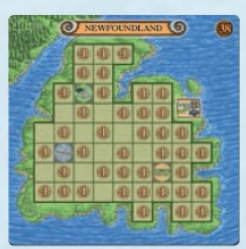

Newfoundland

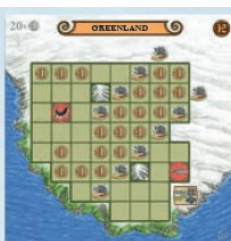

Greenland

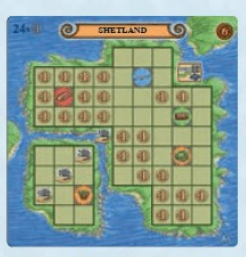

Shetland

The designer presents

A Feast for Odin as more than

a simple board game, but

directly describes their

endeavor as a storytelling one.

The game is promised to

function as more than just a

form of entertainment, but also

as a form of historical literacy where 'cultural achievements' of the Viking Age will be relived and retold in a format that attempts to mimic old Icelandic/Norwegian sagas. Sagas which, both 
historically and through this game, communicate a variety of cultural, familial, economic, and militaristic aspects of Viking Age society. ${ }^{93}$ Similarly, A Feast for Odin attempts to communicate the cultural, social, and economic history presented in a variety of Icelandic/Norwegian sagas. This game highlights how the designer sought to use $A$ Feast for Odin to communicate primary source knowledge through the medium of a board game. My analysis seeks to highlight the choices the designer made and how they impact - positively and negatively- the historicity of the game.

The opening of the rulebook states the intention of $A$ Feast for Odin. It immediately challenges typical preconceived notions that players will bring about the historical period. The designer notes the word 'Viking' is a verb, that is, something that Northerners (Northman), "towards the end of the first millennium", would go on - otherwise known as a raid. The designer, instead, specifies that the players will be "reliving the

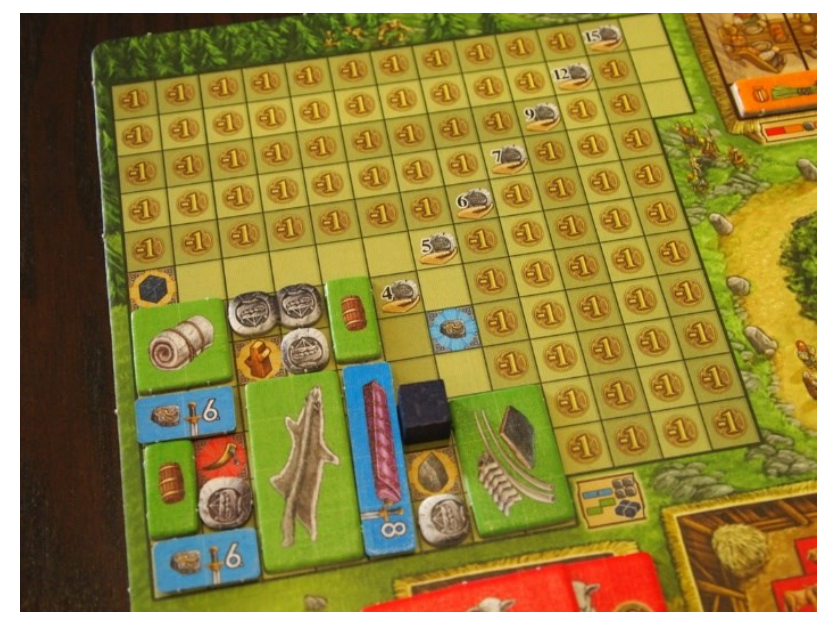

Figure 11: From https://www.creakingshelves.com/a-feast-forodin-review/, showing how goods are placed on the player board-including furs, bedrolls, casks, a bolt of cloth, as well as bones and meat from hunting.

cultural achievements, mercantile

expeditions, and pillages" of those normally called "Vikings". Instead of jumping into how to play, the rulebook shows an interest in questioning expected narratives and is offering access to the real experience of the past. This is consistent with a game that describes itself as "a saga in

\footnotetext{
${ }^{93}$ This game, and both the mechanics and narratives it deploys, is especially instructive for chapter three of my project - an annotated rulebook for Divided Kingdom, 561. Just as this game emerges from the sagas, I was inspired by Gregory of Tour's Historia Francorum and seeks to gamify the history presented in this sixth-century text.
} 
the form of a board game" because it prioritizes storytelling as the goal of the game and more specifically, a historicized version of storytelling.

In the previous two case studies, I have sought to discuss what kind of historical literacy is being communicated through these board games. A Feast for Odin demonstrates a clear attempt at facilitating a complex historical discussion through its design. Not only are the game mechanics designed to reflect a conversation about historical practices and relationships within the 'Viking Age', but the designer makes the effort through extra-textual information that the goal of the game is to communicate knowledge of the represented period through the reading of the rulebook and almanac (described below) as well as through participation in the game. Historical knowledge is not relegated to extratextual information alone though, it is embedded within the design of the game's mechanics. The purpose of the almanac, as well as reading through the rulebook, is to better understand how exactly the game communicates historical knowledge.

The almanac was released in an expansion for A Feast of Odin in 2018 called A Feast for Odin: The Norwegians and was written by self-described "historical-scientist journalist" Gernot Köpke. ${ }^{94}$ Köpke admits in the almanac that his research was largely "internet-based" and consulted multiple sources found on Wikipedia as "A truly detailed reproduction would be far too extensive." 95 The twenty-page booklet describes, in alphabetical order, the historical background of all the game's components, Norse mythology, as well as some extra information on notable Norwegian historical figures from the Viking Age. The entries range from about fifty to two hundred words and engage with the Old Norse language, direct quotes from Icelandic and

\footnotetext{
${ }^{94}$ Board Game Geek, https://rpggeek.com/boardgameexpansion/216788/feast-odin-norwegians.

95 Gernot Köpke, Almanac, 2018, page 20.
} 
Norwegian sagas, and some references to other medieval writers outside the sögur (saga) genre. ${ }^{96}$ While the almanac does not contain footnotes or any evidence of engagement with secondary sources, it showcases an effort to engage with the primary source material on the period the game is attempting to represent. The designer attempts to justify their decisions regarding the game's mechanics - why farm products were represented by peas, flax, beans, grain, cabbage, and fruit or why robes and tunics were used to represent clothing trade goods. The design decisions are given a historical justification rather than a purely mechanical one. The entry for "Silver Coins", for example, reads:

There was a period of overlap after coins had begun circulating, that Norsemen still paid with hacksilver. There were silver dinar with the image of Charlemagne, Arab dirham (up to 100 million Arabic coins were taken to the north by the Vikings), or, thanks to the tribute extorted in England (Danegeld), more and more Anglo-Saxon coins. Only in 1150 did a complete switch from a 'silver weight exchange economy' to a 'coin currency economy' take place in Sweden. The folding scales for hacksilver were no longer used. In their place were silver coins, whose value remained coupled to the value of silver - for example: the so-called Silver Standard in Denmark until the 19th century. From 997 on, Denmark minted its own silver coins and gradually displaced the Arab and European coins (perhaps even earlier in York). Recovered coins often show evidence of being picked at by the Vikings using a 'counterfeit

\footnotetext{
${ }^{96}$ Adam of Bremen is quoted along with quotes from the Greenland Saga, Egil Saga, the King's Mirror, and the
} writings of the Icelandic lawspeaker Haukr Erlendsson. 
money tester' (a simple knife), so that their authenticity and purity could be detected. $^{97}$

The description goes far beyond how silver coins operate in the game but gives a background and justification as to why silver coins were used to both textually and physically represent coinage/monetary value in the game.

The almanac does more than justify the mechanical choices of $A$ Feast for Odin. It engages in extended discussions of the historical background for different game aspects, and even expands beyond what is included in the game to discuss notable Norwegian Vikings to give the player a sense that they are re-enacting and reliving the experiences of these historical figures by playing the game. Metzger and Paxton argue that games will tend to prioritize the playability of a game over 'realism' and 'historical accuracy'. In contrast, A Feast for Odin actively provides justification for their design choices that is grounded in an engagement with historical text rather than from "received [historical] values or cultural assumptions." 98 The inclusion of the almanac follows suit with the designer's intention of "how in-game concepts relate to the game's theme." 99 The almanac is an extended

- One tile of each type may be placed horizontally to take up more space at the table (like salt meat in the example below). All other tiles of that type must be placed vertically (square tiles are exempt from this rule, as it does not matter).

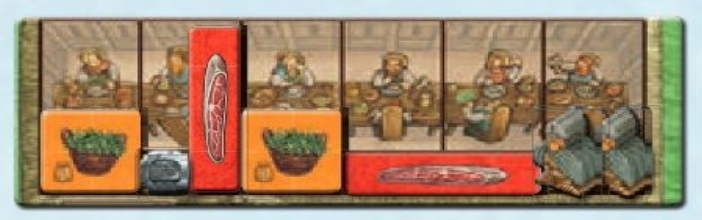

You should serve salt meat only once per feast to be efficient. Bean dishes, on the other hand, can be served multiple times without penalty.

Every tile you place on the "Banquet Table" must cover at least one of the squares below the table and fit in the allowed space (it cannot overhang). If you are not careful, you may have to inefficiently place several tiles vertically to follow this rule.

Figure 12: From page 10 of 'A Feast for Odin' rulebook showing the rules for setting the "Banquet Table"

\footnotetext{
${ }^{97}$ Almanac, page 16.

${ }^{98}$ Metzger and Paxton, "Gaming History," 533.

${ }^{99}$ Almanac, page 1.
} 
justification of how the historical themes of the game are imbedded in its mechanics. There is no indication that the inclusion of the almanac was called for by players. No reviews cite the historical content of the almanac as a 'welcome addition' or comment on its function aside from the mechanical changes made by the expansion. The discussion thread found on BGG created by the almanac's designer, Gernot Köpke, has minimal fan engagement. ${ }^{100}$ Rather, the almanac seems to be an extension of the creator's desire to construct a more historically grounded and justified game experience.

In Metzger and Paxton's framework for how historical games deploy history, A Feast for Odin falls into their category of 'legitimization.' Legitimization "rhetoric" presents a game as a plausible form of historical representation - one that can be considered 'academic'. Like the almanac of A Feast for Odin, Metzger and Paxton point out games that deploy legitimization rhetoric feature historical encyclopedias that include facts about the subject matter being represented - or at least loosely connected to the gameplay. These encyclopedias provide ingame textual information that informs the player of historical facts when they become relevant to the gameplay experience. They do not always line up with the mechanical structure of the game itself. They can be irrelevant to the game processes and the narrative that unfolds from those mechanical choices - often, they only serve as a form of legitimization that appeals to historically-minded players that seek to engage with a more 'realistic' or 'authentic' game experience. ${ }^{101}$ The criticism leveled at this form of historical deployment is that is opens the game up to criticism about the accuracy of the presented historical facts and interpretations. To Scott Metzger and Richard Paxton, this disconnect can undercut their "educational

\footnotetext{
${ }^{100} \mathrm{https}$ //boardgamegeek.com/thread/2023534/expansions-almanac-almanach-fur-erweiterungen.

${ }^{101}$ Metzger and Paxton, "Gaming History," 552-3.
} 
legitimacy." ${ }^{102}$ Metzger and Paxton are correct that encyclopedias, and in the case of A Feast for Odin the almanac, cannot live up to the expectations or communicate the level of historical complexity that academic history is accustomed to. The Almanac, and the "internet-based" research that comprises it, cannot alone communicate complex history. It is the intermingling of historical data and the game's mechanics that develop a narrative from its processes that can communicate a form of complex narrative history. This extra-textual information found in the almanac serves the purpose of elaborating on the historical connections between game mechanic and historical fact that may not otherwise be clear to the players.

An example of the interconnectedness of historical processes and game mechanics can be shown by how food operates in in A Feast for Odin. As noted above, a feast must be held for your Vikings (workers) and the more Vikings in your population, the more food you must provide for them. The mechanics of the feast demand that you provide a variety of different foodstuffs. Players cannot place two categories, orange foods (peas, flax, beans, grain, cabbage, fruits) and red foods (salted meat, milk) next to goods of the same colour. Also, players may not place the same type of food in the same directional way twice (if a player had two salted meats, one would have to be placed vertically and the other horizontally, see figure 12). Meaning, players cannot feed their Vikings (living and breathing people with dietary needs) a diet consisting solely of salted meat or solely of fruit. Furthermore, the shape of the different goods (which much be placed so that they cover a certain number of squares without overlapping) differs, making some foods easier to serve than others (with the result of satisfying your Viking host). The inclusion of a variety of foodstuffs alone communicates the varied diet of medieval Scandinavians, but $A$ Feast for Odin goes further to communicate the fact that Vikings had an

${ }^{102}$ Metzger and Paxton, 552. 
understanding of what a balanced diet consisted of. The game formulates a complex and historically grounded idea of diet through the mechanical structure of forcing the player to provide a variety of goods in order to satisfy the action of feeding their Vikings. If the player fails to do this, they will suffer penalties that may lose them the game.

The historical game space created in A Feast for Odin attempts to actively engage with and inform about the historical past. Without reading the almanac, the game communicates the complexity of the 'Viking Age' diet through the mechanics of the 'feast' rule as well as the representation and inclusion of a variety of foodstuffs. As Marc Arnaudo illustrates, "by facilitating certain actions and disincentivizing others, they [the designers] channel the players' behaviour in specific directions and play a pivotal role in the shaping of the overall experience [narrative]." 103 The mechanical structure of a game has the power to disincentivize certain actions over others. Guiding a player towards a particular set of actions can create a represented historical space where particular motivations of historical actors can be better understood -i.e., what actions are available and most likely to be taken by an actor within their given historical context. In the example of the feast mechanic in A Feast for Odin, the player must recreate the diet of Viking age people or be penalized - therefore failing in their role as leader of their community. There is an important distinction to make here between 'limiting' and 'disincentivizing.' The former implies that there are fewer options provided to the player while the later suggests that certain options or choices within the game are discouraged through game penalties (which could lead to the loss of the game). The options are still available to players to showcase a variety of historical possibilities while simultaneously demonstrating historical plausibility through game penalties. Disincentivizing rather than limiting certain actions allows

\footnotetext{
${ }^{103}$ Arnaudo, Storytelling in the Modern Board Game, 39.
} 
the player to strategically think through the designed options available to them and learn how the game represents a complex historical space that is filled with possibilities and various outcomes.

Jeremiah McCall adds to the conversation of creating historical 'goals' for the players within the game space by stating "players can certainly ignore designer goals or substitute their own goals. Still, historical games are usually, if not always, designed with explicit goals for the player agent to achieve." 104 The goal in a historical game that seeks to communicate a complex history, will be one that the player/represented historical agent would want to achieve given the sociocultural and political historical space being represented. The ability for a player (who is playing as a historical agent) to diverge from that goal represents the individual will and unpredictability (or non-conformity) of legitimate historical actors. The mechanical framework of the game is there to illustrate what kind of response that action - either deviating from or adhering to the prescribed goal - would receive in the represented historical space.

Jeremiah McCall uses the term "historical problem space" when referring to a game's ability to create a historical conversation out of the designed function of the game and the narrative that results from the process of playing it. To analyse the impact of the created historical problem space an understanding of the agents involved, their roles and goals, the components of the game, as well as the choices available to the player is needed. To successfully analyze and create a game, it is important to understand it as a type of ecology with all of the above-mentioned factors working in tandem to create a process that responds to player actions in a manner that is congruent to the historical space being represented. In A Feast for Odin, failing to provide a historically congenial diet for the player's Vikings results in failure.

\footnotetext{
${ }^{104}$ McCall, "Historical Problem Space.”
} 
Building longships and sending a portion of your population to form a colony has the result of lessening the burden of providing food which communicates a narrative that agrees with academic theories on Viking expeditions and settlements - the burden of agricultural viability in Scandinavia. The mechanical structure incentivises certain actions that then communicates a particular historical narrative. In a case of $A$ Feast for Odin, those narratives are communicating a complex understanding of the social, cultural, and political motivations of Viking Age Society. The particular interconnectedness between mechanic, narrative, and historical fact seen in $A$ Feast for Odin is insightful for how a game can be constructed to communicate nuanced and complex understandings of history through a board game and will be utilized in the third chapter of this thesis.

\section{Conclusion - Board Games as a Viable Medium}

This Chapter has analyzed a collection of historically-themed board games to understand how game designers have approached the subject of communicating narratives about the past. Each case study analyzed here has presented a different level of complexity in its historical depictions. These selected games have utilized history in one of two ways: either as an interconnected part of the narrative-making process (A Feast for Odin), or as a thematic overlay with no tangible connection to the progression of the narrative being created (Wallenstein). In other words, historical processes either inform the progression of the narrative (i.e. affecting its outcome) or are a 'theme' applied to game mechanics that could be replaced by any other narrative operator. Within these case studies, when historical knowledge (facts, dates, figures, events, etc.) is closely tied to the mechanical structure of the game there is a better chance for communicating complex ideas of the past. The feast mechanic in A Feast for Odin took a historical narrative about Viking Age diets (one that also upended commonly held tropes) and created a mechanic around that 
narrative - meaning that players had to engage with that particular historical idea in order to succeed in the game. I have shown throughout this case study that history can be applied to board games in a variety of different ways with varying levels of connection to the actual operation of the game as well as the narrative that it is communicating.

Simply, the objective of a game is to win. The process and path to that victory requires the player to understand the underlying system of the game - the rules, the mechanics, how it operates, and responds to player actions. If that underlying system is developed in tandem with complex historical narratives, meaning that it tangible and clearly links historical processes with the mechanical processes of the game, then the player is simultaneously learning the relationships and motivations of the game/historical world being played/represented. The linkages between game mechanic and historical process can be simple like in Wallenstein's randomized warfare mechanic that links with the historical process of warfare being chaotic and not always 'logical.' The linkages can also be more complex like in Western Empire's system of calamities that affect a civilization to a greater or lesser degree based on how their culture has evolved or 'advanced.' These connections apply meaning to historical narratives. The operation of the game, its mechanical system, its many procedures, have the potential to represent complex sociocultural systems of the past.

The material covered in this chapter has aided the development of the next chapter, the annotated rulebook of the game developed for this project - Divided Kingdom, 561. Primarily, I have used my analysis of how the studied games have interconnected historical knowledge with the structure and function of the game itself. Through a concerted look at the connection between historical narrative and game function I have designed my own case study of a board game to showcase their potential for communicating a complex argument about the past. 
The annotations used in the following chapter are present to elaborate on the connection between the mechanics of the game and the associated research that went into its development. While the goal of the project is to show that merely through reading the rulebook and playing the game the participants can understand the historical arguments being made, the annotations are there to legitimate the historical research that went into the game's development.

What follows the annotated rulebook is a project journal that details my findings from developing the rulebook and elaborates on many of the design choices. 
Chapter Four: Annotated Rulebook - Divided Kingdom, 561

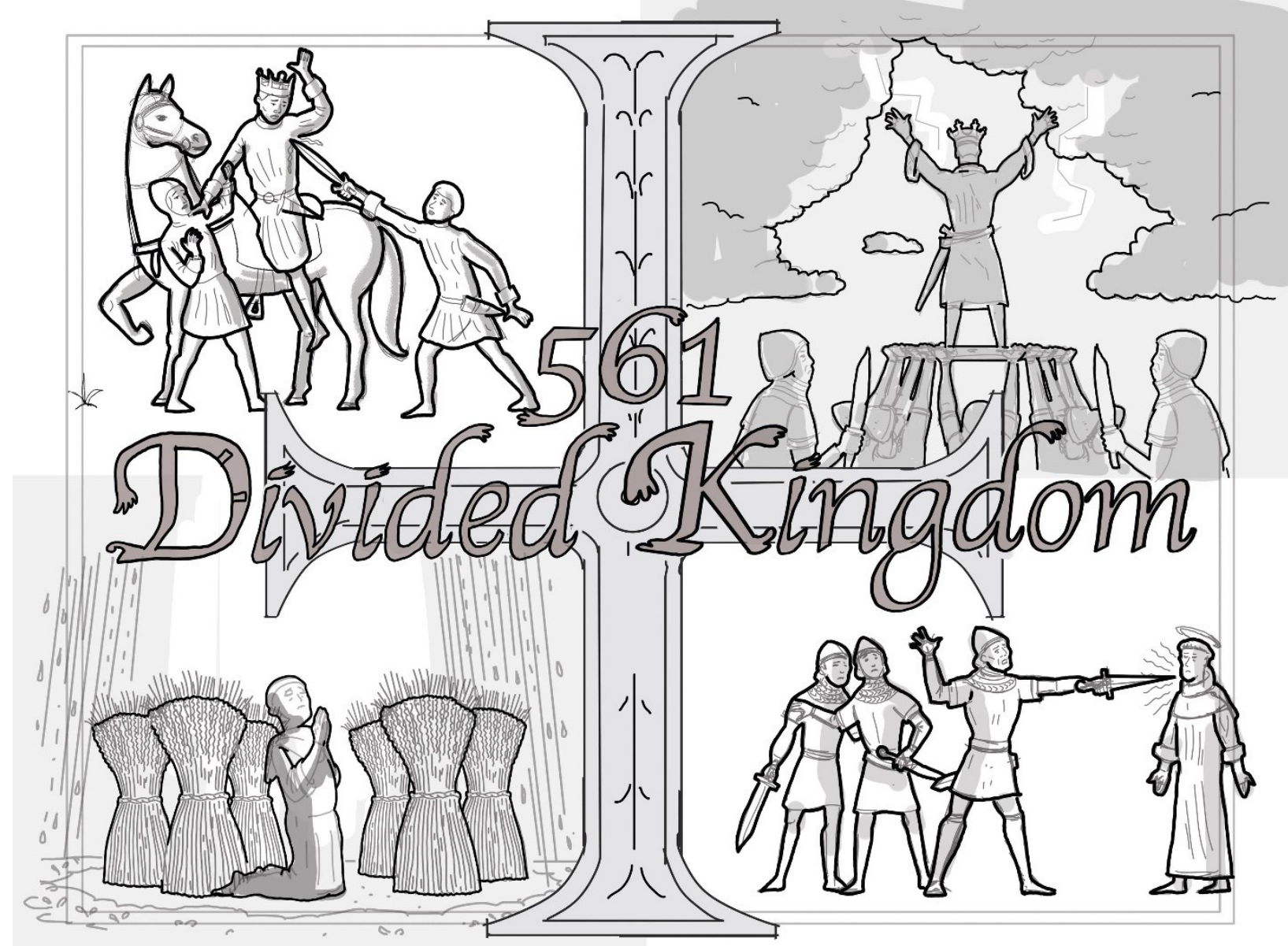

Figure 13: Cover illustration for Divided Kingdom, 561 by: Alex Hawley, 2021. See description of illustrations before the rulebook's Introduction.

Before the annotated rulebook is present there are a few notes to mention.

- Within this rulebook italics represent 'fluff' text that has no direct impact on the gameplay but is meant to give a contextual background to the design decisions of the game and the historical arguments that it is attempting to communicate. These would be included for players of the game to read.

- Any red text included indicates direct or paraphrased quotes from Gregory of Tours. $H F$ indicates a reference from the Historia Francorum. These are included in many of the game's cards to show the players where the inspiration for the action/event/character came from while simultaneously showcasing

- Expanded footnotes are present to elaborate on design decisions and provide the historical background to those choices. These would not be included in the normal versions of the rules. 
The cover illustration depicts four scenes from Gregory of Tours:

The top-left illustration depicts the assassination of King Chilperic (HF VI.46): "While these people were proceeding on their way with all their plunder, Chilperic, the Nero and Herod of our time, went off to his manor of Chelles, which is about a dozen miles from Paris. There he spent his time hunting. One day when he returned from the chase just as twilight was falling, he was alighting from his horse with one hand on the shoulder of a servant, when a man stepped forward, struck him with a knife under the armpit and then stabbed him a second time in the stomach. Blood immediately streamed both from his mouth and through the gaping wound, and that was the end of this wicked man."

The top-right illustration depicts the assassination of King Sigibert (HF IV.51): "In that year lightning was observed to flicker across the sky, just as we saw it before Lothar's death...The King in his sinfulness took no notice of Saint Germanus. He advanced to the royal villa of Vitry and assembled the entire army around him. They raised him on a shield and elected him as their king. Two young men who had been suborned by Queen Fredegund then came up to Sigibert, carrying the strong knives which are commonly called scramasaxes, and which they had smeared with poison. They pretended that they had something to discuss with him, but they struck him on both sides. He gave a loud cry and fell to the ground. He died soon afterwards."

The bottom-left illustration depicts the wheat bushel miracle (HF IV.34): "A few days later it happened that the monks carted three bushels or more of their grain out of their barn and set it to dry in the sun, telling the young novice to watch over it. They went off to rest and he was left in charge of the grain. Suddenly the sky became overcast, a great wind blew up and it looked as if a downpour of rain might fall on the heap of grain. When the young monk saw what was happening he did not know what to do. Even if he called the others, it was clear that they could never cart all this grain back into the barn again before the rain fell. He therefore gave up the attempt and concentrated on praying to God that no drop of rain might fall on the corn. He threw himself on the ground as he prayed. The cloud divided, the rain poured down all round the corn, but not a single grain was wetted, if what I have heard is true. The other monks, with the abbot at their head, came running to collect in the grain, for they realized what was about to happen. This was the miracles which they saw, and, when they looked for the monk in charge of the corn, they found him prostrate in prayer a few yards away. When the abbot perceived what had occurred, he lay down in prayer beside the monk. The rain passed over and the abbot finished his prayer. He then told the youth to get up and ordered him to be seized and beaten. 'It is for you, my son,' said he, 'to grow more and more humble in the fear and service of God, not to puff yourself up with prodigies and miracles.' He had him shut in his cell for a whole week and made him fast in expiation of his sin, to prevent him from becoming too pleased with himself and so that he might learn to mend his ways."

The bottom-right illustration depicts the miracle of Maxentius (HF II.37): "At that time on the outskirts of Poitiers there dwelt a saintly Abbot called Maxentius, who lived as a God-fearing recluse in his monastery. There is no point in my giving the name of the monastery, as it is now called the Cell of Saint Maxentius. When the monks saw a squadron of troops coming nearer and nearer to their monastery they begged their Abbot to come out of his cell to give his blessing to 
the soldiers. He was a long time coming, and they were so frightened that they burst the door open and pushed him out of his cell. He showed no fear. He walked towards the troops, as if to ask them not to molest him. One of the soldiers drew his sword to strike Maxentius over the head. His arm went stiff on a level with the Saint's ear and his sword fell to the ground. The soldier in question knelt at the Saint's feet and asked his forgiveness. When his companions saw what had happened, they rushed back to the army in great consternation, for they were afraid that they might all pay for it with their lives. The blessed Saint rubbed the man's arm with holy oil, made the sign of the Cross over him, and he immediately recovered. As a result of what Maxentius had done the monastery remained unharmed. He performed many other miracles, as the diligent reader will discover if he peruses the Abbot's Vita." 


\section{Introduction}

The game presented in this rulebook is not a simulation of sixth-century Frankish Gaul. It is a representation of the world that Gregorius Florentius, Bishop of Tours, communicates to us through his Historia Francorum - the ten books comprising the history of the Franks. Gregory was but one member of the religious authority in Merovingian Gaul, however, his writing is one of the few sources for this period that has survived. While Gregory is not always a truthful author, his narrative reveals the importance of a variety of dynamic relationships during this period.

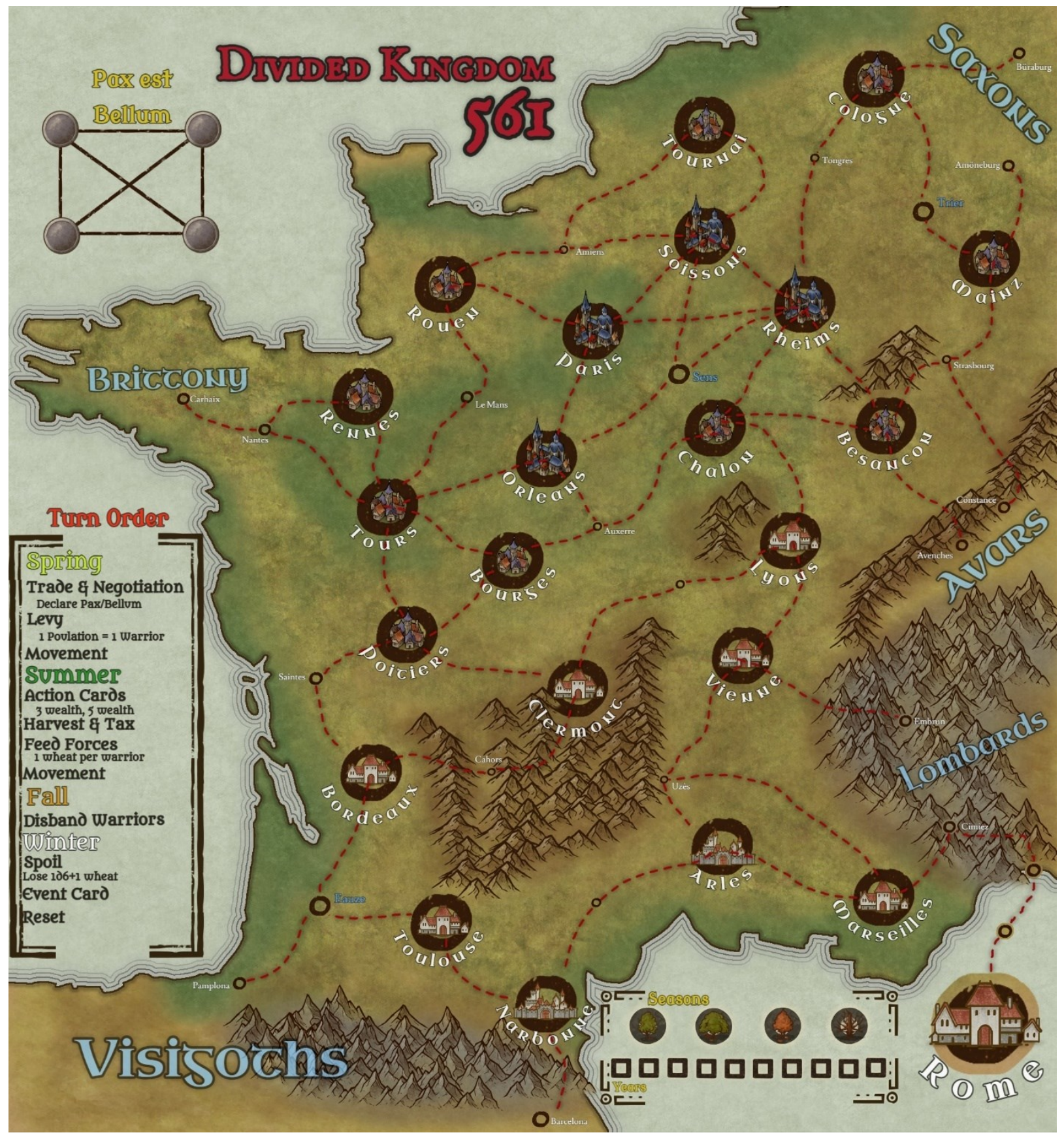

Figure 14: Game Board 
During the sixth century Christianity has become firmly rooted into the foundation of GalloRoman society. A complex network of bishops and the ecclesiastical provinces they administer the faith to spreads from Brittany to Cologne and from Bordeaux to Arles. Cults of saints start to rise in popularity and devotion centres around miraculous relics of Christian martyrs. The new Frankish elite has established itself as the rulers of a post-Roman Gaul, marketing their own historical lineage as the Merovingians - descendants of the mythical Merovech. King Chlothar, like his father Clovis before him, united the kingdom (regnum) of Frankia under one ruler through ruthless political and military efforts, surviving his other brothers who were kings in their own right, and putting down his son Chramn's attempt at usurpation. In the fifty-first year of his reign, on the first anniversary of killing Chramn, Chlothar fell ill with a fever and died. In that year, 461, his four living acknowledged sons carried his body to be buried in the church of Saint Medard in Soissons. The regnum that Chlothar had only recently brought together would be divided once more.

You will rule over a divided section of Frankia either in tandem with the other sons of Chlothar, or in rivalry. There are many agents that will aid you in your endeavour from all walks of life: the people of the many civitates in your domain, the nobles of Frankia, the bishops and abbots that are heralds of the spiritual world, as well as the regents - both kings and queens - that administer and rule your regnum. Use the agents that will aid you in unifying Frankia, discard those that stand in your way, and manipulate all else to achieve your goals. Frankia stands divided, will you be the one to unite it?

\section{The Rules}

\section{Set Up}

Place the Game Board (fig. 14) and the Metropolitan Bishoprics board (fig. 15) at the center of the table. Next, each player will take a Regnum board (fig. 16). This is where players will place

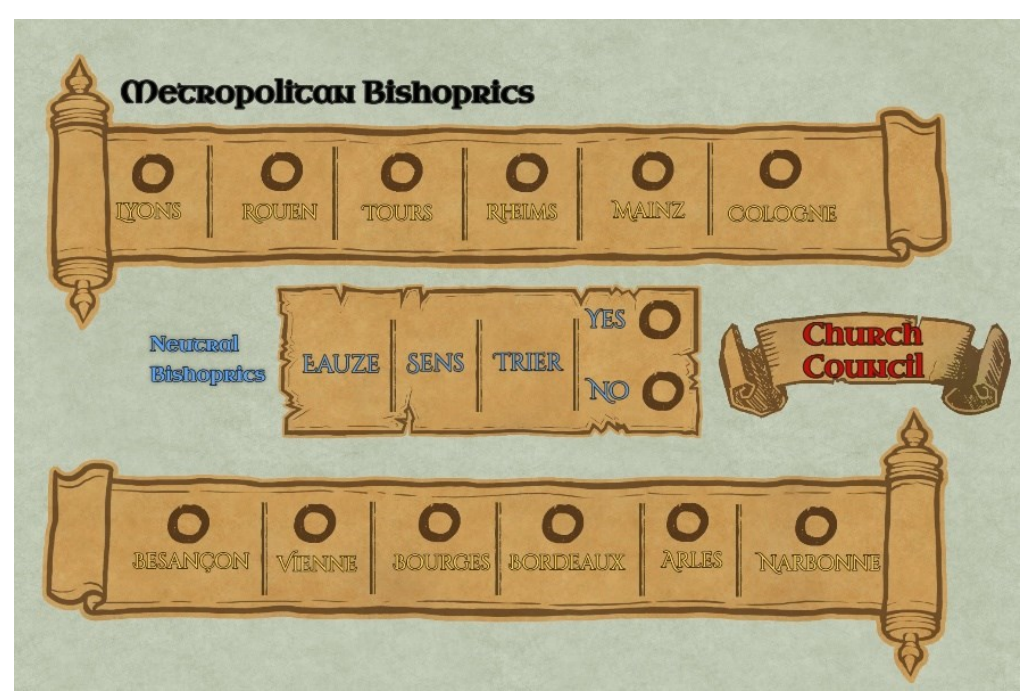

Figure 15: Metropolitan Bishopric Board used for tallying church council votes and control of the metropolitan bishoprics their characters and keep track of their resources. Then, set up all the appropriate decks in separate piles (indicated on the back of the cards): Character cards, Relic cards, Church Council cards, Scenario cards, and Event cards.

Each player will have, in their chosen colour, a Court piece, three Dux pieces, three Bishop pieces, and twenty warrior cubes.

Players must select one of the four kings - Charibert, Guntram, Chilperic, and Sigibert. The King cards determine what Civitas the player takes as their starting

position. Take the corresponding Civitas card and place the number of population tokens as indicated on the Civitas card. Players will also take the corresponding Queen card and any other 
Agent cards that are indicated on their King card. Each King card indicates their starting number of faith, honour and wealth:

- Charibert / Marcovefa (5 Faith, 12 Honour, 5 Wealth)

- Starting Civitates: Paris (Capital), Bordeaux, Poitiers, Rennes, Rouen, Tours.

- Starting Characters: Leudast, Germanus

- Guntram / Austrechild (8 Faith, 8 Honour, 5 Wealth)

- Starting Civitates: Orleans (Capital), Arles, Besancon, Bourges, Chalon, Lyon, Vienne.

- Starting Characters: Namatius, Mummolus

- Sigibert / Brunhild (8 Faith, 10 Honour, 5 Wealth)

- Starting Civitates: Rheims (Capital), Cologne, Mainz, Marseilles, Clermont.

- Starting Characters: Firminius, Egidius

- Chilperic / Fredegund (6 Faith, 6 Honour, 15 Wealth)

- Starting Civitates: Soissons (Capital), Toulouse, Tournai

- Starting Characters: Meovech, Clovis

Each player will draw a random Secret Agenda card from the four available and should keep them hidden from other players. These cards represent the long-term goals of the players and will contribute to their final victory point total at the end of the game.

\section{Victory Conditions}

A player wins the game by accumulating the most victory points at the end of the game (10 game rounds/years). Victory points are totaled at the end of the game through a variety of ways:

1. 3 VP for every controlled Civitas

2. VP equaling Faith total

3. VP equaling Honour total

4. VP equaling Wealth total

5. 2 VP for each Noble agent in your court

6. $2 \mathrm{VP}$ for each Bishop/Abbot agent in your court

7. $10 \mathrm{VP}$ for every Relic on your regnum board

8. 8 VP for each completed objective of a Scenario Card, or 30 VP for completing them all.

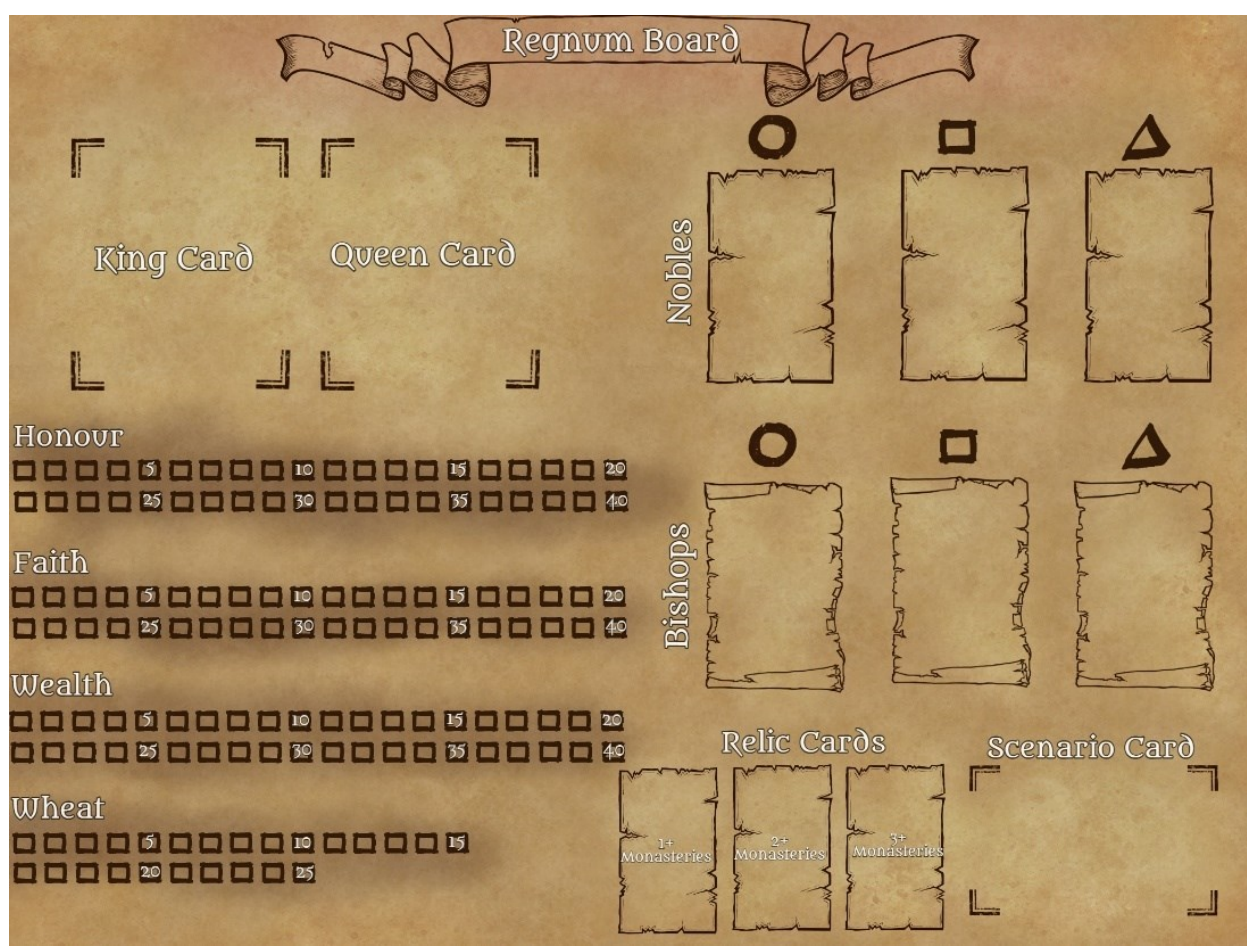

Figure 16: Regnum Board. Each player has one of these to track their resources, relic cards, scenario card, and any characters in their court

\section{Resources}


In this game there are four types of resources that players will try to amass: Faith, Honour, Wealth, and Wheat. Two of them, faith and honour, represent abstract values that have weight in the wider communities in Merovingian Gaul. These resources are tracked on a player's regnum board. The values cannot go below the lowest value and can never go above the highest value on each individual track.

Honour is an important yet abstract resource in the game of Divided Kingdom, 561. It represents the prestige and public power held by the elite in Merovingian society, but especially kings and nobles. While honour functioned alongside faith and is at times indistinguishable from it in a heavily Christianized society, this game defines honour along Frankish lines. Martial actions are one of the greatest forms of honourable expression as they bring physical rewards to your followers (e.g. new lands and treasure) and reinforce an individual's role as protectorand therefore their role as lord and administer of large groups of people.

For Kings, their ability to look after their followers and supporters directly affected their honour and therefore standing in the wider Frankish society. Their role as king and leader of the large network of Frankish and Gallo-Roman elites depended on their capacity to lead martial expeditions and reward the loyalty of their followers with wealth, titles, and territory.

Faith is unsurprisingly at the center of Gregory's works. His corpus of literature aside from the Historia Francorum revolves around the lives of saints and the many miracles attributed to them. Faith is undoubtedly an abstract resource in the world of Merovingian Gaul and shifted in meaning depending on the spiritual authorities in charge. What was considered a viable form of faithful expression also constantly shifted depending on who it was expressed by - queens, kings, bishops, and abbots all had differing expectations in the ways they expressed their faith.

In the game Divided Kingdom, 561 faith is a representation of how well individuals within Merovingian Gaul prioritized the teachings of the church in Gaul; whether they respected the holiness of official spiritual positions such as monks, bishops, and priests as well as the holy ground and space they maintained. Gregory is not shy in his denouncing of unholy individuals that do not prioritize or respect the cultivated practices and spaces of religious figures - either overtly through pillaging monasteries and appropriating church land, or more subversively through disrespecting the opinions and authority of church figures.

\section{Turn Order}

The game takes place over ten years and each year is split into the four seasons. Players track which season it currently is and after the final winter season (space furthest to the right) the year marker gets moved to the next space to the right and the Spring phase begins. Each season is broken into several phases that are performed in sequential order:

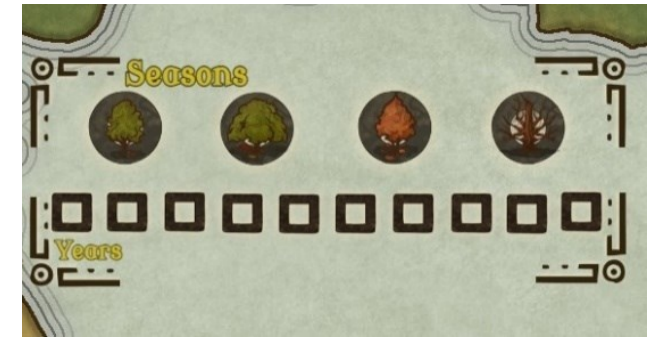

Figure 17: Season and year tracker on the main game board 


\section{Spring}

1. Trading and Negotiation: ${ }^{105}$ During this phase, players may freely discuss informal deals and strategies as well as make declarations of war and peace.

a. During this phase players will be able to exchange action cards in their hands. Players may never show the action cards in their hand and when they trade, action cards must be passed face down as to not reveal them to any player.

b. During the trading phase, players may discuss anything and may promise anything to other players. What can be traded, and if agreed upon, must be traded: action cards, wheat, civitates, wealth, and relics. Anything else such as future promises are not guaranteed. It is suggested that players get creative with their negotiations and trading.

Example: Sigibert is discussing a trade with Chilperic. He would like to have Chilperic's support in the upcoming battle against the invading Saxons. For that support, he promises 5 wealth to be paid immediately and Chilperic agrees. In the future, Chilperic can follow through with this agreement or go back on it, there is nothing but his reputation holding him to his promise.

c. Only after the trading phase is complete may players discuss what was traded, but they do not have to be truthful.

d. Declaring Peace/War: This is the phase where players may change their status on the War and Alliance chart. Players will have three copies each of the two cards:

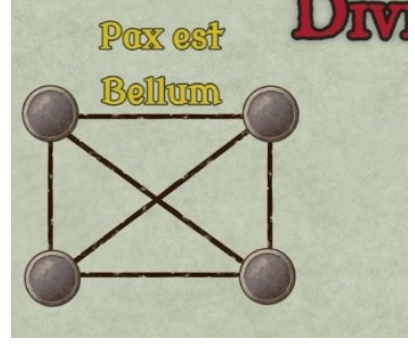

Figure 18: Pax and Bellum chart, tracks which players are at war

\section{Bellum and Pax.}

these cards with one another, either secretly or openly. If two players trade Pax cards with one another this means they are no longer at war and must indicate that on the War and Alliance chart. If one player gives a Bellum card to a player that means they are at war and must indicate so on the War and Alliance chart.

2. Levy ${ }^{106}$ : Players make an Honour Roll, the lowest roll levying first, followed by each player in ascending order. Players decide how many population tokens they want to levy and convert to warrior cubes.

\footnotetext{
${ }^{105}$ Including a phase like this was important for imparting a sense of control over the game's outcome and narrative development on the part of the players. By building a structured phase wherein players can communicate their public (as opposed to secret) goal and agendas, the relationship between the historical characters the players are inhabiting can be better defined. The hopes of the game designer are that the other structured rules and defined order of operations will guide the players to use the trading/communication phase to establish relationships that help to elaborate on the historical relationships between opposing Merovingian rulers.

${ }^{106}$ There was no identifiable 'standing army' during this period. Rather military forces were made up of enlisted individuals for a short period of time and would be gathered a comes (count), dux (duke), or potentially the king; see Sarti, Perceiving War and the Military in Early Christian Gaul, 2013, 25. Not all 'able bodied' individuals would be enlisted for campaigns, but men within a civitas could have been called upon; see Sarti, "The military, the clergy
} 
a. When you levy warriors, population markers get converted into warriors. A player must signify the population has been levied by replacing a population token with a levied token.

b. Dissent markers will affect how much of the population you are able to levy. Each dissent marker will prevent you from levying one of the population markers (to a minimum of 1 ).

Dissent While Levying Example: Chilperic is going to levy warriors from his civitas of Rouen. Rouen currently has 6 population tokens on it and 3 dissent tokens. This means that Chilperic can only levy a maximum of 3 warriors. c. When you convert population tokens into warrior cubes, you place the warrior cubes on the board for every population token replaced with a levy token. The warrior cubes are placed on the civitas space on the board that corresponds to the civitas card they were levied from.

\section{Movement}

a. Players make another Honour Roll. Starting from the highest roll going down, players take turns in order, choosing a group of warriors/characters/court to move.

i. Warrior Movement: Each warrior may move any number of spaces (following the red lines indicating Roman roads) as long as they do not enter a space with enemy warriors, and they do not end their movement in a civitas that is controlled by a player they are at War with.

ii. Character Placement and Movement: Nobles, Bishops, and Courts all move differently.

1. You may place any Bishops you control that are not currently on the board in a controlled civitas and move them up to five spaces. Bishops cannot enter a civitas controlled by a player they are At War with.

2. The Court may move three spaces (as they never travel light). ${ }^{107}$ They may take any friendly warriors with them as they move. If they enter a space with warriors/court or a civitas they are At War with, they will initiate combat.

3. You may place any Dux figures you control that are not currently on the board in a controlled civitas and move them up to five spaces. They may take any friendly warriors with them as they move - if they do, they are allowed to enter a space with enemy warriors or a civitas owned by a player they are At War with.

b. *If movement is ever interrupted by an ability, action card, combat, or anything else that affects the character moving, that movement is immediately ended.

and Christian Faith in sixth-century Gaul," 2017, 164. Within the confines of this game, a player is technically able to enlist the entire populations of the civitates they control, however this would drain the entire workforce - not allowing the player to harvest as many crops or collect taxes through wealth. The population have a military, economic, and agricultural purpose. The same people that harvest the crops and constitute the source of taxation also serve as the basis of the 'military' - if it can be called such a thing. A player will need to understand that diverse role to utilize them to their full potential.

${ }^{107}$ Courts would move their treasury around frequently, sometimes storing it at a villa (HF IV.22), but also whisking it away if they ever thought it would be in danger of theft ( $H F$ VI.41). Kings would also travel with a personal armed retinue which is the closest thing that could be considered a 'standing army'; see Sarti, Perceiving War, 2013, 159. 


\title{
Summer
}

1. Draw Action Cards: Each turn, players may pay 3 wealth to draw an Action Card. Then, they may pay an additional 5 wealth to draw a second Action Card. If a player ever has more than seven cards in their hand at one time, they must discard down to seven, retaining the cards of their choosing.

2. Harvest/Tax: Controlled territories with unused population tokens are flipped to their used side and 1 wheat or wealth is gained per token flipped this way.

3. Feed Forces: ${ }^{108}$ Players must pay 1 wheat for every warrior they have currently on the board. Every warrior not fed will be disbanded and converted back into a population token, replacing a levy token with a population token flipped to its 'used' side.

a. For every warrior that you cannot feed you lose 1 honour.

4. Movement Takes place in the same sequence as in the Spring phase.

Fall

1. Disband Warriors: Each warrior must be disbanded unless stated somewhere else. To disband warriors, a player will remove warrior cubes and replace them with levy tokens on a controlled territory with a population token flipped to the 'used' side. Players will continue to do this until they have no warriors left to disband.

\section{Winter}

1. Spoil: Players lose $1 \mathrm{~d} 6+1$ wheat. If players end up with no wheat, each of their territories gains 1 dissent token.

2. Draw Event Card: Draw a new event card (even if one is still in play, unless it is a repeat of the one in play then discard that card and draw a new one).

3. Reset: Population token are flipped back to their 'unused' sides. Players can convert wealth to faith if they have monasteries

\begin{abstract}
Alliances
There are two official diplomatic relationships that a regnum can have with one another: At Peace and At War. Players can alter their status with one another through official declarations during the Trading and Negotiation phase through the use of their Bellum and Pax cards OR surprise the other during the movement phase and initiate a combat without warning - however this will drastically affect their honour.
\end{abstract}

\section{Bellum and Pax Cards}

Each player is given a Bellum (War) and Pax (Peace) card to use. During the Trading and Negotiation phase they will be able to exchange these cards to alter their relationship on the Bellum est Pax chart in the top left of the game board. You can only give a player a Bellum card if you are not at war with them and only give a player a Pax card if you are at war with them. Each card resolves in the following way:

\footnotetext{
108 There is little information on how, if at all, levies were cared for by the kings and nobles that called them to military service - specifically when on campaign. Gregory relates a story that a returning host of Frankish warriors from Italy had to sell their weapons to buy food $(H F X .3)$. Soldiers had to be provided for in one way or another, so the in-game action of 'feeding' troops represents foodstuffs that could come from a variety of different sources but ultimately could be at risk of running out if not accounted for.
} 
Bellum - An official declaration of war has been delivered to you. Ready yourself. You must now indicate that you are At War with the regnum that issued this declaration to you.

Pax - Your enemies have extended an offer of peace to you. Will you accept? Give them your Pax card to agree to the peace treaty and indicate that you are no longer at war. Or ignore their plea and return the card to them. They will not see peace this day.

\section{Combat Rules}

Warfare was a common part of Frankish life...

Combat may take place when two different player's Warriors/Court enter the same space. Once that occurs, consult the list below for the potential outcome:

1. Invaders will always initiate combat with other Warriors/Courts

2. Players who are At War with each other will always initiate combat

3. Players moving into a space currently occupied by another player's Warriors/Court that they are not At War with may decide to attack or not. If they do so, they will lose 10 honour and immediately indicate they are At War with each other on the Bellum est Pax chart.

If combat takes place, players will initiate a series of Combat rounds. Each combat round consists of a combat roll and casualties.

\section{Combat Rolls}

For combat rolls, each player will role a d12. Action Cards or Characters traits may affect these rolls. However, a roll of a 1 on the die always counts as a 1 - it cannot be modified. This means modifiers will not Generally, action cards must be played before the rolls are made and can only be played during combat if the card says so. Otherwise, the following modifiers are applied to the rolls:

1. The player(s) with more warriors will add +1 , if they have double or more, they will add +2 instead.

2. If a Bishop is present in the space where the battle is taking place, its controlling player may decide which side to give a blessing to by spending 3 faith. The chosen side will gain +1 to their combat roll.

3. If a Dux figure is present in the space where the battle is taking place its controlling will add +1 to their combat roll.

4. If a Court is present in the space where the battle is taking place its controlling player will add +3 to their combat roll.

5. After adding up all modifiers, the players roll. The highest roll wins this combat phase, honour then faith break ties.

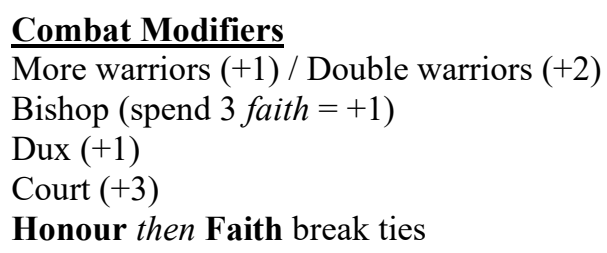

\section{Casualties}

After a combat roll is made and a winner is decided, the loser of the combat will remove $1 \mathrm{~d} 3$ of their warriors who are 


\section{Retreat and Defeat}

1. Combat will continue until a player elects to retreat or loses all of their warriors.

2. If one side has no warriors left, then they lose the combat. If they only have a Dux figure left, then they must roll a d12: A roll of 1-5 means the Dux is killed and the associated character card is discarded. A roll of 6-12 means the Dux survived and retreats to the nearest nonenemy space.

3. After each round of combat (after casualties are resolved), a player may elect to retreat. If they do so, they must move all of their figures to the closest controlled or neutral civitas. This must avoid other combat scenarios if possible. They are considered to have been defeated and lose that combat.

4. A player who loses a combat will instantly lose 3 honour. If their Court participated in the combat, they lose 5 honour instead. The losing player will also lose 3 wealth.

5. A player who wins a combat will gain 3 honour, if their court was a part of that combat they earn 5 honour. The winning player will also gain 3 wealth.

6. After the combat is resolved, if it took place in a civitas, place a dissent token on its corresponding civitas card.

*For special rules on fighting invaders go here.

Sieges

When a player's Court or Warrior(s) (accompanied by a $d u x$ ) enters a civitas controlled by another player they are at War with, they may decide to initiate a siege. As a rule: If applicable, you must initiate a combat before you can initiate a siege, meaning there cannot be any enemy warriors/court in the civitas that you intend to siege. After combat a siege may be initiated immediately.

Once a siege is initiated, the player who controls the civitas being besieged may levy the amount of population on that civitas minus the amount of dissent tokens on the civitas. Combat is then resolved as normal, except once the player who initiated the siege wins two combat rolls, they successfully take the civitas and combat ends.

The player who initiated the siege has the option to retreat after each combat roll, following the normal rules under Retreat and Defeat.

If the player who initiated the siege successfully wins two combat rolls, they immediately take control of the civitas and remove all dissent tokens if they have a higher honour value than the previous owner of the civitas.

\section{Bishops}

Bishops held a considerable amount of power in sixth-century Gaul. During Late Antiquity and the early Middle Ages, Gallo-Roman aristocratic families saw the Church as an avenue, complementary to their secular power, to pursue advancement, gain resources and represent local concerns. ${ }^{109}$ Becoming a bishop meant you had spiritual authority over a large group of people, even potentially the new Merovingian royalty. They were spiritual officials who filled the political power gap left behind by the Roman Empire and wielded their political, economic, and

${ }^{109}$ Raymond von Dam, Leadership and Community in Late Antique Gaul, University of California Press, $1985,144$. 
spiritual positions to the benefit of themselves, their families, and the idea of a unified Gallic church

In Gregory's narrative, there are 'good' bishops and there are 'bad' ones. Some bishops were driven more by greed than by the duties of their spiritual office, which Gregory characterizes as evil. Good bishops, leave behind temporal concerns and seek to fulfill the will of God and the Saints.

Bishops' powers can only be activated one a year. Each bishop will have a special ability in addition to the following universal ones:

1. Preach: You may pay 3 faith to remove a dissent token from the civitas that this bishop is in.

2. Provide for the people: You may pay 5 wealth and 5 faith to increase the population of the civitas this bishop is in.

\section{Nobles}

Nobles represent a huge swath of elites that filled martial, judicial, and administrative roles during the sixth century in Gaul. They came from both Gallo-Roman and Germanic backgrounds, some gaining their aristocratic position in society under Roman rule and others new to the rank of elites through martial service to Frankish kings who subsequently granted them land rights and titles.

Counts would be in charge of administering the region of a civitas (city). A dux (duke), although not fully defined, would usually administer a much larger region such as a province. A patrician would be a very high honour given to the right hand of the king. It was a title that alluded back to Roman occupation and brought with it a lot of prestige. A patrician would often lead military campaigns in the name of the king - Mummolus filled this role for King Guntram who seemed to not partake in many campaigns himself.

\section{Civitates $^{110}$}

Players are able to take control of the 22 different cities, or civitates (civitas sg.) that represent both the major urban centres of Francia as well as the surrounding rural areas. The civitas cards are used to manage the population of a player's regnum - as sources of income and fighting men. They were often ruled by counts and had one or multiple bishops oversee their spiritual needs. A civitas card can have multiple components on it:

\section{Population Tokens}

Population tokens represent the number of inhabitants that are in each civitas. These people represent the workforce, and military force, of your regnum. It is your duty to protect them against threats and shepherd them through the physical world. Each civitas has a starting number

\footnotetext{
${ }^{110}$ Gregory discusses 'citizens' of different cities sparingly, sometimes with additions such as "senior" or "poorer" but more often than not as a monolithic group that could have a modicum of influence in secular and ecclesiastical decisions. Citizens had the power to demand the appointment of bishops to lead their community (see $I V .15, V I$. 36 ), but also represented groups that kings wanted to appease $(V .17)$. They could also ban together at times to refuse military service or occupation $(V .26)$. I wanted to implement a rule(s) that showed the players that the places they interacted with had living and breathing people - they are ruling over people rather than just places.
} 
of population tokens ranging from 2-6. However, throughout the game the number of population tokens can go up and down. In the game, there are only 100 population tokens. If there is ever an absence of population tokens, a player cannot increase a civitas's population anymore until a population token becomes available.

Population tokens have two uses: for - Levying (Spring) and Taxing/Harvesting (Summer). See the Turn Order for more detail on this action.

Population tokens have two sides, Used and Unused. When a population token is flipped to its Used side, it cannot be levied or used to collect any resources.

\section{Monastery Tokens}

Monastery tokens are placed on a civitas card, often as a result of an action card. These represent the urban and rural communities of monks that existed throughout Gaul. ${ }^{111}$ They are places of devout worship, and their members follow a particular set of rules that guide their life and devotion to God.

1. Players that have a civitas with a monastery may convert up to 3 wealth into faith (for each monastery that they have) during the reset phase. The conversion rate is $1: 1$. If a player has a total of 2 monastery tokens on civitates they control, they can convert up to 6 wealth into faith. Meaning, they lose 6 wealth and gain 6 faith.

2. Only once they have a monastery can players possess the relics of saints.

\section{Dissent Tokens}

Dissent represents the citizens of a particular civitas becoming dissatisfied with their count or king. Dissent and the resulting unrest will directly affect the number of warriors that can be levied from it, as well as how easily it can be taken over by another king.

1. If a battle is fought in a civitas space that civitas gains a dissent token

2. Bishops and some nobles can both place and remove dissent tokens (see Bishops)

\section{Capital}

When Chlothar died and his sons inherited his kingdom, Gregory tells us that they each took over the former realms of one of their uncles (who ruled before Chlothar united Gaul) taking a city as their 'seat of power', 'chief city', or capital. Although Gregory remarks the cities of Paris, Orleans, Soissons, and Rheims (IV.22) being 'seats of power' for these kings, they frequently travelled throughout their kingdom with a large entourage as well as their treasuries. They would rely on the nobles of their realms to host them when they passed through.

Each player starts with a capital (as indicated on your King card). If at any point that civitas is taken by a player or invaders you must choose a new civitas you control to be your capital. If a player took your capital, they gain 10 honour. If you lose your capital, you lose 10 honour.

If a player does not have a king (i.e. flipped to its heir side) and your capital is taken, your kingdom is defeated and the player immediately exits the game. The other players take turns taking control of one civitas the defeated player controlled. The order of choosing is determined

\footnotetext{
${ }^{111}$ Yaniv Fox, Power and Religion in Merovingian Gaul: Columbian Monasticism and the Frankish Elite, Cambridge University Press, 2014, 3.
} 
by an honour roll, the highest result going first followed by the second highest etc. After all the defeated player's civitates are claimed by the remaining players the same process is done for the defeated player's character cards. ${ }^{112}$

\section{Church Councils}

Church councils could range from local gatherings of bishops within a single ecclesiastical province to the less common multi-province councils that numerous members around Gaul were expected to attend. Provinces themselves were even expected to hold annual or bi-annual councils.

Numerous subjects would be brought up at these councils, often having a central issue to discuss determined by the bishop or royal official who called them. ${ }^{113}$ They ranged from adding new canon laws regarding how bishops should act and administer their sees, to specific accusations against bishops who committed sins and broke canon law. Gregory retells the accounts of a few church councils, and they are often filled with dramatic and accusatory speeches and behind the scenes dealings (HF - IV.47, V.18, V.20, VI.1, VI.38).

Church councils will happen sporadically throughout the game. Sometimes an event will initiate one or a player must call one as a result of an action card (to represent a bishop driven council). When a church council is called, unless otherwise stated, a church council card will be drawn to determine what will be voted on. Councils can range from targeting a specific player for a lack of faith or cooperation with the church, to a Gaul-wide call for peace. Players each have a yes and no card that they will use to vote. Players will want to weigh their options while voting, as the outcome could help them directly or more indirectly by punishing another player. Deals can be made behind the scenes between players for their support in a vote.

\section{Hosting a Council ${ }^{114}$}

Before voting takes place, players will have to determine who will host the church council. Players will make a wealth bid to host it at a civitas they control. The player who bid the highest gets to host the council (honour then faith break ties). ${ }^{115}$

A church council card will have a descriptive text describing what will be negotiated and eventually voted on - often adding new religious laws or coming to a ruling on a particular event pertaining to both spiritual and secular authorities. There will be an outcome based on whether

\footnotetext{
${ }^{112}$ Queen regents were frequently targeted by other kings and nobles as they were seen as precarious in their role as regent. Fredegund faced multiple enemies after King Chilperic died, ranging from bishops, nobles, and other royal figures (Dailey, 124). Brunhild, acting as regent for her son, is chided by a prominent noble for giving him orders when in reality her son was king (HF VI.4). The later chronicles of Fredegar detail Brunhild's eventual fall from power and accusation of regicide that led to her execution, (Dailey, 119).

${ }^{113}$ Gregory Halfond, The Archeology of Frankish Church Councils, 57.

114 The councils in this game showcase how the Church, at least in part, exerted its power over the larger Christian community but also secular affairs. Gregory Halfond's work is of great use for this mechanic of the game as he not only provides a throughout history and description of the structure of Frankish church councils but also provides an appendix of both official and 'dubious' councils held during the Frankish period. In the appendices, dates, locations, attendance, and subjects discussed, are all given when available. See Appendix A and B in: Gregory Halfond, The Archeology of Frankish Church Councils, p. 223.

115 Ibid., 65; Gregory also notes that even if the king did not convene a council, the bishops would confer with the king on certain decisions involving secular matters (V.20, V.27, V. 36, VI.1).
} 
the council is passed or not. Some action cards allow players to add additional effects to a church council card, depending on if it passes or not.

Once a church council is called all play stops and players must decide to vote on the church issue revealed by the church council card. Players have as many votes as they have controlled metropolitan bishoprics - as indicated on the Metropolitan Bishoprics board. Players first choose in secret either a yes or no card, once all players have chosen, cards are revealed simultaneously. The neutral metropolitan bishoprics (and any others not controlled by players) will vote together as a block at random, adding to the total count for yes or no.

\section{Invaders}

Gregory tells us of multiple incursions of

Example of a Church Council: The church council card "Excommunication" has been drawn. All the players simultaneously reveal their "Yes" or "No" cards. Chilperic and Guntram voted "Yes" while Sigibert and Charibert voted "No." Chilperic has control of 3 metropolitan bishoprics and Guntram 2 which means a total of 5 votes for "Yes." Sigibert has control of 5 metropolitan bishoprics and Charibert 2 which means a total of 7 votes for "No." A random "Yes" or "No" card is drawn to determine how the three neutral bishoprics vote. A "Yes" is drawn which means the council card is voted "Yes" by a margin of 8 to 7 . outside forces into Gaul that kings and certain nobles had to deal with on a sporadic basis. Gregory mentions Saxons, Huns (more accurately Avars), Lombards, Bretons, and Visigoths violently entering Gaul and sacking towns. These forces would stay for entire seasons, living off the crops produced by local inhabitants. Either kings or lesser nobles would lead a force to expel these invaders, often able to defeat the less organized forces. The conflicts would frequently end with the Frankish forces extracting a monetary tribute from the invading force, and sometimes following them back into their territory as an invading force.

1. The invader card (Saxon, Avar, Longobard) stays on the board until the associated cubes are removed. If a repeat event card is drawn while still on the board, that event card is ignored and a new one is drawn. This means that if a Saxon Invasion card is drawn while an event card of the same name is still on the board, it will be discarded. If a different Invasion card is drawn (Avar Invasion, Longobard Invasion), than that card's effect still takes place.

2. All invasion event cards place three warrior cubes at different locations. Each movement phase, those warrior cubes will move to one adjacent region. If there is a choice then it will prioritize first moving to an unoccupied space, then the space with equal or fewer warriors than itself. It will not move if it cannot meet these move conditions. This means invaders cannot freely move into a space with more warriors than itself.

3. When invader cubes move into a civitas, that civitas gains 1 dissent token. If invader cubes start a movement in a civitas, they will not move. They are considered to be raiding the lands around the more densely populated areas of Gaul. Instead, roll a d12:

a. 1-3: Add a dissent marker to the civitas

b. 4-6: The controller of the civitas loses 5 wealth

c. 7-9: The controller of the civitas loses 5 wheat

d. 10-12: Remove a population token from the civitas 
If a result is rolled that cannot be fulfilled - meaning the player cannot lose any more of a resource or if there are no population tokens left to remove - the invaders will move instead following their normal movement rules.

4. Fighting Invaders: When initiating combat against invaders, the player to your right will roll for them. Invaders are always considered to have a Dux leading them and therefore always get $\mathrm{a}+1$ to their roll in addition to any modifiers gained from number of warriors will fight until they have no more warriors.

\section{Honour Roll}

Each player roles a d12 and adds a bonus to that roll depending on their honour respective to other players. The player with the highest honour will add +3 to their role, the player with the second highest honour will add +2 to their roll and so on all the way to a bonus of +0 for a four-player game. Players with higher faith will win ties, if there is still a tie wealth will break ties.

\section{Wealth/Faith Bid}

Some instances, such as hosting a church council, will require players to make a wealth or faith bid. Players must write down a number on a piece of paper ranging from 0-40. Players cannot write a number down that is higher than the

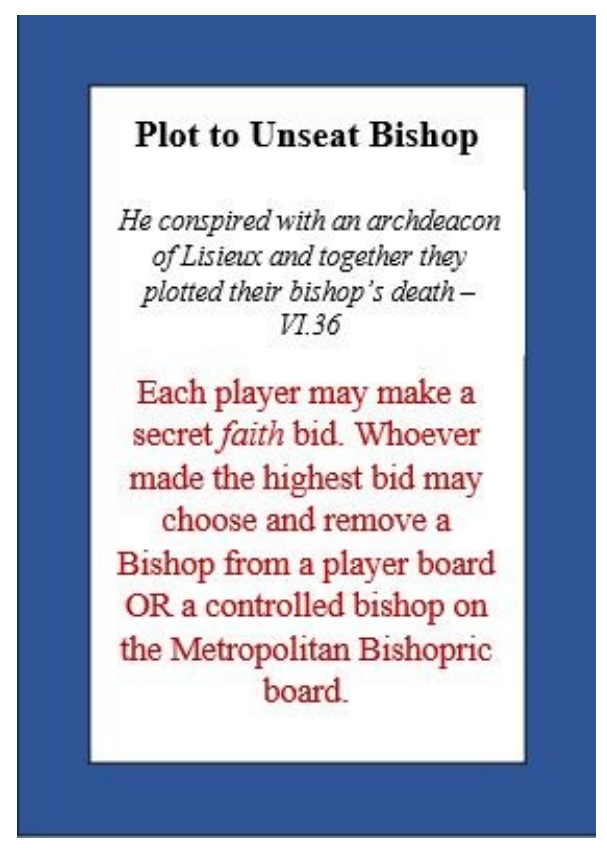

Figure 19: Event card example amount of wealth or faith (depending on what is being asked for) they currently have. When all players have written down a number, they simultaneously reveal them. The player who wrote down the highest number wins the bid, and they must immediately lose that amount of whatever

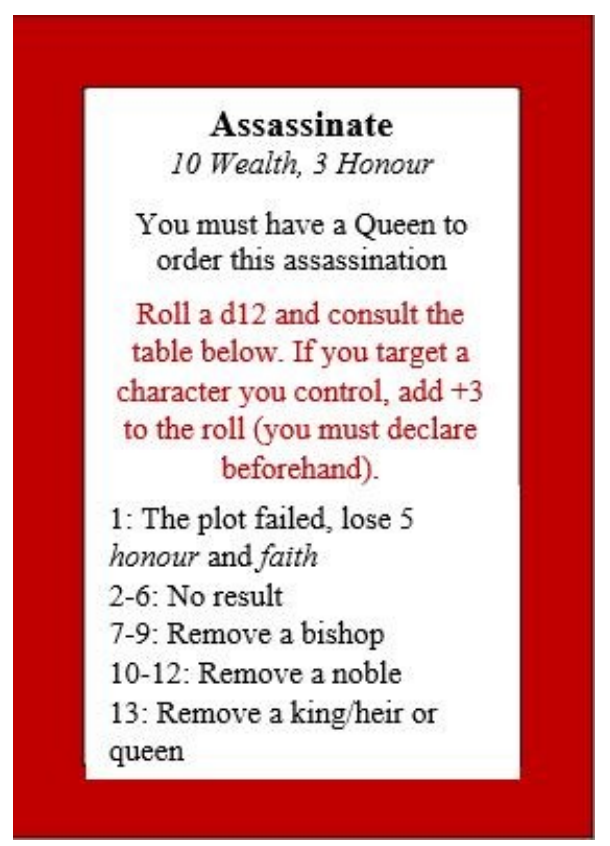

Figure 20: Action card example resource is being wagered. Players who did not win the bid do not have to lose the amount they wrote down. If there is a tie, all tied players must roll a d12. The highest result wins the bid.

\section{Event Cards}

An event card is drawn from the event card deck every Winter phase. Event cards are distinguished by their blue border (see figure 19). Event cards can affect one player or multiple players. Event cards represent the constant shifting environment, politics, and miraculous events that Gregory describes in his Historia Francorum.

\section{Playing Action Cards}

Action cards can be purchased from the action card deck during the Summer phase. They are distinguished by their red border. Action cards will sometimes prompt you when they can be played, often during a particular phase or 
season. If it is not specifically listed on the action card when it can be played, it can be played at any time. To play an action card, you must meet and prerequisites if it has any (control of a character or have enough of a resource). After you declare that you will play an action card, you must pay its cost before triggering its effect.

\section{Rolling Dice}

As a rule, whenever rolling a d12, a roll of a 1 on the die is never modified. This is referred to as a natural one. During combat, as well as for some action, character, and event cards, modifiers will be applied to die rolls. No modifiers can alter a natural one.

\section{Character Cards}

Your court is made up of a plethora of different characters that inhabit your kingdom. They represent the elite figures of Frankish and Gallo-Roman society. Aside from you king and queen, characters are broken up into two categories: Nobles (denoted by a green boarder) and Bishops (denoted by a yellow border). Character cards are most commonly purchased through action cards, but some other cards will let you draw one from the character card deck and play it on your regnum board.

As a rule, you cannot freely remove a character from your regnum board. Characters can only be discarded by character abilities, event cards, action cards, or any other instance that requires you to remove a character card. If you draw a character card but do not have a free spot on your regnum board to place it, you must discard it.

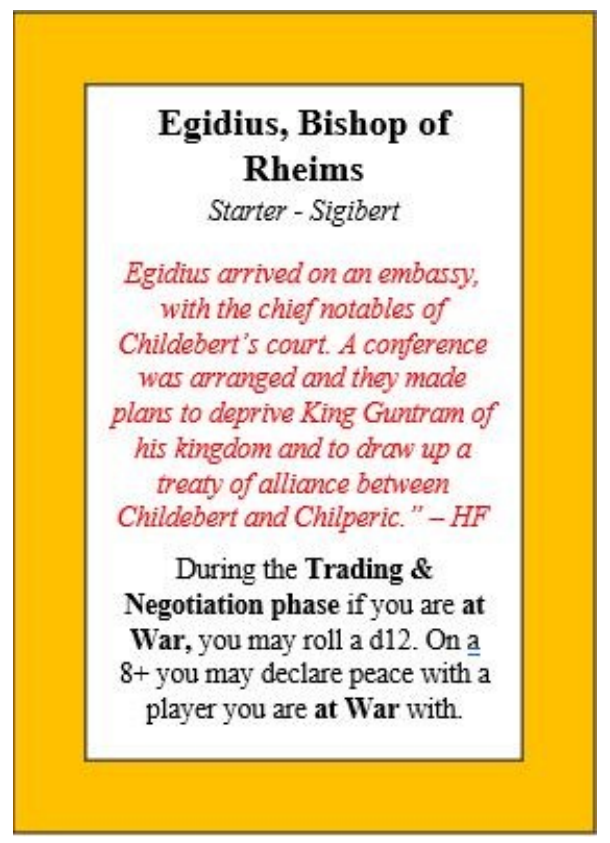

Figure 22: Bishop character card example

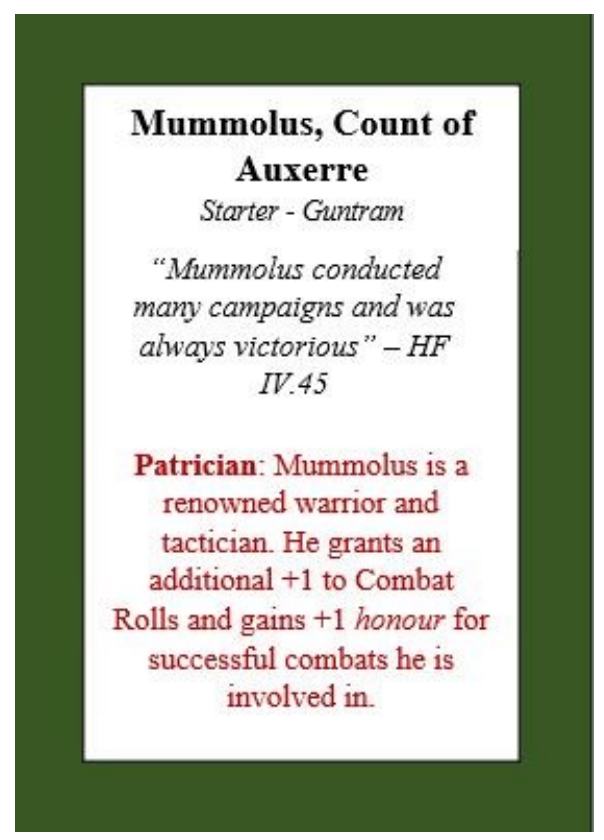

Figure 21: Noble character card example 


\section{Game Components}

\section{Action Cards}

Each card will have a frequency of availability, i.e. how many copies are within a deck (High, Medium, Low).

- Advanced Planning (Medium): You must have a noble character in your regnum to play this card. You may levy and move first this year.

- Assassinate (Low) Cost: 10 Wealth, 3 Honour: You must have a Queen to order this assassination. Roll a d12 and consult the table below. If you are assassinating a character you control, add +3 to the roll. You must declare if you are choosing a player in your own kingdom before rolling.

- 1 ( 1 on a die always counts as a 1 , regardless of any bonuses): The assassination failed and was traced back to you. You lose 5 honour and 5 faith.

○ 2-6: The assassins died during their task. No result.

- 7-9: You may choose a bishop to assassinate.

- 10-12: You may choose a noble to assassinate.

- 13: You may choose a king/heir or queen to assassinate.

- Bountiful Harvest (Medium) 5 Faith: You collect +5 wheat in the Harvest/Tax phase if you are collecting at least 1 wheat already.

- Build Monastery (Medium) 7 wealth: You must have at least 10 faith to build a monastery. Place a monastery token in a civitas you control that does not already have a monastery token - this will let you play relic cards and collect faith each turn.

- Burglarize Church (Low-Medium) 4 honour, 8 faith: Target a civitas that contains warriors you control. The owner of the civitas loses 8 wealth and you gain 8 wealth.

- Call a Church Council (Medium) 5 wealth: You must have at least 15 faith to call a council.

- Consular Procession (Low) 15 wealth: Your court must be in your capital to play this card. You host a procession and declare yourself Consul and Augustus. You gain 10 honour. "In Saint Martin's church he stood clad in a purple tunic and the military mantle, and he crowned himself with a diadem." - HF II.38

- Council Addendum: Accuse Bishop (low): You must have at least 20 honour. Must be played before church council voting takes place. During council proceedings you level accusations against a bishop. Choose a player's bishop. If the council vote passes, the bishop is convicted, and their character card is discarded. "Surely you knew what the canons of the Church have prescribed for such a case?" - Chilperic accusing Bishop Praetextatus during a council - HF IV.18

- Council Addendum: Restore Bishop ${ }^{116}$ (low): You must have at least 20 faith. Must be played before church council voting takes place. During the council's proceedings you bring up the wrongful dismissal of a bishop in the previous year. If the council vote passes you may choose a bishop character card from the character card discard pile and add it to your regnum board.

- Collect Relic (Medium) Cost: 10 wealth: You must have at least 20 faith to collect a relic. You must also have a monastery in one of your controlled territories to house this

\footnotetext{
${ }^{116}$ A council restored Bishop Marcus of Orleans in 549; see Gregory Halfond, The Archeology of Frankish Church Councils, 227.
} 
relic, you cannot have more relics than you have monasteries. Draw a relic card from the relic deck and place it next to your regnum board.

- Demand Peace (Low-Medium) 4 honour, 4 wealth: You must have at least one Bishop character and control of at least 4 metropolitan bishoprics. You gather together bishops from around Gaul to sign a petition to your rival king demanding an end to hostilities. Target player who you are at war with must either decide to cease hostilities or lose 8 faith. If they declare peace, they cannot initiate combat with another player for the rest of the year.

- Denounce Miracle (Low): Play immediately after an action card with the word "miracle" in its title was played and before it's effect is resolved. Rumours abound around Gaul about a potential miraculous event taking place. You converse with multiple bishops, monks, and other notable religious figures and decide that indeed, what was previously rumoured to be a miracle, was not one.

- Donate Inheritance (Low-Medium): Play after a character card is discarded. Roll a d12 to determine where that character's inheritance goes.

○ 1-4: Their inheritance stays within the family, nothing happens.

- 5-12: Donation to the church, the controller of the discarded character card loses 8 wealth and gains 4 faith.

- Easter Celebration (Low) 3 Wealth: Can only be played in the Spring and if you have a relic. Return your King to your capital to host an Easter procession. Gain 5 faith and move your court to your capital. The court cannot move this Spring movement phase. HF Text: "He sent the relics of a great number of saints on ahead, and then marched into the city himself. He celebrated the feast of Easter with great joy and happiness, and brought his son to be baptized" - VI.27

- Emergency Levy (Low) 2 Wealth, Faith, Honour, Wheat: This card may be played at any time. You may choose two territories and levy up to three population in each.

- New Ruler (Low): You must have at least 25 honour. Play when your court is in a civitas that has at least 5 dissent tokens on it. Take control of that civitas peacefully. Dissent tokens are removed.

- Garner Influence (Medium) 5 Wealth: You must have 10 Faith. If you have a bishop character on a non-neutral metropolitan bishopric that you do not control, take control of it.

- Garner Support (High): You must have 10 Honour. Draw two character cards and choose one to purchase and add to your regnum board. Shuffle the other back into the deck.

- Galswinth's Miracle: Play after a character card has been discarded. Gain 8 faith. "A lamp suspended on a cord burned in front of her tomb. One day, without anyone touching it, the cord broke and the lamp fell to the stone floor. The hard stone withdrew at the point of impact and the lamp penetrated it just as if it had been made of soft material, and there it stood embedded up to its middle without anything being broken." - HF IV.28

- Go on Pilgrimage (Medium): Collect the "Pilgrimage" scenario card and add it to your regnum board. "In the fifty-first year of his reign King Lothar went on a pilgrimage to the entrance to Saint Martin's church, taking with him many gifts. When he reached Tours he visited the Saint's tomb and confessed to all the evil deeds which he had committed in his thoughtlessness." - HF IV.21 
- Host Banquet (Low): ${ }^{117}$ Play during the Fall. You must have 25 or more honour to host a banquet. You invite the other courts and the leading men among your own regnum to come to your capital for a banquet. Move your court to your capital. You may return any number of characters you control to your capital, gain 2 honour for each character moved this way. Other players that you are not at War with may move their courts to your capital. If they do so, they may convert any amount of wealth into honour. You gain the amount of wealth converted this way. "Sigibert assembled the leading men of his kingdom, ordered a banquet to be prepared and married Brunhild with every appearance of joy and happiness." - IV.27

- Incite Conflict (Low) 3 Wealth, 5 Honour: Play as soon as two allied or neutral players' Warriors/Courts enter the same space. They must engage in combat, following all the normal rules of combat and the associated honour penalties with attacking a neutral/allied player.

- Infiltration (Low) 6 Wealth: ${ }^{18}$ You send spies to a rival regent, attempting to gather pertinent information. Choose a player and roll a d12:

○ 1: Your spies are discovered and traced back to you. Lose 5 honour

- 2-5: Your spies found nothing.

○ 6-10: Your spies recovered some documentation. Take a random action card from target player's hand.

- 11: Look at target player's action cards and take one.

- 12: Look at target player's secret agenda.

- Martial Training (Medium) 5 Wealth: You must have a noble character in your court to play this card. When you levy your population this turn, you may place 3 extra warrior cubes in any territory that you are already levying in.

- Miracles of Saint Martin (Medium): You must control a civitas with a monastery to play this card. Choose one: Choose a character, they cannot move in the next movement phase OR prevent a character card from being discarded. "Saint Martin's power is shown just as much by the punishment meted out to fools as it is by the grace accorded to those who have been cured" - HF V.6

- Negotiate with Invaders (Low) You must have a bishop and at least 25 faith OR have a noble and 25 honour. "Bretons attacked the cities of Nantes and Rennes. They seized a vast amount of booty, ravaged the fields, stripped the vineyards of their grapes and captured the inhabitants. Bishop Felix sent a deputation to the Bretons: they promised to make good the damage." - HF V.31. You send a group of delegates to negotiate with the invaders. Roll a d12.

○ 1-5: Your negotiations falter and false promises are made. Nothing happens

○ 6-11: Invaders in a space with a bishop or noble character you control are removed from the game.

- 12: Same as above and you gain 5 wealth.

- Papal Appeal (Low) 5 faith: Roll a d12. If you are the player with the most (or tied) faith, add +2 to your roll. On a $5+$ you prevent one of your bishop characters from being

\footnotetext{
${ }^{117}$ Leadership and Community in Late Antique Gaul, 206. Von Dam discusses the role of bribery in the Frankish courts, often which come in the form of 'gifts' while visiting or being hosted by a king.

118 Spies, or speculatores, were a relatively common tool of espionage for kings, queen, and lesser secular authorities to gather personal information from enemies ( $H F V .14)$, but also for the use in official military endeavours such as reconnaissance of troop numbers (HF II.42).
} 
discarded. "They appeared before Pope John III and put forward the plea that they had been dismissed with no reasonable cause given." - HF V.20

- The Lord's Favor (Medium) 2 Faith: Play before combat rolls are made. The player with the highest faith value in this combat adds +2 to their roll, honour breaks ties.

- Ride Fast (Medium) 1 Wealth: Play immediately after moving an agent, you may move that agent again (following all normal restrictions).

- Potio pulveris sepulchri (low): You must have a relic and at least 25 faith. You make an infusion of dust from the tomb of a saint to cure your ailments. Prevent an assassination attempt or the death of a character through combat. - VSM.II.1

- Sue for Peace (Medium): Play after a player refuses your Pax card. They may reconsider, if they still refuse to give you a Pax card in return, they lose 5 faith.

- Surprise Storm (Low-Medium) 3 Faith: Play before combat rolls are made. The player who initiated this combat must move immediately to the closest adjacent controlled or neutral space, ending combat.

- Unfortunate Absence (Low) 4 faith: Play when a Church Council is being held and before voting takes place. Roll a d3, you may choose that many metropolitan bishops and vote for them, regardless of who originally held influence over them.

- Purchase Relic from Jewish Traders (Low) 5 wealth: Some Jewish traders have come across some important religious relics they are willing to sell. Draw a relic card and add it to your regnum board if you are able. The priest Cautinus had a good relationship with the Jewish community around him and frequently bought goods from them - potentially some holy relics. IV. 12.

\section{Bishop Figure}

The bishop figures represent your bishop characters on the board. They can move five spaces normally. Each one has a distinctive shape - square, circular, and triangular. The shapes correspond to the bishop character cards on each player's regnum board to differentiate between a player's three different bishops.

\section{Civitas/Civitates Cards}

These represent the twenty-two controllable civitates, most of which are the metropolitan

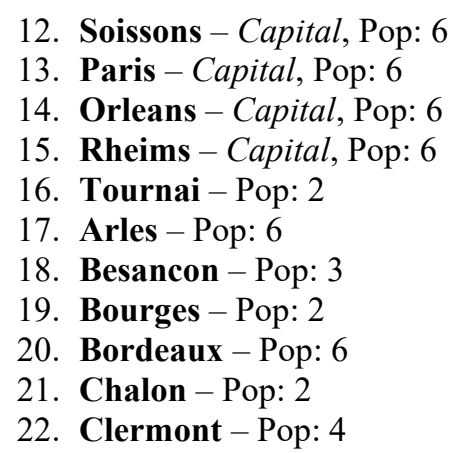

1. Cologne - Pop: 5

2. Lyon - Pop: 4

3. Mainz - Pop: 2

4. Marseille-Pop: 6

5. Narbonne - Pop: 3

6. Poitiers - Pop: 4

7. Rennes - Pop: 2

8. Rouen - Pop: 2

9. Toulouse - Pop: 6

10. Tours - Pop: 3

11. Vienne - Pop: 2

bishopric for the various provinces. Here population, taxation, and wheat collection will be listed. Population will also be kept track of here with population tokens. 


\section{Character Cards}

Bishops $^{119}$

1. Leontius - Bishop of Bordeaux, 2 faith \& 2 honour: You may spend 5 faith and 5 honour to expel another bishop in the same space as Leontius. Their character card is discarded from their player's Regnum board. "[Leontius] writes to tell you that he has expelled Cymulus from his see..." - HF IV.26

2. Germanus - Bishop of Paris, Starter (Charibert): If Germanus is in your court, you get +1 vote towards any church council. If the council card is Excommunication, you get +2 votes. "They were both excommunicated as a result by Saint Germanus the Bishop." - HF IV.26

3. Praetextatus - Bishop of Rouen, 5 faith: "Humble yourself before him and confess that you did indeed commit the crimes of which he has accused you." - HF V.18

a. Frame Pratextatus: At any time, you may roll a d12 and try to depose this bishop to gain the lands he has laid claim to.

i. 1-7: Your attempts to depose Praetextatus fail, lose 2 faith $\&$ honour.

ii. 8-12: You successfully depose Praetextatus, gain 10 wealth and discard this character card.

4. Domitianus - Bishop of Angers, 4 faith \& 1 wealth: Domitianus only spends 2 faith removing dissent tokens instead of the normal amount.

5. Domnolus - Bishop of Le Mans, 3 faith \& 2 honour "[Domnolus] begged the King not to submit him, a simple man, to the boredom of having to listen to sophisticated arguments by old senatorial families, or to counts who spent all their time discussing philosophic problems." - HF VI.9

6. Felix - Bishop of Nantes, 5 wealth: As long as you control Felix you may spend wealth as though it was faith. "Felix was a man whose greed and arrogance knew no bounds." - HF V. 5

7. Victorius - Bishop of Rennes, 5 faith: Victorius only spends 2 faith removing dissent tokens instead of the normal amount.

8. Sigismund - Bishop of Mainz, 3 faith \& 2 wealth: During the Feed Forces step of Summer, if Evantius is in the same space as warriors you control you can ignore feeding three of them.

9. Egidius - Bishop of Rheims, Starter (Sigibert): During the Trading \& Negotiation phase if you are at War, you may roll a d12. On a $8+$ you may declare peace with a player you are at War with. "Egidius, Bishop of Rheims, arrived on an embassy, with the chief notables of Childebert's court. A conference was arranged and they made plans to deprive King Guntram of his kingdom and to draw up a treaty of alliance between Childebert and Chilperic." - HF VI. 3

10. Tetricus - Bishop of Langres, 4 faith \& 1 honour: Tetricus only spends 3 wheat and 3 faith when increasing the population of a civitas instead of the normal amount.

11. Evantius - Bishop of Vienne, 3 faith \& 2 honour: During the Feed Forces step of Summer, if Evantius is in the same space as warriors you control you can ignore feeding three of them.

12. Priscus - Bishop of Lyon, 3 wealth \& 2 faith: As long as Priscus is in your court, you may spend faith as though it was wealth.

\footnotetext{
${ }^{119}$ Bishops played an integral role in Merovingian society. Kings saw them as tools to promote peace and "administrative order," see The Medieval Way of War, 33-34. The cost for Bishops in this game are often a mix of faith and wealth as purchasing the position of bishop was a frequent practice and often needed royal approval (which could be gained through 'gift' giving, see Leadership and Community in Late Antique Gaul, 206.
} 
13. Licerius - Bishop of Arles, 5 faith: During the Feed Forces step of Summer, if Licerius is in the same space as warriors you control you can ignore feeding three of them.

14. Ferreolus - Bishop of Eauze, 4 faith \& 1 honour: During the reset phase, if Ferreolus is in the same space as your court, you gain 3 honour. "He was a learned person, given to intellectual pursuits, and he had composed a number of volumes of Letters, in the style of Sidonius." HF - VI. 7

15. Namatius - Bishop of Clermont, Starter (Guntram): Instead of moving Namatius during a movement phase, you may pay 5 faith and search the action card deck for a "Build Monastery" card and put it into your hand (if you do not already have one) then shuffle the deck. "It was he who built by his effort the church which still stands and which is considered to be the oldest within the city walls." - HF II. 15

16. Syagrius - Bishop of Autun, 3 faith \& 2 honour: If Syagrius is in your court, you get +1 vote towards any church council.

17. Droctigisel - Bishop of Soissons, 3 wealth \& 2 faith: Anytime that Droctigisel would be discarded roll a d12. On a 7+ Droctigisel is not discarded. "Everyone agreed that he ate and drank far more than is seemly for a bishop, but no accusation of concupiscence was ever levelled against him." - IX. 37

18. Solonius and Sagittarius - Brother Battle Bishops, 2 faith, honour, wealth: For every successful Combat Roll in which Solonius and Sagittarius modified, you gain 3 Faith. Instead of seeking protection in the heavenly Cross, they were armed with the helmet and breastplate of this secular world - IV.42

Nobles

1. Merovech - Son of Chilperic, Starter (Chilperic): "Bringing with him everything that he possessed, he placed it all beside the tomb of Saint Martin and prayed that the Saint might succor him and grant him this favor that he might win the kingdom - V.14"

a. Tonsure: You may send Merovech to a monastery, remove this card from the game, gain 8 Faith. You must have a monastery to perform this action.

b. Merovech generates 2 honour in the reset phase instead of the normal amount.

2. Mummolus - Count of Auxerre, Starter (Guntram): “Mummolus conducted many campaigns and was always victorious." - IV.45

a. Patrician: Mummolus is a renowned warrior and tactician. He grants an additional +1 to Combat Rolls and gains +1 honour for successful combats.

3. Clovis - Son of Chilperic, Starter (Chilperic): "Now that my brothers are dead, 'he kept saying, 'the entire kingdom comes to me. The whole of Gaul is mine to command" - $H F V$. 39

a. Quick Retreat: Before casualties are resolved in a combat that Clovis is involved in, Clovis may retreat two spaces towards the nearest controlled/allied territory.

b. Accuse of Treachery: You may execute Clovis and claim his treasury, remove this card from the game, gain 8 wealth. Clovis' treasurer was fetched back from Bourges by Chuppa, Master of the Stables to Chilperic, and handed over to the Queen - V. 39

4. Firminius - Count of Clermont, Starter (Sigibert): Firminius was chosen to lead the attack on the city of Aries and coordinated with Audovarius to surround the city. They extracted oaths of allegiance to his king Sigibert from its citizens. - IV. 30

a. Siege tactician: If Firminius takes part in a siege you add +1 to any combat rolls $\mathrm{OR}+2$ if there is another noble you control present. 
5. Leudast - Count of Tours, Starter (Charibert): "He arrested Galienus and the Archdeacon Plato, loaded them with chains, and paraded them before the Queen, fettered and in their underclothes" - HF V. 49

a. Arrest: You may attempt to arrest another noble or bishop character in the same space of Leudast, if you do roll a d12.

i. 1-3: The arrest failed, lose 5 honour

ii. 4-8: You lost the opportunity, nothing happens

iii. 9-12: You seize your target and take their possessions. If the space is a civitas add a dissent token and gain 4 wealth.

6. Dragolen -3 honour \& 2 wealth: "Dragolen was a silly, thoughtless fellow. 'You see this rope?' he asked. 'I have used it to tie up quite a few other culprits, whom I have handed over to the King." - HF V. 25

a. Track Down: During the movement phase in spring, Dragolin may forfeit all actions for the year to move to a space containing another Dux and prevent them from taking any actions this year as well (actions refer to anything involving the character such as moving or using any character card or action abilities).

7. Austrapius - 3 honour \& 2 faith: "Duke Austrapius had good reason to fear Chramn and he therefore sought sanctuary in the church of Saint Martin." - HF IV. 18

a. Find Sanctuary: Austrapius cannot be discarded if he is in a space with a monastery

8. Berulf - 3 honour \& 2 wealth: "Duke Berulf marched into the Bourges area, with the men of Tours, Poitiers, Angers and Nantes." - HF V. 49

a. Charismatic general: Every time you levy warriors from a civitas that Berulf is in or adjacent to, you may ignore the affects of one dissent token per civitas for the purposes of levying.

\section{King Cards}

All king character cards have a reverse "Heir" side that is flipped to if the current king ever dies. They are assumed to be the next legitimate heir to the throne and the current Queen becomes the Regent of the Regnum and is flipped to the Regent side.

1. Charibert ${ }^{120}-5$ faith / 12 honour / 5 wealth

- Provinces: ${ }^{121}$ Paris (Capital), Bordeaux, Poitiers, Rennes, Rouen, Tours (population total: 23)

\footnotetext{
${ }^{120}$ Charibert is a difficult character to define as Gregory only mentions him briefly as he dies shortly after becoming king. The focus of Charibert's representation by Gregory is his conflict with the clergy (particularly the Bishop of Paris) over marrying two sisters and the appointment of bishops which lead to his eventual excommunication and death (HF IV.26). While Gregory focuses on Charibert's tense relationship with the clergy, scholar Gregory Halfond concludes from other textual sources such as the poet Fortunatus, that Charibert was not that overtly blasphemous and contentious with clergy members - he was even compared to the biblical David and Solomon. However, in this game, I am borrowing from Gregory of Tours account more than others or the later detailing and rectifying of accounts by scholars such as Halfond (although his arguments are well made and valid). Gregory I. Halfond, “CHARIBERT I AND THE EPISCOPAL LEADERSHIP OF THE KINGDOM OF PARIS (561-567)," Medieval and Renaissance Studies, Vol. 43, Issue 2, 2012: 1-28.

${ }^{121}$ The dividing of Chlothar's kingdom in 561 among his sons is described by Gregory (HF IV.22), noting each capital, or "chief city," which they ruled from. Gregory describes them taking over the old kingdoms of Chlothar and his brothers Chlodomer, Childebert, and Theuderic - taken by Chilperic, Guntram, Charibert, and Sigibert respectively. The allocation of each Civitas to the kings is based upon the extensive map work in: Alexander Callander Murray, From Roman to Merovingian Gaul: A Reader, Broadview Press, 2000, 662-667.
} 
- Uphold Frankish Tradition: Anytime you would gain honour, gain an additional 1. Also, anything that requires you to pay honour, you pay 1 less.

- God's Wrath: If your faith ever reaches zero, your wife dies. Discard Marcovefa from your regnum board. "The King refused to give up Marcovefa: but she was struck by the judgement of God and died." - HF IV. 26

2. Guntram -8 faith / 8 honour / 5 wealth

- Provinces: Orleans (Capital), Arles, Besancon, Bourges, Chalon, Lyon, Vienne (population total: 25$)$

- Rotate Court: Once during the reset phase you may draw an action card. If it is a noble you may replace it with a noble already in your court (or add it if you have non). Otherwise, shuffle the character deck. ${ }^{122}$

- Friend of the Church: Instead of participating in a wealth bid to determine who will host a church council, you may pay 7 wealth and become the host automatically.

3. Sigibert -8 faith / 10 honour / 5 wealth

- Provinces: Rheims (Capital), Cologne, Mainz, Marseilles, Clermont (population total: 22)

- Competent General: When your court is involved in a combat, roll two combat dice and choose the best result. ${ }^{123}$

- Reckless Soldiers: You add an additional dissent marker to a civitas if combat took place there and your court was present.

4. Chilperic - 6 faith / 6 honour / 15 wealth

- Provinces: Soissons (Capital), Toulouse, Tournai (population total 14)

- Youngest King: All honour costs you must pay for action cards or abilities are increased by 1

- Plotter: Your second action card only costs 3 wealth instead of 5.

Heir Side (Opposite side to all King Cards) - The following things happen when you flip your King Card to this side:

- Your honour becomes 5 .

- If you have more than one Noble character on your regnum board randomly discard down to one.

- Return your court to your capital.

- Flip your Queen card to their "Regent" side.

- If the Heir is ever assassinated or if something requires you to remove your King from the game, you immediately lose the game.

Queen Cards

1. Fredegund - Queen of King Chilperic: "...that enemy of God and man, Fredegund" HF IX. 20

\footnotetext{
${ }^{122}$ Guntram frequently rotated the position of his patrician, first appointing Celus (IV. 24), then appointing Mummolus IV. 42.

${ }^{123}$ Gregory's descriptions of Sigibert often revolves around his military prowess and campaigns against outside forces such as invading Saxons and Avars as well as his brothers. Sigibert was likely put in this position as defender quite frequently due to his regnum being on the eastern border of Frankia, as well as fragmented around Frankia. See $H F$ V. 15, IV. 49-51.
} 
- Enemy of the Episcopate: Anytime that you discard/remove a bishop card which you or another player controls, gain 3 wealth.

- Expert at Assassination: You may spend 10 wealth to search the Action Card deck for a card named Assassinate and put it into your hand (shuffle the deck afterwards). You also get +2 to your roll when you use the card Assassinate.

Fredegund - Queen Regent

- Unholy ruler: When donating to monasteries the conversion rate is now 2 wealth to 1 faith instead of the normal 1 to 1 exchange rate.

- Draw Support: You may spend 5 wealth during the Action Card phase to draw a character card and purchase it. You do not have to pay the wealth cost of any character card added to your regnum this way.

2. Brunhild ${ }^{124}$ - Queen of King Sigibert: "When Queen Brunhild learned of this, she was greatly incensed at the wrongs being done to her faithful supporter. With a vigour which would have become a man she rose in her wrath and took her stand between the two enemy forces - HF VI. 4"

- Advisor of the Treasury: All wealth costs are reduced by 1

Brunhild - Queen Regent

- Protection: You may cancel the effects of any action card played by a player by paying 20 in any combination of faith, wealth, or honour.

3. Austrechild ${ }^{125}$ - Queen of King Guntram: "the medicines which they compelled me to take have brought my life to ruin, rapidly stealing the light of this world from me. And so I beg you to swear an oath to slay them with this very sword the moment the light leaves me, lest my death go unpunished." - HF V. 35

- Advisor of the Treasury: All wealth costs are reduced by 1

- Wrathful: If Astrechild were to die/be discarded, discard a random bishop you control and lose 5 honour and faith.

$>$ Austrechild - Queen Regent

○ Powerful Sons: After you resolve the effects of succession (reduced honour, loss of noble, return of court to capital), gain 10 honour and draw character cards until you have drawn a Noble, then place that card on your regnum board for free. Shuffle the rest into the character card deck.

4. Marcovefa - Queen of King Charibert

- Advisor of the Treasury: All wealth costs are reduced by 1

Marcovefa - Queen Regent

○ Of The People: You may spend 5 wealth to remove a dissent counter from the civitas your court is in.

- Former Nun: Ignore the wealth cost to build monasteries.

\footnotetext{
${ }^{124}$ Gregory frames Brunhild as an antithesis to Fredegund, "This young woman was elegant in all that she did, lovely to look at, chaste and decorous in her behavior, wise in her generation and of good address" (HF. IV.26). Gregory also notes the difference in their birth, noting Sigibert specifically searched for a daughter of nobility in response to his brother, Chilperic, marrying one of his servants (Fredegund). E.T. Dailey Queens, Consorts, and Concubines: Gregory of Tours and Women of the Merovingian Elite, Brill, 2018, 120, 126.

${ }^{125}$ Austrechild, like Fredegund, represents a 'biblical villain' in Gregory's narrative - lowborn and sinful. The quote used for her character is one of the few passages Gregory writes about her; Dailey, Queens, Consorts, and Concubines, 97.
} 


\section{Church Council Cards}

These cards will be used to determine what topic the current church council will convene to discuss and vote on. These cards could be drawn due to action cards or event cards. A player may be asked to find a specific council card or, at other times, they will be asked to draw one at random.

1. Property Dispute: A bishop in Tournai is in dispute with the count of Tournai over a piece of land that was supposedly granted to the church by the previous count. Who is in the right and who will be granted the land?

- If passed: It is decided that the bishop is the true owner of the land. Those who voted "Yes" gain 8 faith, lose 5 honour, and lose control of one metropolitan bishopric

- If voted down: No decision is agreed upon and the king votes in favor of the noble. The player that hosted the council gains 10 honour.

2. Excommunication: Tensions have grown between the spiritual authorities and one of the kings who continually disregards the pleas of the bishops of their regnum. Drastic action may be required. The player with the lowest faith (lower honour breaks ties) will be excommunicated if this church council gets enough support.

- If passed: The chosen player is excommunicated, their faith becomes 0 , they lose control of all their metropolitan bishoprics, and must discard all of their bishop character cards in their court. They then receive the Penance scenario card.

- If voted down: Each player (including the chosen player) receives 12 honour for protecting Frankish customs above church beliefs. ${ }^{126}$

3. Renounce Bishop: ${ }^{127}$ A bishop has abandoned their post and has committed crimes against his see and God. You must now convene to determine what to do with the bishop in question. No host is determined for this council as it is a internal ecclesiastical affair.

- If passed: The bishop is removed from his see and from the church community. A random bishop is discarded from a player's regnum.

- If voted down: The council cannot come to a decision and is called off. Each player loses 8 faith.

4. Ecclesiastical Intervention: "A dispute now began between the two Kings Guntram and Sigibert. King Guntram called a council in Paris of all the bishops in his realm, to decide which of them was in the right." - IV.47 Bishops have been called to meet and help settle a dispute between warring factions. Randomly choose two players of those who are At War with each other. If no players are at

\footnotetext{
${ }^{126}$ This particular church council is based off of King Charibert's excommunication by Bishop Germanus. Charibert was urged to divorce his second wife Marcovefa and threatened with excommunication. Charibert refused. Gregory Halfond also relates other incidents of Charibert challenging the authority or religious officials. The council card here is to showcase the real ability for secular (and even more so Germanic) officials to ignore the dictates of ecclesiastical power and the potential benefits of that (Honour in game terms but also increased authority in historical terms). See Gregory Halfond, "Charibert I and The Episcopal Leadership of the Kingdom of Paris (561 567)," Viator, Vol. 43, Issue 2, 2012, page 2.

${ }^{127}$ Church councils were convened to both depose and reinstate bishops to their see regularly. See Appendix A in: Halfond, The Archeology of Frankish Church Councils.
} 
war, randomly choose two players that are neutral with one another. Otherwise, choose two random players.

- If passed: The two chosen players take the advice of the bishops and must remove their At War status

- If voted down: The two chosen players lose 5 faith

\section{Dux Figure ${ }^{128}$}

These figures represent the noble characters in your court. Each player can maintain three Dux's at a time. Each one has a distinctive shape - square, circular, and triangular. The shapes correspond to the Noble character cards on each player's regnum board to differentiate between a player's three different nobles.

\section{Event Cards}

1. Plot to Unseat Bishop: Each player may make a secret faith bid. Whoever made the highest bid may choose to remove a Bishop from a player's Regnum board OR a controlled bishop token (of any player) on the Metropolitan Bishopric board. "He conspired with an archdeacon of Lisieux and together they plotted their bishop's death." - VI.36

2. (x2) Epidemic Erupts: A plague sweeps through the whole of Gaul. Each player must roll a d6 for every territory they control. On a 1-4, that territory loses a population marker. HF Text: Great numbers of them were carried off by a whole series of malignant diseases - VI.14

3. Famine Spreads: No crops survive the winter storms. Players lose all their wheat and set their tracks to 0 . Until another event card is revealed, players cannot have more than 15 wheat. "Frost nipped at the vineyards...then came a terrible storm which battered down the vines and the crops... One epidemic after another killed off the flocks, until hardly any remained alive." - HF VI.44

4. (x2) Avar Raids: Nomadic horsemen from the east look for fertile land and wealth. Place three warriors in both Avenches and Constance.

5. (x2) Longobard Raids: The Longobards from Norther Italy have come seeking wealth in the land of Gaul. Place three warriors in both Embrun and Cimiez. They will follow the invader rules in the rulebook. "The Longobards will invade Gaul and they will destroy seven cities, because the wickedness of those cities has grown great in the eyes of the Lord" - Hospicius, HF VI.5

6. Brittany Raids: The Bretons seek the wealth of Frankish lands and send out bands of raiders. Place two warriors in both Carhaix and Nantes. They will follow the invader rules as laid out in the rulebook. "The Bretons invaded the Nantes region. They stole property, attacked country estates and led off a number of captives." - HF IX.18

\footnotetext{
128 The exact function of a $d u x$ (translated as 'Duke' by Lewis Thorpe) is unclear and not concretely defined in the Germanic context. According to Laury Sarti, the role encompassed governmental, judicial, but most prominently military duties on behalf of royal authorities. Sarti indicates that a dux or patricius would function as a governor of a larger region while a comes (count) would govern a civitas. I am using it here in particular to differentiate from the many comes (counts) and other 'noble' figures that constituted the aristocracy of Merovingian Gaul. Players will only have access to three physical agents on the board that will command their armies and facilitate particular action cards depending on their location and a Dux according to Sarti would be the closest applicable term/role; Laury Sarti, Perceiving War and the Military in Early Christian Gaul (ca. 400-700 A.D.), Brill, 2013, 35.
} 
7. St. Martin's Tomb Sacked: The player with the lowest faith can decide to add five to their treasury and take a relic card from any other player. If they do so, they must disband one warrior if possible; if not they lose five faith. "They stole a deal of gold and silverware... having gone so far as to walk on the Saint's tomb" - HF VI.10

8. (x2) Saxon Raids: Saxon warriors from the north descend upon unsuspecting villages. Place three warriors in Buraburg and Amoneburg. They follow the invader rules in the rulebook. "The Saxons scattered through the villas of the near-by towns, seizing booty, making prisoners, and causing great destruction" - HF IV.42

9. (x2) Disenfranchised Noble: The court with the lowest honour randomly determines a noble they control that becomes the disenfranchised noble. The player with the highest honour may decide to lose three honour and gain that noble in their court. Otherwise, that noble is executed and discarded from the game.

10. Traitorous Noble: Each player with a Noble makes an Honour Roll. The lowest role (honour then faith break ties) places a random Noble card next to the event card. The associated Dux figure moves to the closest controlled civitas that does not contain a Court and raises a levy of half the population rounded up, as well as takes control of any warriors of the controlling player located there. Replace the warrior cubes of the player's colour with invader cubes. The territory is now considered a neutral civitas.

11. Jewish Petition to Rebuild Synagogue: The player in control of Orleans may decide to pay 5 wealth to gain 3 faith and remove all dissent markers on the civitas. "They sang my praises...in the hope that I should give an order that their synagogue, which was destroyed some time ago by the Christians, should be rebuilt from public funds." - HF VIII. $1^{129}$

12. Visiting Visigothic Delegation: ${ }^{130}$ Players make an Honour Roll to host the envoys. The Visigothic King has sent a delegation to your court, looking to extend goodwill to you and your people in an effort to ease any tensions or possibly gain an ally. Will you (choose one):

a. Debate their Arian Christian beliefs: Roll a d12 - on an 7+ you gain 5 faith, on a 12 you gain 8 faith instead, anything else and you lose 3 honour.

b. Marriage Alliance: Suggest marrying off one of your daughters or sons. Gain 8 wealth but lose 1 population on a civitas you control as a gift of slaves for the Visigoths.

\footnotetext{
${ }^{129}$ Guntram, the king in question here, did not aid the Jewish community and instead (as Gregory notes) took the opportunity to slander the Jewish community living in Orleans and saying such an act would be "contrary to the Lord's will" ( $H F$ VIII.1). I see an opportunity here, however, to illustrate the active roll some Jewish communities took in Frankish Gaul. They formally petitioned the king seeing it as a viable route for community justice and reconciliation - one that Gregory suggests would be possible if the king were not "wise."

130 The Frankish and Visigothic kings had a tenuous relationship. Gregory relates points of contention around religious belief. In $H F V .38$, Gregory relates the story of King Sigibert's daughter, Ingund, being married off to a Visigothic prince. While cordial diplomatic relations existed between the Franks and Visigoths enough to facilitate this royal marriage, Gregory focuses on the persecution of Ingund and other "Catholic Christians" faced in Arian Visigothic Spain. Gregory's intention on trying to highlight the heretical nature of Arianism is also highlighted in his 'mock' debates which he relates back to his readers. In HF IX. 15 he tells his readers of the Visigothic council of Arian and Catholic Bishops set up by King Ricared. After the debate, it ends in the Arian king's conversion to 'Catholicism.' Furthermore, in HF V.43, Gregory relates his personal disputes with an Arian envoy over the existence of the trinity. Unsurprisingly, Gregory comes out the victor. This event card is used to showcase the dual relationship that existed between the Franks and Visigoths (at least as how Gregory relates it): One of religious contention, but also potential alliance building and negotiation.
} 
13. Forced Jewish Conversion: In the year 582 C.E., Chilperic forced a large number of Jews to be converted to Christianity. Most had no choice but to accept or face death or imprisonment. Many feigned conversion, but still practiced their beliefs and traditions in secret. Gregory does not relate violence against Jewish communities to the kings directly but redirects the blame to the king's servants who were Jewish converts to Christianity shifting the blame of violence and death onto Jewish bodies - HF VI.17. Each player gains 8 faith and removes a total of 3 population tokens from among any number of civitates they control.

14. Jewish Synagogue Destroyed: The Jewish community in the civitas of Clermont becomes the target of violence as their synagogue is burnt down by a mob of Christians. The local bishop, Avitus, calls for the conversion of the Jewish community. All of those who do not comply flee to Marseilles. Clermont loses 1 population and gains a dissent marker and Marseilles gains 1 population.

15. Visigothic Invasion: Visigothic forces have entered Frankia. If a player controls the civitas of Narbonne they lose control of it, and it becomes neutral. Place 5 invader warrior cubes in Narbonne and 3 in both Barcelona and Pamploma. Then, draw the scenario "Expel the Visigoths." "Recared, the son of Leuvigild, advanced as far as Narbonne and captured a certain amount of booty inside Frankish territory" - HF VIII.38

16. Church Council Called: Draw and resolve a council card. "The King now convened a council of all the bishops of his kingdom and ordered the affair to be investigated thoroughly." - HF V. 49

17. Provincial Council: A provincial council in convened in

\section{Levy Tokens}

These are placed on a civitas card, one for each levied 'Unused' population token. During the disband phase, levy tokens are replaced with population tokens flipped to their 'Used' side for each warrior disbanded.

\section{Metropolitan Bishoprics Board}

This board determines which players have control and influence over the 15 different Metropolitan Bishoprics. Eauze, Sens, and Trier are indicated as neutral metropolitan bishoprics which means a player can never gain control of them. All of the other bishoprics have a space for a player's colored token to be placed, indicating control over it. When voting takes place during a church council, a player has as many voted as they have controlled metropolitan bishoprics.

Controllable Metropolitan Bishoprics

1. Lyons 
2. Rouen

3. Tours

4. Rheims

5. Mainz

6. Cologne

7. Besancon

8. Vienne

9. Bourges

10. Bordeaux

11. Arles

12. Narbonne

Neutral Metropolitan Bishoprics

1. Eauze

2. Sens

3. Trier

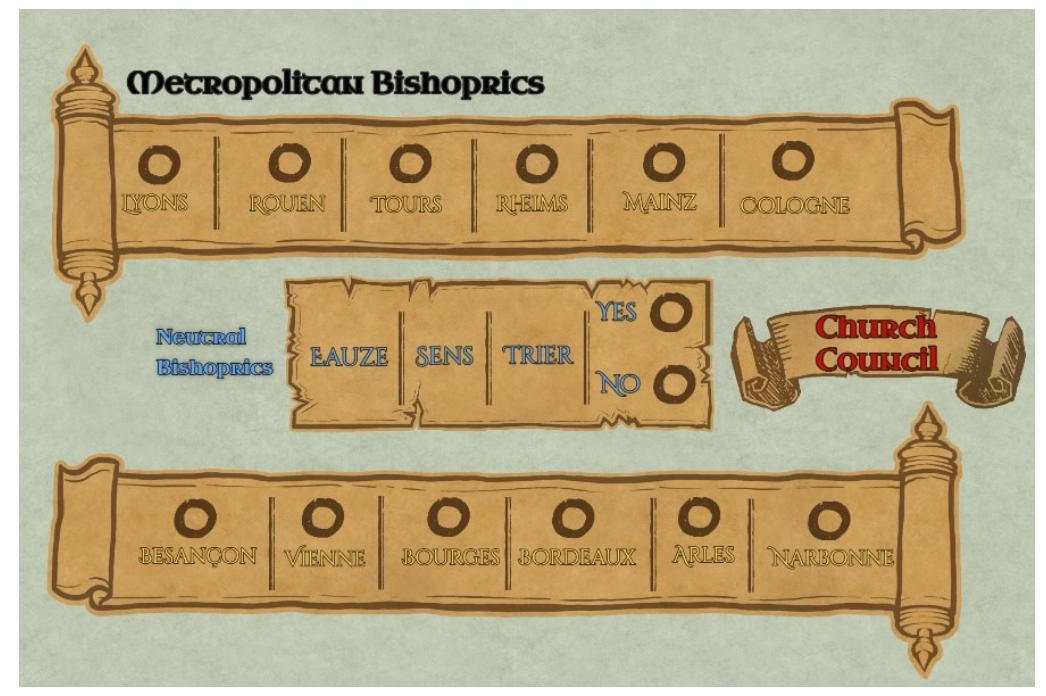

\section{Monastery Token}

Players who have a monastery token on a territory they control may, during the Reset phase, convert wealth into faith by donating to the monastery.

\section{Population Tokens}

Population tokens are placed on a civitas card to show how populous the region is. Population tokens have two sides: 'Used' and 'Unused'. During the Harvest and Tax phase, players will flip 'Unused' population tokens to their 'Used' side.

Population tokens can also be used to Levy warriors. In this case they are replaced with levy tokens. Population tokens flipped to their 'Used' side cannot be levied.

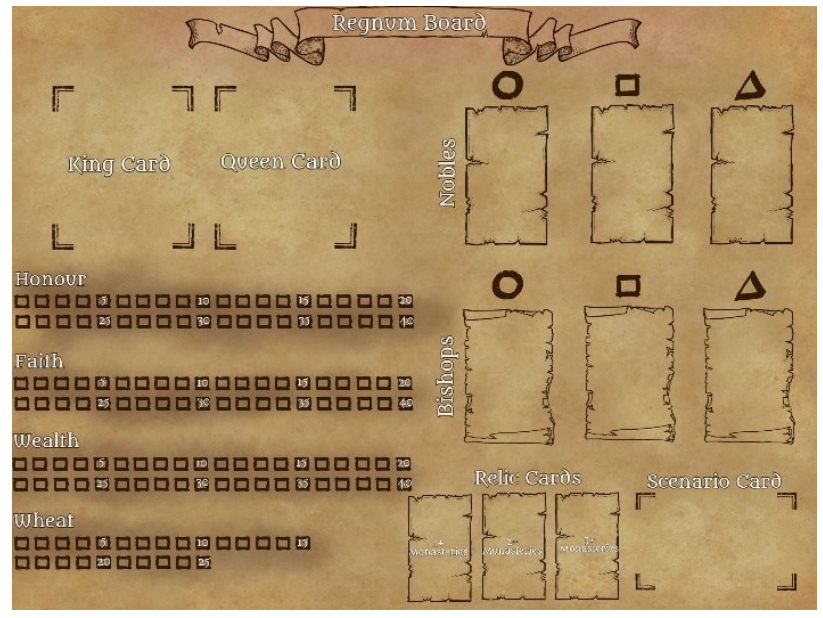

\section{Regnum Boards}

Each player will have a Regnum board (twosided one used for play and the other with a historical description of the player's regnum). Players will place their character cards here track their faith and honour

\section{Relic Cards}

Relic cards can be purchased through action cards (if the player controls a monastery ). They have varying benefits such as increased

faith generation or military benefits. A player cannot have more relics than they have monasteries. If a player, through the loss of a territory, loses a monastery and are left with more relics than monasteries, they must randomly give one of their relics to the player that took their territory with a monastery. 
1. Cappa Sancti Martini: As long as you control this relic, you opponents in combat do not get the typical +1 to combat rolls for having more warriors than you

2. Verum Crucis: Gain 3 faith during the reset phase OR 5 faith if you control the civitas of Poitiers. The fragment of the True Cross was sent to Saint Radegund by the Emperor Justin II and the Empress Sophia.

3. The Thumb Bone of Saint Sergius: Once a year before combat rolls are made you may use this relic. Roll a d12. You get +1 to your roll if you have the most (or tied) faith. On a $10+$ you win the combat, and your opponent must retreat. "A certain king in Eastern parts had obtained possession of the thumb of Saint Sergius the martyr, and that he had attached this to his own right arm... When he raised his right arm the enemy troops would immediately turn in flight, as if they had been vanquished by the martyr's miraculous power." - HF VII.31

4. The Bones of Saint Germanus: While you control this relic, Bishops cost 1 less resource of your choice to recruit.

5. The Tunic of Saint Vincent: While you control this relic, you may ignore dissent tokens for the purposes of levying during a siege. Used by the besieged inhabitants of Saragossa as a banner to which they marched behind, imploring God to take pity on them. King Childebert took it back to Paris where it lays now. - HF. III.29

\section{Secret Agendas}

Players are given a secret agenda at the beginning of the game. These cards should remain hidden from other players as they detail extra VP you can obtain by the end of the game through completing unique objectives. There are two copies of each secret agenda, so some players may have the same goals.

1. Queen Regent: The queen of your kingdom exerts her influence in the court and the machinations of the regnum, her will seemingly dominant above anyone else.

- At the end of the game, have your queen be the regent of your regnum.

- Have at least 30 Faith by the end of the game. ${ }^{131}$

- Successfully assassinate a character (keeping their card as proof).

2. Faithful Ruler: You are a true follower and champion of Orthodox Christianity as professed by the Supreme pontiff in Rome. You may be a ruler on earth, but there is only one true Lord.

- Host a church council OR complete the pilgrimage scenario.

- At the end of the game, have the highest (or tied) Faith value of all the players.

- At the end of the game, control the most (or tied) Metropolitan Bishoprics.

3. Germanic Tradition: While you were born a Christian, you still remember and seek to preserve the Germanic traditions of your ancestors. Afterall, it was only two generations ago that your Grandfather Clovis converted. ${ }^{132}$

\footnotetext{
${ }^{131}$ Faith was a key weapon for women during the early Middle Ages. It was one of the few ways in which they could exert independence, power, and control over themselves and others.

132 The distinction presented in this game between Gallo-Roman and Germanic has been argued by historians and archeologists along both ethnic and cultural lines. (Andrew Gillet, On Barbarian Identity, 179). The differentiation presented in this game between the two distinctive ethno-cultural groups is in the roles they inhabit in the game. Many of the bishop characters are labeled Gallo-Roman since many of them came from Roman senatorial backgrounds, have been educated in Roman schools. Counts, dukes, and other secular officials are characterised
} 
- At the end of the game, have three nobles on your Regnum board.

- Have the highest (or tied) Honour value of all the players by the end of the game.

- Have at least 4 Germanic characters on your Regnum board.

4. Uniter of Frankia: You will follow in the steps of your father, Chlothar, and your grandfather, Clovis, and unite Frankia under one king.

- At the end of the game there must be at least one player who has a king card flipped to the Heir side OR one player that has already lost the game.

- At the end of the game have at least 30 honour.

- At the end of the game control at least 11 civitates.

\section{Scenario Cards}

These represent immediate goals that players will have to overcome. Events, councils, and some action cards may require a player to draw or find a particular scenario to complete.

1. Penance: ${ }^{133}$ You have been shunned by the church and must perform penance for your wicked deeds. You may return your court to your capital. If you do so, it cannot move for the next 2 years, and you cannot initiate any combats with a Dux or your court.

Afterwards, discard this scenario and gain 10 faith. If you refuse to follow these steps you can no longer gain faith as a resource. ${ }^{134}$

2. Imperial Petition: The Byzantine Emperor Maurice has petitioned you to send a military expedition into Northern Italy to defeat the Lombards harassing Rome. You have two years (starting next year) to send your Court or a Dux (along with any amount of warriors) to Embrun or Cimiez. Once there, you must fight a combat against 8 warriors. If you win the combat, you gain 15 wealth and 15 honour. "Some years before he had received fifty thousand pieces of gold from the Emperor Maurice to rid Italy of the Longobards." - HF VI. 42

3. Expel the Visigoths: This scenario is open to all players. This scenario ends when all the Visigothic warrior cubes are removed from the board. The first player to successfully siege and take the civitas of Narbonne receives an additional 10 honour and 10 wealth.

\footnotetext{
under the Germanic or more specifically 'Frankish' ethno-cultural distinction. This distinction represents the new secular elites that entered Gaul through migrations more than a century earlier, those who could not trace their lineage back to Roman senators or who had not received a 'Roman' education. Gregory makes only a few overt distinctions and has been criticized by "patriotic teutons" (Lewis Thorpe, Introduction, History of the Franks, 34) for exaggerating the violence of the Merovingians (being a Gallo-Roman himself), K. G. Kries, De Gregorii Turonensis episcopi vita et scriptis, Breslau, 1859, passim.

${ }^{133}$ Penitence was an identifiable practice used by the church to punish/reprimand secular figures such as soldiers, counts, and potentially kings. Although Sarti states that it was a practice under dispute by the Frankish church until the end of the sixth century, Gregory mentions its use (see HF V. 36) by a count who had been barred from the church, Laury Sarti, 180.

${ }^{134}$ Although there were concerted attempts to reprimand and convince kings of their wrongdoings by bishops and other ecclesiastical officials, they could only do so much to change the minds of royalty. Charibert refused to take the advice of multiple bishops and divorce his second wife who was a former nun and sister of his first wife. As a result, he was excommunicated. The repercussions of his excommunication are unknown but Gregory attributes Charibert's death to it. Halfond, Medieval Way of War, 29. I wanted to give players an option to ignore the suggestion of Penitence if they so chose - yet still face the penalty of being removed from the religious community and having any ability to benefit from it (in the form of collecting and using the resource of faith).
} 
5. Convert the Arians: If a bishop is present in a space where a combat or siege against Visigothic warriors is won, the player who controls that Bishop gains 3 faith.

4. Pilgrimage: You must begin your pilgrimage at the start of the Spring phase. When you begin your pilgrimage, choose a civitas or the Rome space and place a pilgrimage token there. Once you begin, you must return your court to your capital. Your court can only move one space during the movement phase, each consecutive space costs 2 wealth. Your court cannot take warriors with them or engage in any combat. Each civitas with a monastery on it that you enter, you gain 2 faith. Keep track of how many spaces you have moved, at the end of your pilgrimage you gain that much faith multiplied by 2 . Your pilgrimage ends when you enter the space with your pilgrimage token on it and collect your faith. You gain an additional 10 faith if your pilgrimage token was placed in Rome. ${ }^{135}$

5. Patronize the Cult of Saint Martin: This scenario is always available to players. End your movement phase with your court in the civitas of Tours. You pay to add to the tomb and other cult sites of and give your prayers to the martyr. You may spend 5 wealth to gain 2 honour and 2 faith.

6. Patronize the Cult of Saint Julian: This scenario is always available to players. You embark on a holy pilgrimage to the monastery in Brioude and offer your prayers to Saint Julian. End your movement phase with your court in the civitas of Clermont. You may spend 5 wealth to gain 2 honour and 2 faith.

\section{Warrior Cubes}

When population tokens are levied, they are converted into warrior cubes (in the color of the player in control of the province) that are then placed on the board in the corresponding province. These function as military units for their corresponding regnum.

${ }^{135}$ Pilgrimages to Rome were rare but certainly taken by individuals who wanted to have a strong show of faith. 


\section{Chapter Four: Project Journal}

The annotated rulebook presented in chapter three of this thesis seeks to provide an example of how, through the medium of a board game, a complex historical argument could be made. It was my intention to highlight the possibilities and probabilities of different historical scenarios in sixth-century Frankish Gaul. The arguments that I chose to present through the function of the game were designed to inform the player about the social, cultural, and political frameworks that Gregory of Tours presents in his Historia Francorum. Silences in Gregory's narrative have been supplemented by secondary research to provide a more comprehensive understanding of sixth century Gaul and elucidate Gregory's narrative that is full of bias and morality-based story structures.

By possibilities and probabilities, I am referring to a counterfactual approach to history that presents a historical argument in a way that avoids teleological assumptions about the past. The game does not focus on highlighting what indeed did happen in the past as observable through primary and secondary research, but rather focuses on the conditions and sociocultural relationships that existed to produce those outcomes.

Without a defined end to the game (because the end is determined by the players and is designed with different win conditions), players are able to explore the correlation between their (and their fellow players') actions and the responses to their actions. This cause-and-effect structure was intended to help understand the world Gregory is relating to us, and the structure of morality that defines it (or at least how Gregory defines it).

Instead of explicitly explaining the outcomes of observable sociocultural historical realities, the game presented in this project allows players to explore the represented 
sociocultural reality as communicated in the Historia Francorum (and supplemented by secondary source research) and discover the possible outcomes that derive from playing the game. I decided to engage with the idea of 'play' because it affords the players/learners to come to conclusions themselves - guided by the rules of the game.

There are many difficulties when it came to the design of this game and the inclusion of a historical argument. Encapsulating an entire historical context in a codified and framed space presented many challenges. The scope of my focus was a large section (a range of 345 pages in translation) in the Historia Francorum which spanned roughly thirty years. Moreover, it encapsulated aspects of Merovingian life such as the role of kings, queens, nobles, bishops, abbots, citizens, abstract ideas of faith and honour, outside cultural groups such as the Saxons, Avars, and Byzantines, and much more.

The scope that I had chosen, and the medium in which I worked in, necessitated that I abstract many of those ideas stated above into condensed versions of themselves. I chose not to detail the complex system of oaths between kings and nobles, or the set of different titles such as count, duke, or patrician that could be awarded to them; I did not go into detail about the political intricacies of appointments to bishoprics and the complex map of ecclesiastical sees that spread over Frankia. These ideas themselves could be games in their own right or explored in a larger project.

Game designers are limited by the medium that they work in as well as what will be understandable and approachable to their players. Too much complexity in a game's design will hinder the player's ability to understand the historical argument being made - just as confusing jargon and poor sentence structure can confuse the reader of a piece of written historical work. 
It was my intention to reveal to the readers of this project that presenting complex arguments of the past (such as the function and role of Frankish church councils or the conditions faced by Jewish people in Frankia at this period) is possible within the medium of a board game. Negotiating the scale and specificity of my historical arguments was essential at the beginning of this project because I wanted to end this project with a completed and coherent game that then had complete and coherent historical arguments.

If I were to have chosen a more specific and niche subject - such as a church council and how bishops officially determined the role of church authority in secular affairs, I could have potentially facilitated a more complex understanding of that subject with more nuanced clarification. With any form of historical research there is the inevitability of simplification or the leaving out of information due to constraints for time and space. However, for the purposes of this game, and my historical argument, I wanted to represent the scope and scale of Merovingian Gaul that was present in Gregory of Tours' Historia Francorum - a work that spanned centuries of historical time.

\section{$\underline{\text { Design Decisions }}$}

It is always tempting when designing a historical game to fall back on designing for convenience and playability. Some historical facts or realities might be altered or forgotten because it makes the game easier to design, play, or advertise. Often, tropes can be fallen back on because they are familiar, or complexity may be generalized for clarity in the gameplay. This is one of the biggest difficulties and hurdles when designing a historical game. Which comes first? Playability or 'historical accuracy'? It ultimately comes down to individual decisions surrounding what is included and what is not. When designing a game (as opposed to writing a paper), space is not 
always a luxury. Things will have to be left out or simplified in order to be communicated through a physical space or within a simplified rule.

It is important to note that omission does exist both in game design and within the process of history and academia. Everything cannot be covered, and certain nuances have to be left out that are not relevant (or when space does not allow) to the main thrust of the project. This game is attempting to highlight multiple sociocultural aspects of the Merovingian world as told by Gregory of Tours, including but not limited to gender, religion, social structures, warfare, and political landscapes. The society and culture that Gregory relates to us is not a complete picture, but there are important elements that can be drawn from it in relation to a plethora of sociocultural factors such as religion, politics, gender, and Gallo-Roman and Frankish social structures.

One worry I had while designing the game was whether players would pick up on the historical arguments I was creating. Would the players even understand that this game's goal is to present a historical argument? Adding short 'historical introductions' to integral sections of the rulebook (Bishops, Queens, Invasions, Church Councils) presented the reader with an idea of how that aspect of the game was based in historical research. The introductions focused on the arguments I was making in the rules of the game. It was my intention that after reading these historical primers players would be more receptive to the arguments being made through the rules.

Dice

The inclusion of dice was a key component in imparting a sense of counter-factuality in the game world. Certain actions and character abilities that were historically plausible (assassination, denouncing bishops, warfare, etc.) were not inevitable. King Chilperic was indeed 
assassinated, but that outcome was not an inevitable one. Adding the aspect of uncertainty and randomness that comes with rolling a die allows the players to understand that the actions they are enacting were not inevitable ones. Not only dice, but cards were necessary additions to the function of the game to help impart important ideas around understanding and engaging with the past.

\section{Cards}

The integral function that cards play in the game (character cards, action cards, event cards, church council cards, scenario cards, and relic cards) allow for a greater amount of contextual information to be given to the players. Relevant text from the Historia Francorum is often included on each card as well as additional rules (i.e. not explicitly stated in the rulebook) that players do not have to memorize. These action cards allow players to engage with very specific scenarios that Gregory narrates in the Historia Francorum that cannot be expressed in a more generalized mechanic - such as 'church councils' or 'combat.'

The contextual information presented on cards, such as quotes from the Historia Francorum and new rules/actions that progress the game's narrative, take the burden of information gathering off the players and puts it into the construction of the game. Players do not have to memorize the plethora of actions available to them as a king/queen/bishop/noble. What is available to them is in their hand of cards and reiterated to them by the card's text. The cards (whether action cards or event cards) produce curated scenarios or instances of historically informed narratives. Those narratives can then be interacted with by the player in a variety of ways.

Intricacies such as denouncing a bishop, the impact of famines, the outcome of having a low standing within the spiritual community, could all be explored and communicated through a 
singular card rather than a mechanic that players would have to refer to the rulebook or memorize to enact or understand. Having cards explain the sociocultural context of the Historia Francorum, players could understand the response, reaction, and function that the card's action had on the wider world (as represented in the rules of a game). For example, the card "Council Addendum: Accuse Bishop" showcases the acts that could be brough up in a church council suddenly. The player who plays this must have a high honour, meaning they must have a good standing in the wider community to propose accusing a bishop of such an act that would result in deposition.

For the event card "Visiting Visigothic Delegation" players have an option to debate the Arian beliefs of the delegation (which Gregory of Tours has done himself) or propose a marriage alliance (which historically both Kings Sigibert and Chilperic did). Instead of making those options always available to players, it is contained within one scenario to showcase that possibility existed.

The use of text from the Historia Francorum was a central focus for my game design. Presenting an argument about a written source requires engagement with it within its own medium. Although this project focuses on translating the act of history from a written one to a playable one, writing can (and is) still heavily involved. Cards, and the rulebook itself, utilize text to their advantage - although the space allotted for it is more limited than a book or article.

Given more time and a budget for artistic additions, I would include illustrations for most cards - fully utilizing the visual medium of board games. This, in addition to other illustrations throughout the rulebook could aid the players in understanding some key visual elements of sixth-century Frankish Gaul. 


\section{Quotes}

Using quotations from Gregory of Tours was important for establishing both legitimacy in the game's historical validity, as well as establishing the idea that players were largely playing through Gregory's narrative (which was also reinforced in the introduction to the rulebook) or a game that was at least heavily based in Gregory's narrative.

The quotations that are present in the game require contextualization to offer any legitimate historical knowledge. I did this by choosing relevant quotes that justified and elaborated on the action or event that was taking place. For the action card "Go on Pilgrimage" I provided the quote: "In the fifty-first year of his reign King Lothar went on a pilgrimage to the entrance to Saint Martin's church, taking with him many gifts. When he reached Tours he visited the Saint's tomb and confessed to all the evil deeds which he had committed in his thoughtlessness." - HF IV.21. " With this quote I sought to provide a concrete example of the act of pilgrimage. Rather than elaborating in my own words on what a pilgrimage would entail, I supplied a contextual word-for-word (although translated) example of pilgrimage.

The quotes help to differentiate between game-based design decisions and actual historical knowledge. Players could see the quote from Gregory and then compare it to how the action (game-based design decision) interacted with each other to create a historical narrative. The connection between historical text and action is the key to what differentiates traditional written history with 'playing' history through a board game. The text does not function as the historical argument alone, it works in tandem with the process of the game to communicate historical ideas. The use of cards and their ability to impart narrative development and historical knowledge is what makes this case study a board game rather than a roleplaying game. 


\section{Roleplaying versus Board Game}

Roleplaying games (RPGs) offer an expansive experience where players are free to explore an open world that, in a well-developed game, has little to no barriers to 'what is possible' depending on the discretion of the individual running the game. This creates the possibility for complex dialogues and narratives to develop and intimately explore the relationship between and position of multiple characters within the narratives of the represented world. However, this requires an exceptional amount of work for both the narrator (the individual that provides responses to the players' actions) and the player. Firstly, the player would have to be cognizant of the endless number of actions available to their character and the narrator must understand historically justifiable responses to those actions.

Figure 23: Example of travel research through https://omnesviae.org. Bolded locations refer to spaces on the board of Divided Kingdom, 561.
The format of an RPG for the purposes of historical literacy have been explored in the past,

1. Rouen travelling to:

a. Rennes - through Riger, Le Mans, Riger, Tours

b. Tournai - direct

c. Paris - direct

d. Soissons - through Amiens

e. Rheims - through Amiens and Soissons

f. Mainz - through Amiens, Soissons, Reims, Patabus, Cologne, and Musalla

g. Tours - through Paris, Riger, and Orleans

h. Orleans - through Paris, and Riger

i. Chalon - through Paris, Riger, Sens, Auxerre, Arber

j. Besancon - through Beauvais, Amiens, Soissons, Rheims

k. Bourges - through Evreaux, Chartres, Riger, Le Mans, Tours

1. Colognes - through Beauvais, Amiens, Soissons, Rheims, Patabus

m. Lyons - through Paris, Riger, Sens, Auxerre, Auton, Arar, Chalon, Arar

n. Bordeaux - through Evreaux, Chartres, Riger, Tours, Poitiers, Garunna, Saintes

o. Clermont - through Paris, Riger, Orleans, Nevers, Aqvis Bormonis (Bourbon-Lancy), Garunna, Vichy

p. Vienne - through Paris, Riger, Sens, Auxerre, Auton, Arar, Chalon, Arar, Lyons

q. Toulouse - through Evreaux, Chartres, Riger, Le Mans, Tours, Poitiers, Garunna, Saintes, Bordeaux, Agen

r. Narbonne - through Evreaux, Chartres, Riger, Le Mans, Tours, Poitiers, Garunna, Saintes, Bordeaux, Agen, Tolouse

s. Arles - through Paris, and Riger, Sens, Auxerre, Autun, Arar, Lyon, Vienne,

t. Marseilles - through Paris, riger, Sens, Auxerre, Autun, Arar, Lyon, Vienne, Avignon 
most notably in the series Reacting to the Past. ${ }^{136}$ My game, in opposition to the Reacting to the Past model, does not require a facilitator to present and develop my historical argument to the game's participants. It is the intent for the game Divided Kingdom, 561 to be played by varying levels of participants inside and outside of academia and still perceive the same historical arguments being made without the need of a facilitator.

$\underline{\text { Map }}$

The central focus of the board in Divided Kingdom, 561 is a map of Gaul. I made great use of the "Omnes Viae: Roman Route Planner" which was created by Rene Voorburg in 2011 and is an interactive map based on the Roman Tabula Peutingeriana. The route planner can tell you how to get from any one roman settlement to another using only Roman roads. This was of great help when creating the map for Divided Kingdom, 561 as I could track the distance from one city to another using Roman roads, determining what stopping points there were from point A to point B (see figure 24 for an example of the data collected from Omnes Viae).

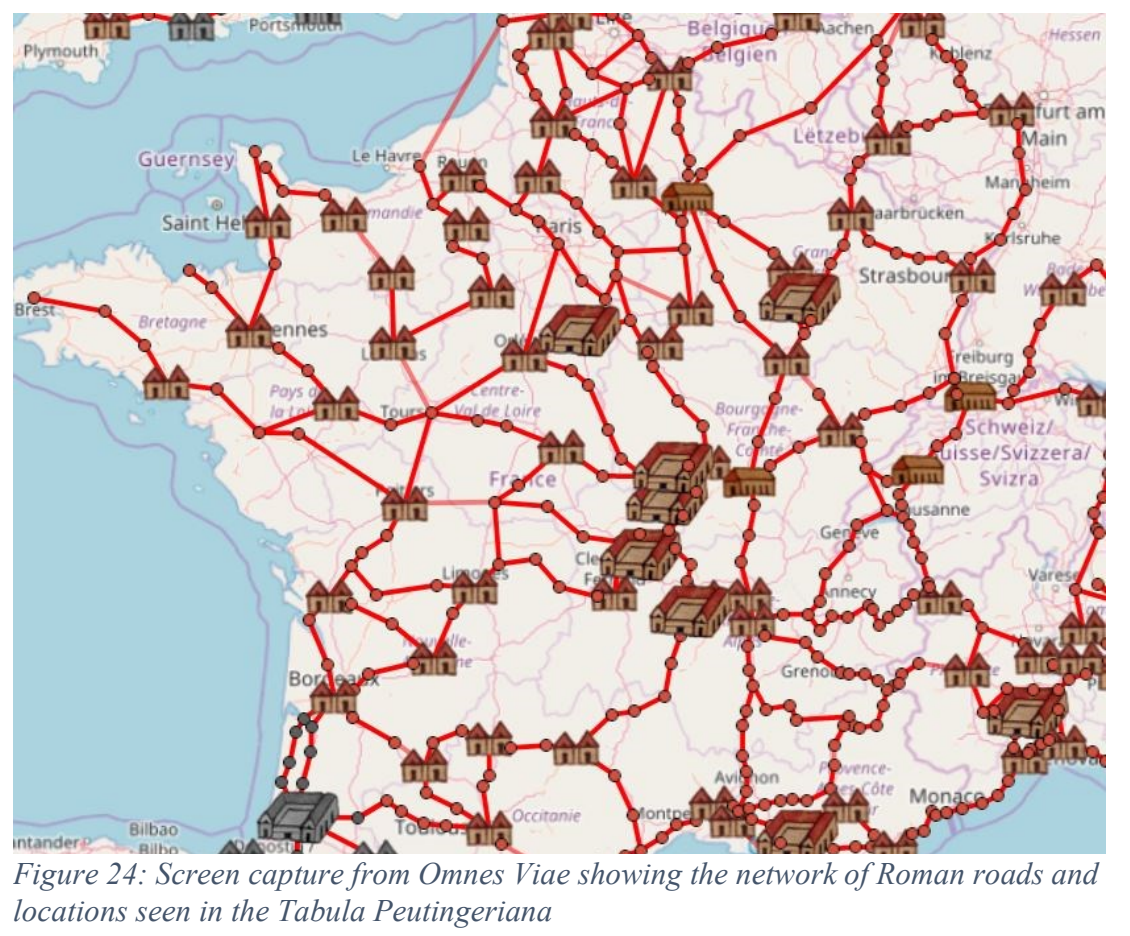

Looking at the data from

"Omnes Viae" that could create a 'route' from one point to another as well as acknowledging other route possibilities by looking at the map of Roman roads itself (fig. 24) I was able to develop a similar network of roads for

\footnotetext{
${ }^{136} \mathrm{https}$ //www.historians.org/teaching-and-learning/teaching-resources-for-historians/reacting-to-the-past.
} 
Divided Kingdom, 561 to reflect the reality of travel in sixth-century Gaul. This method could be further developed and if I possessed more artistic talent, I could represent the system of Roman roads with more accuracy.

$\underline{\text { Intention }}$

My intention to create a board game that actively seeks to posit a historical argument is one of the factors that differentiates Divided Kingdom, 561 from the three historical board game case studies analyzed in chapter two of this thesis. Through my analysis of the historical board game case studies, I sought to showcase that historical board games have the ability to communicate a narrative - irrelevant of whether that narrative is historically 'accurate' or 'complex.' My game's inclusion of annotations was to prove to the reader that diligent research went into the game's design as a historical argument. The annotations used in the rulebook for Divided Kingdom, 561 function as a guide to illuminate the intersection of historical research and game design.

Essentially, my game differs from those analysed in chapter two in how it substantiates and justifies the historical narrative being created. I utilized evidence-based research methods from the practice of academic history such as engaging and showcasing primary source text from Gregory of Tours, use of footnotes, and secondary source research to legitimize this thesis project as an act of History.

\section{$\underline{\text { Conclusion }}$}

The reception of the historical arguments being made in this game are yet to be explored as time did not allow this game to be play tested. Doing so would allow historical game designers to perform follow up interviews with the players and understand how players received the historical arguments being made. 
The difficulty of this project came from not being able to test the operations of the game and understanding how its historical messages would be received by outside observers. Importantly, whether it would be distinguishable to the players if a rule was present for historical purposes or merely reasons of game design. Meaning, is a rule there because it communicates a historical reality or is it present to make the game more 'playable' or 'balanced'?

What this case study did was showcase how game design and historical narrative could be interconnected to present historical arguments. While this project did not showcase the enactment of the game's procedure, it provided an annotated copy of the procedure itself in the hopes that understanding the game's process would showcase the viability of game-based historical literacy.

While the game itself is still in a textual format, it is closer to the medium of a board game than that of written history. What I have provided in the annotated rulebook is a description of the board game's process, how the game functions, and what kind narrative development is possible through the enactment/playing of it.

Through the exploration and development of relevant historical as well as game based pedagogical theories, an analysis of commercial historical board games, and the development of a historical game case study, this project successfully argued for the potential board games have for communicating complex historical arguments. 


\section{Bibliography}

Akkerman, Sanne, Wilfried Admiraal, and Jantina Huizenga. "Storification in History Education: A Mobile Game in and about Medieval Amsterdam." Computers \& Education 52, no. 2 (February 1, 2009): 449-59. https://doi.org/10.1016/j.compedu.2008.09.014.

American Historical Association. "Historical Thinking Skills.” July 13, 2020. https://www.historians.org/teaching-and-learning/teaching-resources-for-historians/teaching-andlearning-in-the-digital-age/the-history-of-the-americas/the-conquest-of-mexico/forteachers/setting-up-the-project/historical-thinking-skills.

Arnaudo, Marco. Storytelling in the Modern Board Game: Narrative Trends from the Late 1960s to Today. McFarland, 2018.

Arnold, Ellen F. "Rivers of Risk and Redemption in Gregory of Tours' Writings." Speculum, Vol. 92, No. 1, 2017.

Bailey, Lisa Kaaren. "Handmaids of God: Images of Service in the Lives of Merovingian Female Saints." Journal of Religious History, Vol. 43, No. 3, 2019.

Begy, Jason. "Board Games and the Construction of Cultural Memory." Games and Culture 12, no. 7-8 (November 1, 2017): 718-38. https://doi.org/10.1177/1555412015600066.

Beresford, Trilby. “'Assassin's Creed: Valhalla' Quest Director on Showing Who Vikings Were as People." Hollywood Reporter. July 12, 2020. https://www.hollywoodreporter.com/heatvision/assassins-creed-valhalla-quest-director-showing-who-vikings-were-as-people-1302368.

Bogost, Ian, and Will Wright. Persuasive Games: The Expressive Power of Videogames. Cambridge, UNITED STATES: MIT Press, 2007. http://ebookcentral.proquest.com/lib/oculcarletonebooks/detail.action?docID $=3338706$.

Booth, Paul. "Book Review: Storytelling in the Modern Board Game." Analog Game Studies (blog), June 16, 2019. http://analoggamestudies.org/2019/06/book-review-storytelling-in-the-modernboard-game/.

BoardGameGeek. "The Pillars of the Earth." October 12, 2020. https://boardgamegeek.com/boardgame/24480/pillars-earth.

Board Game Geek, "Wallenstein Second Edition." https://boardgamegeek.com/boardgame/109125/wallenstein-second-edition.

Bull, Marcus Graham. Thinking Medieval: An Introduction to the Study of the Middle Ages. Houndmills, Basingstoke, Hampshire; Palgrave Macmillan, 2005. 
Chalk, Andy. "Poundmaker Cree Nation Leader Criticizes Cree Portrayal in Civilization 6." $P C$ Gamer (blog), January 4, 2018. https://www.pcgamer.com/poundmaker-cree-nation-leadercriticizes-cree-portrayal-in-civilization-6/.

Chapman, Adam. Digital Games As History: How Videogames Represent the Past and Offer Access to Historical Practice. London, UNITED KINGDOM: Taylor \& Francis Group, 2016. http://ebookcentral.proquest.com/lib/oculcarleton-ebooks/detail.action?docID=4523750.

Chapman, Adam. "Is Sid Meier's Civilization History?" Rethinking History 17, no. 3 (September 1, 2013): 312-32. https://doi.org/10.1080/13642529.2013.774719.

Chapman, Adam, Anna Foka, and Jonathan Westin. "Introduction: What Is Historical Game Studies?" Rethinking History 21, no. 3 (July 3, 2017): 358-71. https://doi.org/10.1080/13642529.2016.1256638.

Choda, Kamil Cyprian. "Facing a Second Death: Narrating and Silencing Hell in the Works of Gregory of Tours." Greaco-Latina Brunensia, 2017.

Clyde, Jerremie, Howard Hopkins, and Glenn Wilkinson. "Beyond the 'Historical' Simulation: Using Theories of History to Inform Scholarly Game Design." Loading... The Journal of the Canadian Game Studies Association. Vol. 6 (9): 3-16.

Collective, Wild On. "Theses on Theory and History," September 21, 2019. http://theoryrevolt.com.

Dailey, E. T. "Gregory of Tours and the Paternity of Chlothar II: Strategies of Legitimation in the Merovingian Kingdoms.” Journal of Late Antiquity, Vol. 7, Issue 1: 3-27, 2014.

Dailey, E. T. Queens, Consorts, Concubines: Gregory of Tours and Women of the Merovingian Elite. Brill, 2015.

Davidson, Drew, and Greg Costikyan. Tabletop: Analog Game Design. Lulu.com, 2011.

Davis, Kevan, Alex Fleetwood, Holly Gramazio, and James Wallis. The Boardgame Remix Kit. Hide and Seek Productions Ltd., 2010.

de Groot, Jerome. Consuming History: Historians and Heritage in Contemporary Popular Culture. Routledge, 2009.

de Jong, Mayke, Frans Theuws, and Carine can Rhijn (Editors). Toppographies of Power in the Early Middle Ages. Brill, 2001.

Despain, Wendy, ed. 100 Principles of Game Design. Web: New Riders, 2012. https:/learning.oreilly.com/library/view/100-principles-of/9780133362688/.

Epstein, Joshua M. “Why Model?” JASSS, October 31, 2008. http://jasss.soc.surrey.ac.uk/11/4/12.html. 
Evans, C. R. Bernard of Clairvaux. Oxford University Press, 2000.

Fisher, Marc, and Jessica Contrera. "Want to Know How Donald Trump Views the World? Try Playing His '80s Board Game." Washington Post, April 18, 2016, sec. Style.

https://www.washingtonpost.com/lifestyle/style/when-you-play-donald-trumps-board-game-youhave-to-become-donald-trump/2016/04/18/9e683c08-00fe-11e6-9203$7 \mathrm{~b} 8670959 \mathrm{~b} 88$ story.html.

Flierman, Robert. "Gregory of Tours and the Merovingian Letter." Journal of Medieval History, 2021.

Fox, Yaniv. Power and Religion in Merovingian Gaul: Columbanian Monasticism and the Frankish Elites. Cambridge University Press, 2014.

Geary, Patrick J. France \& Germany: The Creation \& Transformation of The Merovingian World. Oxford University Press, 1988.

Geselowitz, Gabriela. "The Story Behind Expulsion, the 1970s Board Game About Jews During the Spanish Inquisition," Tablet Magazine, January 25, 2017. https://www.tabletmag.com/sections/news/articles/the-story-behind-expulsion-the-1970s-boardgame-about-jews-during-the-spanish-inquisition.

Gilbert, Lisa. “'Assassin’s Creed Reminds Us That History Is Human Experience': Students' Senses of Empathy While Playing a Narrative Video Game." Theory \& Research in Social Education 47, no. 1 (January 2, 2019): 108-37. https://doi.org/10.1080/00933104.2018.1560713.

Gillett, Andrew (Editor). On Barbarian Identity: Critical Approaches to Ethnicity in the Early Middle Ages. Brepolis, 2002.

Gillett, Andrew. "Telling off Justinian: Theudebert I, the Epistolae Austrasicae, and communication strategies in sixth-century Merovingian-Byzantine relations.” Early Medieval Europe, Vol. 27, No. 2, 2019.

Gonzalo Iglesia, Juan Luis. "Simulating History in Contemporary Board Games: The Case of the Spanish Civil War." Catalan Journal of Communication \& Cultural Studies 8, no. 1 (April 2016): 143-58. https://doi.org/10.1386/cjes.8.1.143_1.

Goffart, Walter. The Narrators of Barbarian History: Jordanes, Gregory of Tours, Bede, and Paul the Deacon. Princeton University Press, 1988.

Halfond, Gregory I. The Archeology of Frankish Church Councils, AD 511-768. Brill, 2010.

Halfond, Gregory I. "Charibert I and the Episcopal Leadership of the Kingdom of Paris (561-567)." Viator: Medieval and Renaissance Studies, Vol. 43, Issue 2, 2012. 
Halfond, Gregory I. (Editor). The Medieval Way of War: Studies in medieval Military History in Honor of Bernard S. Bachrach. Ashgate, 2015.

Hafer, T. J. "5 Things I Wish I Knew before Playing Civilization 6." PC Gamer (blog), October 7, 2016. https://www.pcgamer.com/civ-6-guide/.

Harper, J. Kyle, Michael McCormick, Alexander F. More, and Sonja Eliason. Summary Geodatabase of Epidemics, 312-749AD." Digital Atlas of Roman and Medieval Civilizations Scholarly Data Series, 2017. https://darmc.harvard.edu/data-availability.

Henn, Dirk. Wallenstein. Board Game. Queen Games, 2012.

Howard, Jeff. Quests: Design, Theory, and History in Games and Narratives. Wellesley, Mass: AKPeters, 2008.

Huizinga, Johan. Homo Ludens: A Study of the Play-Element in Culture. Humanitas, Beacon Reprints in Humanities. Boston, Beacon Press, 1955.

Huntemann, Nina B., Matthew Thomas Payne, and Prof. Ian Bogost. Joystick Soldiers: The Politics of Play in Military Video Games. London, UNITED KINGDOM: Taylor \& Francis Group, 2009. http://ebookcentral.proquest.com/lib/oculcarleton-ebooks/detail.action?docID=448316.

James, Edward. The Origins of France: From Clovis to the Capetians 500-1000. MacMillan Press, 1982.

Jones, Shelly and Tanya Pobuda. "An Analysis of Gender-Inclusive Language and Imagery in TopRanked Board Game Rulebooks | Analog Game Studies,” June 10, 2021. https://analoggamestudies.org/2020/12/an-analysis-of-gender-inclusive-language-and-imageryin-top-ranked-board-game-rulebooks/.

Juul, Jesper. Half-Real: Video Games between Real Rules and Fictional Worlds. MIT Press, 2011.

Karppi, Tero, and Olli Sotamaa. "Rethinking Playing Research: DJ HERO and Methodological Observations in the Mix." Simulation \& Gaming 43, no. 3 (June 1, 2012): 413-29. https://doi.org/10.1177/1046878111434263.

Keely, Avril. "Arians and Jews in the Histories of Gregory of Tours." Journal of Medieval History, Vol. 23, No. 4: 103-115, 1997.

Kline, Daniel T. Digital Gaming Re-Imagines the Middle Ages. London, UNITED KINGDOM: Taylor \& Francis Group, 2013. http://ebookcentral.proquest.com/lib/oculcarletonebooks/detail.action?docID=1386406.

Klingshirn, William E. Caesarius of Arles: The Making of a Christian Commmunity in Late Antique Gaul. Cambridge University Press, 1994. 
Klug, Chris. "Dice as Dramaturge." Chapter in: Tabletop: Analog Game Design, Edited by Greg Costikyan and Drew Davidson, Pittsburgh: ETC Press, 2011: 39-47.

Laynesmith, M. D. "Translating St Alban: Romano-British, Merovingian and Anglo-Saxon Cults." Studies in Church History 53 (June 2017): 51-70. https://doi.org/10.1017/stc.2016.5.

Lewis, P.S. Later Medieval France: The Polity. Palgrave Macmillan, 1968.

Lin, Sihong. "The Merovingian Kingdoms and the Monothelete Controversy." Journal of Ecclesiastical History, Vol. 71, No. 2, April 2020: 235-252.

Loebenberg, Abby. "Sneak Attack Anthropology: Experiences with Games in the College Classroom.” Analog Game Studies (blog), June 3, 2018. http://analoggamestudies.org/2018/06/sneak-attack-anthropology-experiences-with-games-inthe-college-classroom/.

Loring-Albright, Greg. "The First Nations of Catan: Practices in Critical Modification." Analog Game Studies (blog), November 9, 2015. http://analoggamestudies.org/2015/11/the-first-nations-ofcatan-practices-in-critical-modification/.

Macklin, Colleen and John Sharp. Games, Design and Play: A Detailed Approach to Iterative Game Design. Addison-Wesley Professional, 2016.

McMillan, David. “A Meeple Pusher Review of: A Feast For Odin.” February 25, 2020. https://boardgamegeek.com/thread/2281562/meeple-pusher-review-feast-odin.

McCall, Jeremiah. "The Historical Problem Space Framework: Games as a Historical Medium." Game Studies 20, no. 3 (September 2020). http://gamestudies.org/2003/articles/mccall.

McCall, Jeremiah. "Historical Simulations as Problem Spaces: Some Guidelines for Criticism." Play The Past, February 22, 2020. https://www.playthepast.org/?p=2594.

Mehar, Aamir. "The Power of Text in Games," Eurogamer. December 8, 2020. https://www.eurogamer.net/articles/2020-12-08-the-power-of-text-in-games.

Metzger, Scott Alan, and Richard J. Paxton. "Gaming History: A Framework for What Video Games Teach About the Past." Theory \& Research in Social Education 44, no. 4 (October 1, 2016): 532-64. https://doi.org/10.1080/00933104.2016.1208596.

Mukherjee, Souvik. "Video Games and Storytelling - Reading Games and Playing Books." Palgrave Macmillan, 2020. https://www.palgrave.com/gp/book/9781137525048.

Munslow, Alun. Narrative and History. Basingstoke, UNITED KINGDOM: Palgrave Macmillan, 2001. http://ebookcentral.proquest.com/lib/oculcarleton-ebooks/detail.action?docID=4763841. 
Murray, Alexander C. Germanic Kinship Structure: Studies in Law and Society in Antiquity and the Early Middle Ages. Pontifical Institute of Medieval Studies, 1983.

Murray, Alexander C. After Rome's Fall: Narrators and Sources of Early Medieval History. University of Toronto Press, 1998.

Murphy, Sheila C. "Half-Real: Video Games Between Real Rules and Fictional Worlds." Cinema Journal 48, no. 3 (March 22, 2009): 142-45.

Onega Jaén, Susana, and José Angel García Landa. Narratology: An Introduction. Longman Critical Readers. London; Longman, 1996.

Pearce, Celia. “Towards a Game Theory of Game.” Electronic Book Review, August 7, 2004. http://electronicbookreview.com/essay/towards-a-game-theory-of-game/.

Peters, Edward (Editor). McDermott, William C. (Translator). Monks, Bishops, and Pagans: Christian Culture in Gaul and Italy, 500-700. University of Pennsylvania Press, 1975.

Pobuda, Tanya. "Assessing Gender and Racial Representation in the Board Game Industry." Analog Game Studies. December 2, 2018. https://analoggamestudies.org/2018/12/assessing-gender-andracial-representation-in-top-rated-boardgamegeek-games/.

Pugh, Tison, and Angela Jane Weisl. Medievalisms: Making the Past in the Present. London, UNITED KINGDOM: Taylor \& Francis Group, 2012. http://ebookcentral.proquest.com/lib/oculcarleton-ebooks/detail.action?docID=1074983.

Roberts, Scott L. "Using Counterfactual History to Enhance Students' Historical Understanding." The Social Studies 102, no. 3 (April 15, 2011): 117-23. https://doi.org/10.1080/00377996.2010.525547.

Rodriguez, John and Flo de Hann. Western Empires. Board Game. 999 Games, 2019.

Rose, E. M. "The Conversion of the Jews of Clermont in AD 576." Chapter in: Mitchell, Kathleen and Ian Wood (Editors). The World of Gregory of Tours. Brill, 2002.

Rosenberg, Uwe. A Feast for Odin. Board Game. Z-Man Games, 2016.

Ryan, Elana Laurel Aislinn. "A Medieval New World: Nation-Making in Early Canadian Literature, 1789-1870," n.d., 319.

Ryan, Marie-Laure. Avatars of Story. University of Minnesota Press, 2006.

Sarti, Laury. "The military, the clergy and Christian faith in sixth-century Gaul." Early Medieval Europe, Vol. 25, No. 2: 162-185, 2017.

Sarti, Laury. Percieving War and the Military in Early Christian Gaul (ca. 400-700 A.D.). Brill, 2013. 
Spencer, Nicholas. "Review: The Medium of the Video Game." Quarterly Review of Film and Video 19, no. 4 (January 1, 2002): 365-68.

Squire, Kurt. "From Content to Context: Videogames as Designed Experience.” Educational Researcher 35, no. 8 (2006): 19-29.

Stenros, Jaakko, Annika Waern, and Markus Montola. "Studying the Elusive Experience in Pervasive Games:" Simulation \& Gaming, October 18, 2011. https://doi.org/10.1177/1046878111422532.

Tarbert, J. P. Marney and Heather F. E. "Why Do Simulation? Towards a Working Epistemology for Practitioners of the Dark Arts." Journal of Artificial Societies and Social Simulation, Vol. 3, no. 4, 2000. http://jasss.soc.surrey.ac.uk/3/4/4.html.

Taylor, Tom. "Historical Simulations and the Future of the Historical Narrative." Journal of the Association for History and Computing, September 2003. http:/hdl.handle.net/2027/spo.3310410.0006.203.

Taylor, T. L. "The Assemblage of Play." Games and Culture. Vol. 4 (4), 2009: 331-339.

Thorpe, Lewis (translator). Gregory of Tours: The History of the Franks. Penguin Books, 1974.

Trammell, Aaron, Emma Leigh Waldron, and Evan Torner. "Reinventing Analog Game Studies." Analog Game Studies (blog), August 1, 2014. http://analoggamestudies.org/2014/08/reinventinganalog-game-studies/.

Watson, William R., Christopher J. Mong, and Constance A. Harris. "A Case Study of the In-Class Use of a Video Game for Teaching High School History." Computers \& Education 56, no. 2 (February 1, 2011): 466-74. https://doi.org/10.1016/j.compedu.2010.09.007.

Whalen, Zach, Laurie N. Taylor, and ProQuest. Playing the Past History and Nostalgia in Video Games. Nashville: Vanderbilt University Press, 2008.

Wolters, Eugene. "Class Struggle the Board Game - The Greatest Thing to Ever ExistCriticalTheory.Com," December 9, 2013. http://www.critical-theory.com/class-struggle-board-gamegreatest-exist/.

Wu, Minerva, and William Dunkel. "The Mermaids of Iedo: Balancing Design and Research in Serious Games.” Analog Game Studies (blog), June 17, 2019. http://analoggamestudies.org/2019/06/the-mermaids-of-iedo-balancing-design-and-research-inserious-games/.

Wynn, Phillip. "Wars and Warriors in Gregory of Tours' Histories I-IV." Francia, Vol. 8, 2001.

Van Dam, Raymond. Leadership and Community in Late Antiquity. University of California Press, 1985. 
Van Dam, Raymond. Saints and their Miracles in Late Antique Gaul. Princeton University Press, 1993.

Voorburg, Rene. Omnes Viae: Roman Route Planner. 2011. https://omnesviae.org/. 